\title{
DIRECT PRODUCTION OF SILICONES FROM SAND
}

\author{
Final Report \\ for Period September 1, 1998 - Sept. 30, 2001
}

L. N. Lewis, F. J. Schattenmann and J.P. Lemmon

\author{
General Electric Company \\ Corporate Research and Technology \\ 1 Research Circle \\ Niskayuna, NY 12309
}

Sept. 302001

Prepared for

The U. S. DEPARTMENT OF ENERGY

Under Contract No. DE-FC02-98CH10931 
1. SUBJECT:

2. PROJECT TITLE:

3. PERIOD:

4. CONTRACT:

5. CONTRACTOR:

6. START/COMPLETION:
Final Report

"Direct Production of Silicones from Sand"

Sept. 1, 1998 to Sept. 30, 2001

DE-FC02-98CH10931

General Electric Company

Corporate Research and Technology

1 Research Circle

Niskayuna, NY 12309

Phase I: September 1, 1998/August 31, 2000

Phase II: September 1, 2000/September 30, 2001

7. CONTRACT OBJECTIVE CHANGES: none

8. TECHNICAL APPROACH CHANGES: none

9. CONTRACT TASKS: 


\section{INTRODUCTION}

Silicon, in the form of silica and silicates, is the second most abundant element in the earth's crust. However the synthesis of silicones (Scheme 1) and almost all organosilicon chemistry is only accessible through elemental silicon. ${ }^{1}$ Silicon dioxide (sand or quartz) is converted to chemical-grade elemental silicon in an energy intensive reduction process, a result of the exceptional thermodynamic stability of silica. Then, the silicon is reacted with methyl chloride to give a mixture of methylchlorosilanes catalyzed by copper containing a variety of trace metals such as tin, zinc etc. The socalled direct process was first discovered at GE in $1940 .^{1-3}$ The methylchlorosilanes are distilled to purify and separate the major reaction components, the most important of which is dimethyldichlorosilane. Polymerization of dimethyldichlorosilane by controlled hydrolysis results in the formation of silicone polymers. Worldwide, the silicones industry produces about 1.3 billion pounds of the basic silicone polymer, polydimethylsiloxane.

\section{Scheme 1.}

$$
\mathrm{SiO}_{2} \underset{-\mathrm{CO}_{2}}{\stackrel{\mathrm{C}}{\longrightarrow}} \mathrm{Si} \stackrel{\mathrm{MeCl}}{\underset{\text { Cu cat. }}{\longrightarrow}} \mathrm{Me}_{2} \mathrm{SiCl}_{2} \stackrel{\text { condens. }}{\longrightarrow} \underset{\substack{\mathrm{Me} \\ \mathbf{S i} \\ \mathrm{Me}}}{\stackrel{\mathrm{M}}{\mathrm{M}} \mathrm{O}_{\mathrm{n}}}
$$

The energy costs associated with the route in Scheme lare mainly a result of the reduction of $\mathrm{Si}(\mathrm{IV})$ to $\mathrm{Si}(0)$ and subsequent reoxidation to $\mathrm{Si}(\mathrm{IV})$. The conversion of silicon dioxide to elemental silicon in an electrochemical furnace at temperatures $\sim 1500$ ${ }^{\circ} \mathrm{C}$ consumes large amounts of electricity and carbon for reduction. Additionally, the production and separation of the methylchlorosilane mixture is energy intensive, involving several distillation steps.

An alternative synthetic route was proposed ${ }^{4}$ to the Department of Energy to avoid reduction and reoxidation of silicon as well as the use of chlorine containing 
intermediates. The proposal consists of a three-step route to silicone polymers starting from silicon dioxide (Scheme 2).

Scheme 2.

$$
\left.\mathrm{SiO}_{2} \stackrel{\text { Step } 1}{\longrightarrow} \mathrm{Si}(\mathrm{OMe})_{4} \stackrel{\text { Step } 2}{\longrightarrow} \mathrm{Me}_{2} \mathrm{Si}(\mathrm{OMe})_{2} \stackrel{\text { Step } 3}{\longrightarrow} \underset{\substack{\mathrm{Me} \\ \mathbf{S i} \\ 1 \\ \mathrm{Me}}}{\longrightarrow}\right)_{\mathrm{n}}
$$

Precedence for Step 1 in Scheme 2 was recently reported by Ono et al..$^{5}$ starting from silica gel and gaseous dimethyl carbonate (DMC) at 500-600 $\mathrm{K}$ to yield tetramethoxysilane in the presence of a catalyst supported on the silica. The employed catalysts include $\mathrm{MX}(\mathrm{M}=\mathrm{Na}, \mathrm{K}, \mathrm{Rb}, \mathrm{Cs} ; \mathrm{X}=\mathrm{OH}, \mathrm{F}, \mathrm{Cl})$. Rice hull ash $\left(92 \% \mathrm{SiO}_{2}\right.$ purity) also reacts with DMC when loaded with $5 \mathrm{wt} \%$ of potassium hydroxide at 625 K. ${ }^{6}$

Earlier examples of the base catalyzed activation of $\mathrm{SiO}_{2}$ using alcohol derivatives include the formation of hexacoordinated dianionic complexes from silica (eq 1). ${ }^{7}$

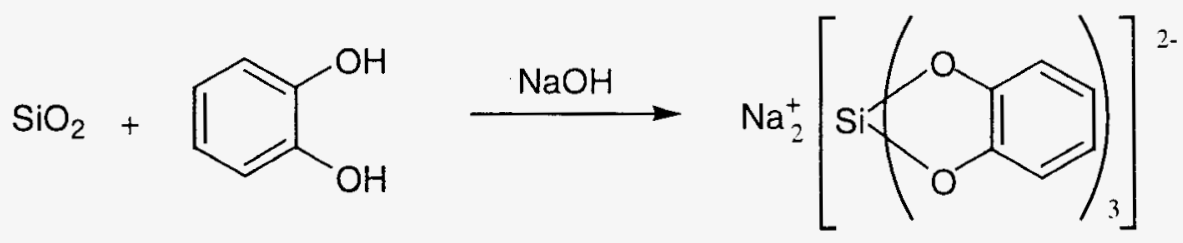

Additionally, Laine and coworkers have shown that silicon dioxide reacts with base and a diol to form a reactive penta-coordinate silicate species (eq 2). ${ }^{8,9}$

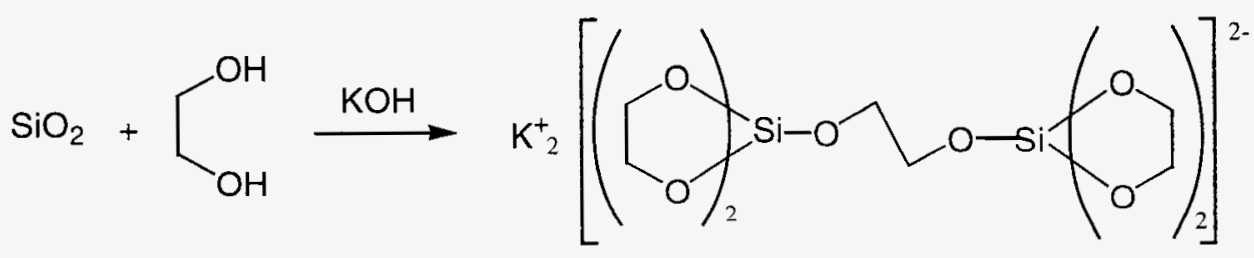


Very few other examples of the conversion of silicon dioxide to silicate-like compounds have been reported. ${ }^{10}$

Currently the only access to dialkyldialkoxysilane from tetraalkoxysilane (Step 2) involves the stoichiometric transformation using Grignard reagents. ${ }^{11,12}$ The hydrolytic polymerization of alkylalkoxysilanes to silicone polymers (Step 3) is a process that is practiced commercially.

The two major challenges connected with this proposed approach to silicones from silicon dioxide are:

- Optimization of the alkoxysilane synthesis from a low-cost silicon dioxide source.

- Innovation of a new process for synthesis of alkylalkoxysilane from alkoxysilane.

This report, summarizes all of the work done under the general term, 'Sand to Silicones'.

\section{REFERENCES}

1. Kirk-Othmer Encyclopedia of Chemical Technology, $3^{\text {rd }}$ ed.; Wiley-Interscience, New York, 1979; Vol. 20, 750-880.

2. Liebhafsky, H. A. Silicones Under the Monogram, John Wiley and Sons, New York, 1978.

3. Warwick, E. L. Forty Years of Firsts, McGraw Hill, New York, 1990.

4. Source: Gelest Catalogue.

5. Ono, Y.; Akiyama, M.; Suzuki, E. Chem. Mater. 1993, 5, 442.

6. Akiyama, M.; Suzuki, E.; Ono Y. Inorg. Chim. Acta 1993, 207, 259.

7. Rosenheim, A.; Raibmann, B.; Schendel, G. Z. Anorg. Allg. Chem. 1931, 196, 160.

8. Laine, R. M.; Blohowiak, K. Y.; Robinson, T. R.; Hoppe, M. L.; Nardi, P.; Kampf, J.; Uhm, J. Nature 1991, 353, 642.

9. Blohowiak, K. Y.; Treadwell, D. R.; Mueller, B. L.; Hoppe, M. L.; Jouppi, S.; Kansal, P.; Chew, K. W.; Scotto, C. L. S.; Babonneau, F.; Kampf, J.; Laine, R. M. Chem. Mater. 1994, 6, 2177.

10. Goodwin, G. B.; Kenney, M. E. Polym. Prep. 1986, 27, 107. 
11. Graefe, J.; Uzick, W.; Weinberg, U. Ger. Offen. DE 3821483 Chem Abstr 112:217263.

12. Goodwin, G. B.; Kenney, M. E. Adv. Chem. Ser. 1990, 224, 251.

\section{Phase I Tasks}

\section{I-1 Synthesis of Silane Intermediate.}

Subtask 1.1 Computational for Silane (MSI). The purpose of this task is the calculation of reactants and products of the proposed reaction scheme to guide and support the synthetic efforts. MSI will carry out extensive computations for the starting organic reagent used in silane synthesis including bond breakage analysis. Also to be determined are equilibrium geometry and calculation of binding energies in the gas phase of key molecular reactants and products. MSI will also construct viable models of silica surfaces including construction of a model ( $\mathrm{SiO} 2)$ n cluster, calculation of geometrical and thermochemical properties of the silica model and initial construction of $\mathrm{SiO} 2$-catalyst structures. At the end of this task, MSI will deliver a report of their findings to GE.

\section{Subtask 1.2 Optimize Synthesis of Silane Intermediate (GE).}

The goal of this task to provide an optimized process for the production of the silane intermediate from $\mathrm{SiO} 2$. GE will optimize the process for the synthesis of silane intermediates from an inexpensive silicon dioxide source. GE will also explore the impact of other reagents and catalysts on the reaction. Optimization of the reactions will be based on conversion of silicon dioxide to the silane intermediates. At the end of this task GE will have an optimized process for producing the silane intermediate from $\mathrm{SiO} 2$.

\section{I-2 Synthesis of Silicone Precursor}

\section{Subtask 2.1.1 Compute Silane from SiO2 (MSI).}

MSI will perform calculations regarding formation of the silane intermediate from SiO'2. This work will include complete construction of $\mathrm{SiO} 2$ with and without catalyst. Theoretical models will be validated against surface experimental data provided by GE. MSI will probe adsorption geometries of organic reagents on catalyzed silica surfaces. They will also calculate the relative energies of initial reactants and determine possible intermediates in conversion of the silane intermediate to the silicone precursor. Finally they will determine possible barrier heights of possible rate limiting steps. MSI will deliver a report to GE when done with this task.

Subtask 2.1.2 Compute Silicone Precursor from Silane Intermediate (MSI). 
MSI will determine the relative energies with respect to initial reactants in the conversion of the silane intermediate to the silicone precursor. They will identify possible metastable intermediates in the formation of the silicone precursor from the silane intermediate. Additionally MSI will determine barrier heights of possible rate limiting steps and calculate the reaction pathway for formation of the silane intermediate. At the end of this task MSI will report their findings to GE.

\section{Subtask 2.1.3 Compute Direct Formation of Silicone Precursor from SiO2 (MSI).} MSI will identify possible meta-stable intermediates in the formation of the silicone precursor from $\mathrm{SiO} 2$. Additionally MSI will determine barrier heights of possible rate limiting steps and calculate the reaction pathway for formation of the silicone precursor. At the end of this task MSI will report their findings to GE.

\section{Subtask 2.1.4 Compile Computational Data (MSI).}

MSI will compile all computed results in the form of a project data base, which will be stored on interactive media such as CD's for use on PC's.

\section{Subtask 2.1.5 Document Computational Data (MSI).}

MSI will write a report summarizing all of their computational efforts.

We include Phase I results because this report overlaps with the end of Phase I and beginning of Phase II. Future updates will only include Phase II results.

\section{A complete report summarizing all of the Task 1 activities is summarized in Appendix 1.}

\section{Subtask 2.2.1a Stoichiometric Synthesis of Silicone precursor (OMG).} OMG will screen metal compounds to find stoichiometric processes that convert the silane intermediate to the silicone precursor. They will employ three gaseous monomers as part of the screen and evaluate up to 50 different potential metal reagents. OMG will report their findings to GE at the end of this task.

\section{Subtask 2.2.1b Catalytic Synthesis of Silicone Precursor (OMG).}

OMG will screen up to 50 different metal compounds and at least three gaseous monomers to develop a catalytic process for conversion of the silane intermediate to the silicone precursor. OMG will have at least one catalytic process and summarize their efforts in a report delivered to GE.

Report on progress to date follows for 2.2.1 a and $b$. They refer to the silane intermediate as TMOS and the silicone precursor as methylmethoxysilanes. 


\title{
The OMG Contribution is given in Appendix 2
}

\author{
Subtask 2.2.2a Conversion of $\mathrm{SiO} 2$ to Silane Intermediate and Silicone Precursor \\ (GE). \\ GE will screen metal compounds to optimize the conversion of SiO2 to the silane \\ intermediate and the silicone precursor. GE will determine the key variables for this \\ process.
}

GE has unexpectedly found a direct pathway for conversion of SiO2 to both the silane intermediate and the silicone precursor. Research efforts were directed towards understanding the direct formation of the silicone precursor. Several metal compounds, possibly responsible for the direct formation of the silicone precursor, were screened as potential promoters. Different ways of introducing such metal compounds were involved: 1. Surface deposition on the SiO2, 2. Sol-gel-type synthetic methods and 3. Hydro-thermal synthesis. A dependence of the silicone precursor production on the presence of metal compounds was found. 10 metals in various chemical environments were screened under a variety of reaction conditions. One promoter with significant activity was identified. The analytic instrumentation was evaluated for the detection of the silicone precursor using statistical quality tools. Further optimization of the conversion of $\mathrm{SiO} 2$ to silane intermediate and silicone precursor is covered in Subtask 2.2.2b and particularly in Subtask 2.2.3. This Subtask is complete and is summarized in Appendix 1

\section{Subtask 2.2.2b Optimize Conversion of $\mathrm{SiO} 2$ to the Silane Intermediate and the Silicone Precursor (GE).}

GE has found a direct pathway for conversion of $\mathrm{SiO} 2$ to both the silane intermediate and the silicone precursor. The variables in this new process will be optimized.

An extensive Design of Experiment based on statistical quality tools was performed exploring the influence of $1 . \mathrm{SiO} 2$ source (with and without metal promoter); 2 . Reaction temperature; 3 . Addition rate of the organic starting material; 4. Carrier gas flow and 5. Catalyst loading. Analysis of the Design of Experiment revealed clear trends in the formation of the silane intermediate and the results as well as subsequent sucessful optimization is covered in Subtask 1.2. Unfortunately, the results did not show clear trends in the formation of the silicon precursor directly from SiO2. Further screening of $\mathrm{SiO} 2$ compounds containing promoters were performed using HTS techniques. HTS techniques are much more powerful to explore large design spaces, which appears to be necessary in this case. Close to 230 different $\mathrm{SiO} 2$ sources with various promoters were screened and in several cases good yields of the silane intermediate were found.

Unfortunately, however, no evidence for the formation of silicone precursor was observed. For more details see Subtask 2.2.3.

Besides screening promoters and $\mathrm{SiO} 2$ sources and varying reaction conditions, the organic starting material was also varied. Six organic materials besides the organic 
starting material were used in reactions involving $\mathrm{SiO} 2$ and catalyst under a variety of reaction conditions. In two cases the formation of silane intermediate was observed, but no formation of silicone precursor could be detected. Three di-functional organic materials different from the organic starting material were used in the reaction with silica to form compounds related to the silane intermediate. This approach would allow isolation of alternatives for the silane intermediate as well as a potentially lower energy pathway to silicone precursor. Unfortunately, no reactivity was found using a fixed-bed reactor with on-line condenser. Further routes to Q' from $\mathrm{SiO} 2$ avoiding the use of the organic starting material will be performed in Phase II employing high throughput methodology.

\section{The Results of the Combinatorial Study of the Minerals is Discussed in Appendix 3.}

This Subtask is complete.

Subtask 2.2.2c Develop a Catalytic Process for Silicone Precursor Synthesis (GE). GE will develop a process for production of the silicone precursor either from $\mathrm{SiO} 2$ directly or from the silane intermediate. At least 50 different metal compounds will be screened as well as at least three organic reagents. A new catalytic process will be developed by the end of this task.

Reactions starting from $\mathrm{SiO} 2$ were explored using HTS technology (Subtask 2.2.3). A wide range of $\mathrm{SiO} 2$ sources, many of them containing other elements have been screened using the 32-column HTS reactor. Results are communicated under Subtask 2.2.2b and Subtask 2.2.3c.

For the transformation of silane intermediate to silicone precursor, several conceptually different approaches were pursued. The first approach focused on fundamental, noncatalytic aspects of this transformation. An unprecedented example of the synthesis of the silicone precursor from the silane intermediate using a transition metal compound was found. Five different metal compounds were screened under various reaction conditions. Two transition metal compounds showed reactivity with the silane intermediate and one complex yielded the silicone precursor.

Two other approaches concentrate on potentially catalytic pathways:

The second approach comprises three different routes and a total of 15 different metal compounds have been screened. The formation of silicone precursor from silane intermediate using the second approach has not been observed. However, activation of the silane intermediate was demonstrated using one of the three pathways.

The third approach is geared towards reactions of the silane intermediate with small molecules on a catalytic surface. Similar to the second approach, activation of the silane intermediate was found and in one case traces of the silicone precursor were detected. Recently, conceptually new reactivity was found. Reaction of the silane intermediate with a reactive reagent unexpectedly lead to the formation of $\mathrm{T}$-resin precursor, a compound closely related to the silicone precursor, in good yield. The silicone precursor 
was also found in lower yield. Subjecting the T-resin precursor to the reactive reagent gives the silicone precursor in substantial yield. The mechanistic pathway for this unusual reaction was established. The mechanism consists of a three-step process and represents a new way to the silicone precursor.

The new reaction was studied in great detail. Besides the T-resin precursor, another valuable product, the organofunctional precursor, was formed. By changing the temperature the product composition can be controlled. Lower temperature generally favors production of the organofunctional precursor, while higher temperature favors production of the T-resin precursor. Several other compounds related to the reactive reagent were identified to also induce this new type of reactivity. Furthermore the reaction was extended to a new class of reagents that also can react with the silane precursor to form the T-resin precursor. This new class of reagents, however, only shows reactivity in the presence of a promoter. This promoter, although not required for the reaction of the silane intermediate with the reactive reagent, also has a positive effect. It significantly lowers the reaction temperature in this reaction. Although not catalytic, this new type of reaction represents an entirely new entry into silicone precursor type chemistry. This conceptually new type of chemistry was also extended to compounds related to Q'. Further research suggests that common bases assist in the reaction of Q' with the reactive reagent. T-resin precursor was detected at much lower temperatures and in higher yields when a base is added. The reaction of Q' with the reactive reagent was also reproduced in a high-pressure reactor. The follow-up research is planned for Task II2. This Subtask is complete.

Subtask 2.2.3a High Throughput Screening (HTS) First Generation. GE will build and run a first generation reactor that will permit HTS evaluation of the new process. This new reactor will permit running about 10 reactions per day.

Design and assembly of the first generation reactor was completed. The reactor allows to screen 32 reactions at a time. After the reactor shake-down was completed a capability analysis was performed. The capability analysis showed sufficiently low variability to distinguish results. The reactor was designed to screen reactions involving $\mathrm{SiO} 2$, but also can easily be modified to use the silane intermediate as starting materials. This Subtask is complete.

\section{Subtask 2.2.3b High Throughput Screening (HTS) Second Generation.}

As discussed last quarter, we focussed on using the 32 tube HTS reactor to evaluate silicate materials The revised proposal stated that in addition to building the HTS reactor we would down select the rapid analytical method from GC, mass spectroscopy or Raman spectroscopy and that we would install and de-bug the data handling methodology. . The reactor has been constructed and de-bugged. We regularly run 32 experiments simultaneously. We downselected a flash gc method which permitted analysis of all 32 product mixtures within a day. Some product mixtures were further evaluated by gcms. A data base was constructed that contained all parameters from each experiment and all the results as well. 


\section{Subtask 2.2.3c HTS Experiments.}

We have completed the main analysis using the HTS reactor. Almost 230 silicate mineral were evaluated for their reaction to produce the silicone precursor directly and/or the silane intermediate. Quadruplicate experiments were run and we ran a low and high control in every 32 column run. The results have been compiled and several "hits" were found. Direct production of the silicone precursor has not been observed. Amorphous silicates and many of the so-called tectosilicates gave the highest activity for formation of the silane intermediate. A few additional reactive candidates were identified. The downselected hits are now being evaluated in the single fixed bed reactor so we can explore other conditions to further optimize formation of the silane intermediate and additionally look for direct formation of the silicone precursor. The HTS reactor is now being used to screen successful candidates for the second step, namely production of the silicone precursor from the silane intermediate.

\section{Subtask 2.3 Preliminary Engineering Economic Analysis (GE).}

GE will write a report summarizing our analysis of the economic feasibility of the new processes.

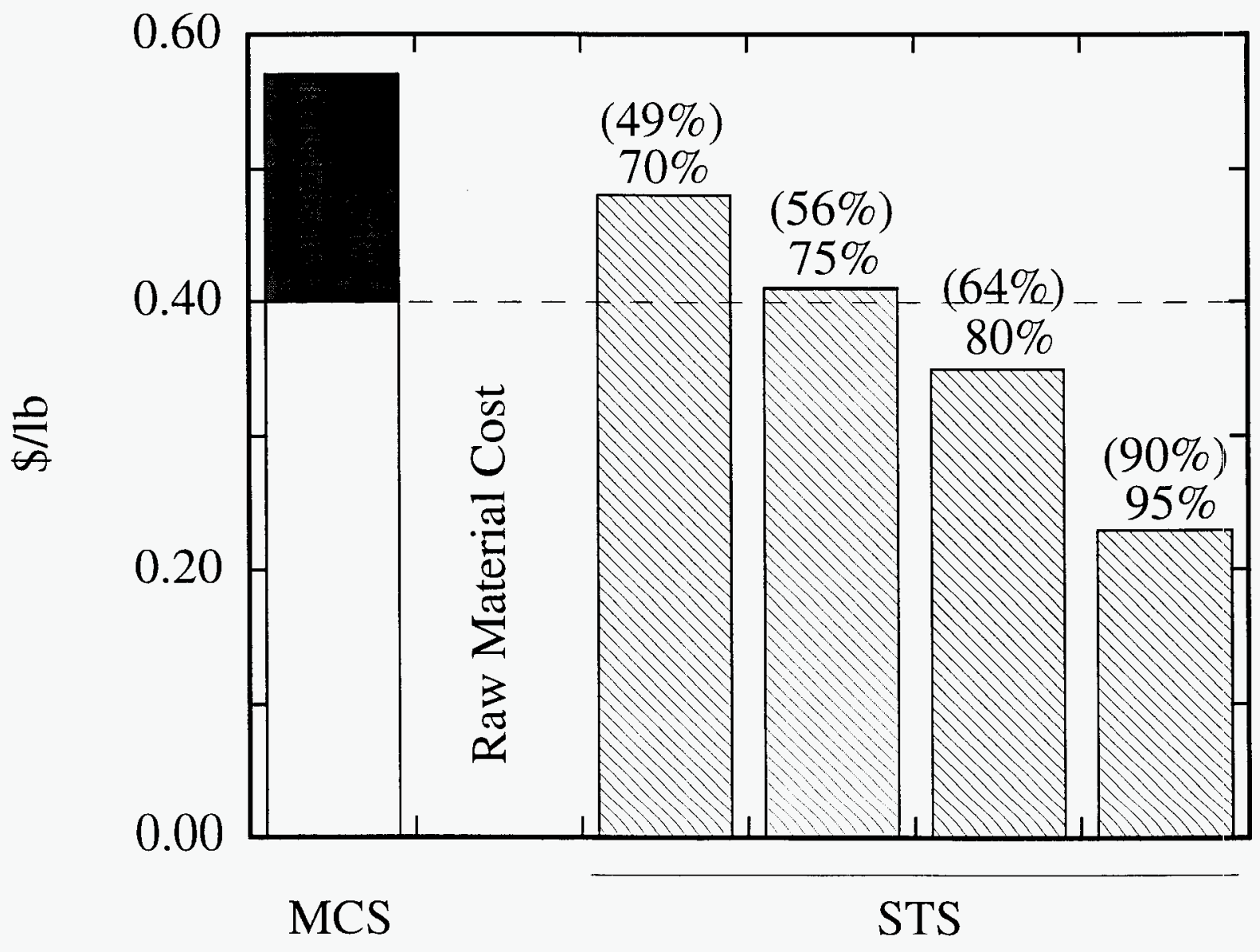


The chart above shows the raw material costs for the current methyl chlorosilane (MCS) process vs. a two-step Sand to Silicones (STS) process. The price per pound (Y axis) is shown for different total conversions (number in parentheses). The STS process clearly produces silicones at a lower raw materials cost. However, the use of dimethylcarbonate to make the silane intermediate (tetramethoxysilane) imparts a too high investment cost for the new process.

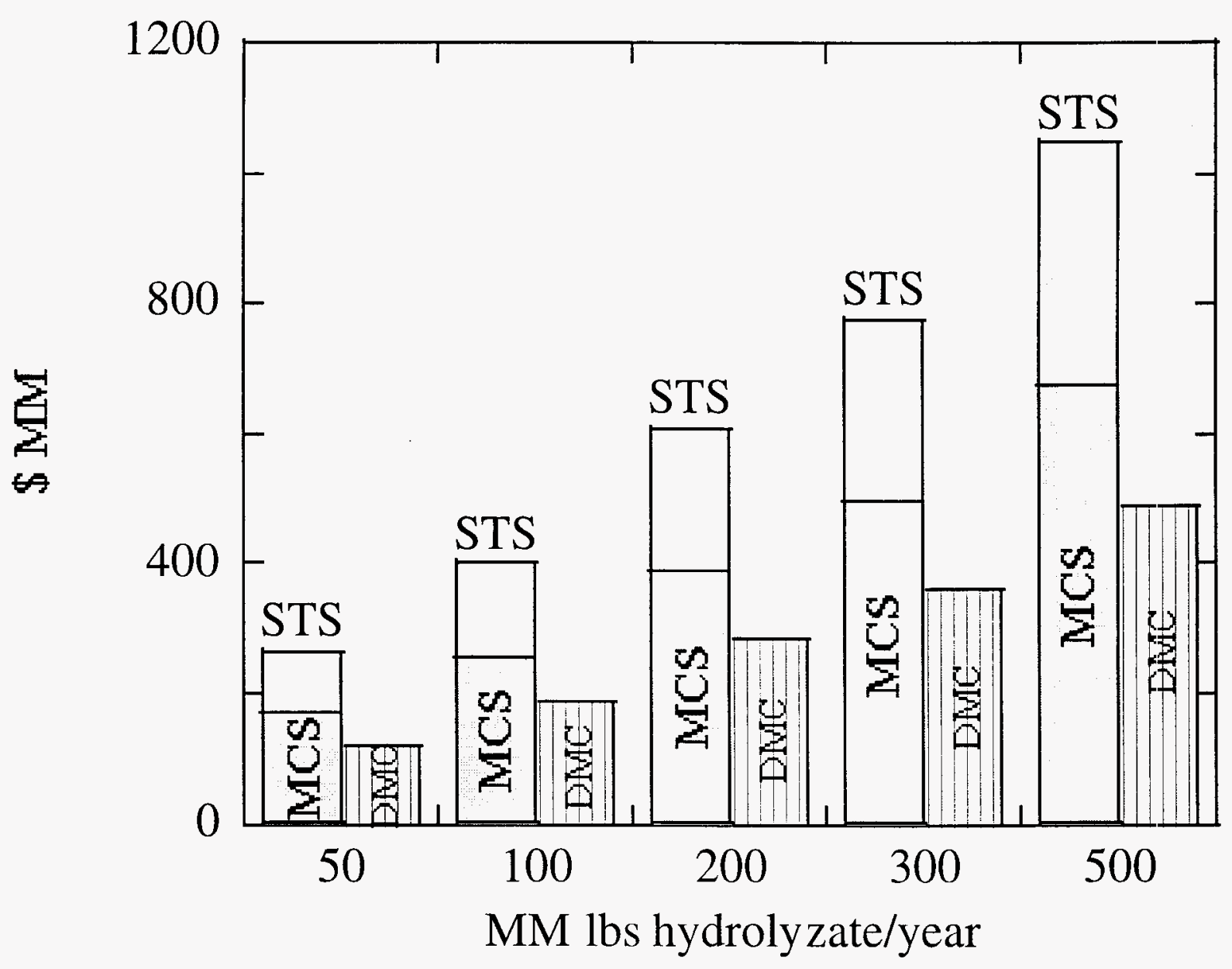

It is the investment cost for DMC that leads us to the conclusion that we need a process based on methanol and NOT on dimethylcarbonate. The DMC-based process will not be economically viable. This task is complete. 


\section{PHASE II}

\section{Phase II (GE and Partner*)}

* As described above, GE did not have a partner in Phase II.

Task 1. Synthesis of Q' from inexpensive raw materials.

This task will employ silicate reagents discovered in Phase I, base and a methanol or other low cost raw materials to form Q'. The other methoxy sources may include dimethyl ether. Also dimethylcarbonate (DMC) could become a viable option if lower cost routes to its formation become available. The synthesis of Q' may require a metal catalyst. Two different high throughput screening (HTS) reactors will be employed for this task. One HTS reactor is the 32 column reactor employed in phase I. Here solid reagents on a frit in a heated zone are exposed to gas or vaporized liquid and the products are collected in a cold condenser and analyzed by flash gas chromatography (gc). The procedure for running this reactor is well worked out. The other HTS reactor is an existing one in our organization and permits 48 or more simultaneous experiments run under high pressure and moderate temperature with stirring. Analysis of products also uses the flash gc. We anticipate that over 500 experiments per year will be performed in the 32-column HTS reactor and that over 200 experiments will be performed in the 48 well HTS reactor. A key one year Go/No Go decision point for this task is $25 \%$ yield or greater of Q' under the conditions described above. Formation of Q' is a critical component of the Silicones from Sand effort. In Phase I we established a high silicon utilization process for formation of Q' from a SiO2 source and DMC. The DMC-based synthesis is not economically viable because of high investment costs for the DMC plant. In order to be economical, a route to Q' from a source other than DMC must be found or we cannot continue our efforts in this area.

Both the 32 column reactor of phase I and the 48 well reactor are in operation. In both cases we are trying experiments with an $\mathrm{SiO} 2$ source and $\mathrm{MeOH}$ feed. The 48 well reactor is run at $200 \mathrm{C}$ and is a "pressure-cooker", closed system.

\section{Combinatorial Library Descriptions}

A general methodology was employed to synthesize catalyst libraries for both systems. This method employed the use of overlapping gradient ternary mixtures of metal ions at regular intervals. This approach allows for a rapid survey of chemical space while minimizing the number of samples. In the case of supported catalyst systems a liquid library of the metals was first generated followed by impregnating the metals into the support material. For unsupported reactions small amounts of the metal powders were loaded in the appropriate ratios using an automated solid handling robot. In some cases further work-up of the catalyst libraries was necessary before reacting, i.e. drying, and metal activation. 
The stand alone fixed bed reactor is also being used to screen for formation of Q' from $\mathrm{SiO} 2$ and $\mathrm{MeOH}$. Some limited success has been achieved but further controls and replicates are needed.

Reactions with Metal Doped Porous Silica and Methanol

\section{Tube Gas Flow Reactor}

Metal doped porous silica libraries were generated as described above, the libraries were reacted in a reducing atmosphere with methanol vapor at $375 \mathrm{C}$ for 3 hours. Several combinations of metals and metal libraries with additional co-catalyst were investigated. These include 42 different gradient metal ternary mixtures, in addition most libraries we reacted with a co-catalyst to form the $1^{\text {st }}$ generation daughter libraries. The overall number of different reactions ran totals 1440, not including reaction standards and blanks. Unfortunately none of the reactions produced any type of $\mathrm{Si}-\mathrm{C}$ bond, typical reaction products observed included rearranged methoxy-hydrocarbons and/or small chain alcohols. Due to the lack of positive results and the breath of experimental reaction space covered, this reaction strategy has been discontinued for more favorable strategy.

\section{Well High Pressure Reactor}

Preliminary results of reacting the doped silica libraries with methanol under a high pressure reducing atmosphere have been promising. Trace amounts of tetramethoxy silane have been observed in a limited number of runs, however replication on a large scale has thus far been unsuccessful. Future plans include continuing screening of doped silica and hypervalent silcates with metal doped supports.

Reactions of Unsupported Metal Mixtures with Methanol and Various Silicon Containing Species

Recently, a protocol for using unsupported metal ternary mixtures with various hypervalent silicates has been developed for the 32 tube gas flow reactor.

Several hypervalent silicate compounds have been prepared and their reactivity will be screened in the HTS reactors. Two silicon ethyleneglycolate potassium salts 1 have been prepared following the prep described by the Laine group (Chem. Mater., 6 (1994) $p$ 2177)

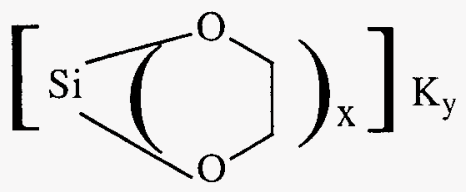

1

Two silicon catecholate sodium salts $\mathbf{2}$ have been prepared following the prep described by the Corriu group (Organometallics, 7 (1988) p 1165). 


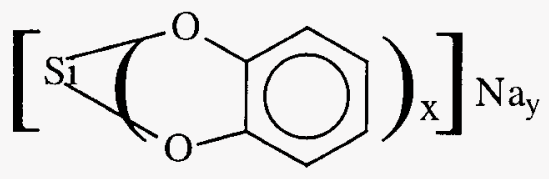

2

Finally tetramethylammonium silicates 3 have been prepared as well. Preliminary results show that in a fixed bed reactor, small amounts of Q' were obtained by reaction of either $\mathbf{2}$ or $\mathbf{3}$ with $\mathrm{MeOH}$. Various hypervalent silicates were combined with metal or metals from libraries. The silicate metal mixtures were exposed to methanol at various temperatures. No Q' formation was noted in any of the experiments. This approach was abandoned.

Task 2. Catalytic Synthesis of T', T'H and D' from Q'.

GE proposes to continue use of fixed bed lab reactors to make T', T'H, D' or related silane from Q' and an inexpensive reagent such as hydrogen, methane or the like. We anticipate that these reactions will be metal catalyzed and the catalyst package may employ one or more metals. GE will perform at least 100 experiments using fixed bed reactors. A one year Go/No Go decision point for this task is $50 \%$ yield of 'T', T'H or D' from $Q$ ' based on a catalyzed process using inexpensive raw materials. Formation of economically useful, high value materials may be possible with our new chemistry. The formation of the higher valued intermediates is viable even based on DMC. However, a process from a silica source and DMC followed by application of our new chemistry is economically viable only if we obtain high yields.

Reactor engineering expertise will be used to also look at reactors other than fixed bed reactors. A lab fluidized bed reactor will also be explored in order to evaluate this chemistry.

The mechanism of the reaction of Q' with the reactive intermediate to form T', T'H and D', which was established in Phase I, was studied in more detail. A byproduct in the reaction of Q' with the reactive reagent, which is formed in the first step of the 3-step mechanism, reacts with the intermediately formed T' $H$ to form $T^{\prime}$. This byproduct is therefore not an innocent byproduct as suspected as first. The reaction of the byproduct with T'H was identified to be a new route to Si-C bonds. In the course of our studies to develop a catalytic process based on the reaction of $Q$ ' with the reactive hydride to form T', we discovered the formation of T' $H$ from Q' using elemental hydrogen and a combination of 2 metals. T'H is a direct precursor to T'. Only the combination of two metals reacts with $Q^{\prime}$, but neither one of the metals by itself, suggesting synergistic effects. Similarly, synergistic effects in the production of T' from Q' and the reactive 
reagent were found using base and the fluoride promoter together. Unfortunately, no positive effects were found using base and promoter in the reaction of Q' with the transition metal based reagents.

During the course of our studies, a mechanistically new reaction starting from Q' was found. When $Q^{\prime}$ is passed through a bed of solid state support, which is intimately mixed with a base, $T$ ' is formed in substantial quantities. This reaction apparently proceeds by a mechanistically different pathway. Preliminary experiments suggest that surface area and particle size of the solid state support most likely is of importance. The exploration of the mechanism as well as general optimization of the reaction is currently under investigation.

A well known reaction for silicon is that with $\mathrm{MeOH}$ to form $\mathrm{Q}^{\prime}$ and $\mathrm{T}^{\prime} \mathrm{H}$. The silicon/ $\mathrm{MeOH}$ reaction is best performed in the presence of a $\mathrm{Cu}$ catalyst. John Lemmon and Dave Dietrich of the GE combi team, proposed the possibility of performing the silicon/MeOH reaction in the presence of $\mathrm{SiO}_{2} /$ base in the hopes that the silicon would somehow activate the $\mathrm{SiO}_{2}$ to react with the $\mathrm{MeOH}$. The combinatorial reactor did confirm a number of cases of silicon reaction with $\mathrm{MeOH}$ in the presence of different metal combinations. However no example of reaction of the $\mathrm{SiO}_{2}$ portion of the bed was found.

\section{Fixed Bed and Bomb Experiments}

Fixed bed experiments were run in attempt to "scale-up" some of the hits from the metal-catalyzed reaction silicon and $\mathrm{MeOH}$. Silicon with a $5 \% \mathrm{CuCl}$ and $50 \mathrm{ppm}$ tin (used typical MCS pre-contact mass) was mixed with $\mathrm{SiO}_{2}$ and $5 \% \mathrm{KOH}$. The mixed silicon silica bed was subjected to a flow of $\mathrm{MeOH}$ at various temperatures and formation or Q' and ' T'H was confirmed by gc and gcms. A number of experiments showed the following: SiO2- alone did not react to give any detectable products. Silicon and copper without added tin did not give products. The approach of reacting silicon and silica was abandoned.

New work focussed on direct production of dimethylcarbonate (DMC) followed by feed to a bed with $\mathrm{SiO}_{2}$ /base. Previous fixed bed experiments showed that $\mathrm{MeOH}, \mathrm{CO}$ and air passed through a bed of Cu catalyst led to formation of DMC. A library of different metals was screened for their ability to catalyze formation of DMC and to test whether in-situ DMC can pass through $\mathrm{SiO}_{2} /$ base to give Q'. No examples were found where "in-series" formation of first DMC then Q' occurred.

We had found that Q' fed over a bed of carbon and $\mathrm{NaOMe}$ with a $\mathrm{MeOH}$ stream at $300 \mathrm{C}$ gave $\mathrm{T}^{\prime}$ and $\mathrm{T}^{\prime} \mathrm{H}$. These results were confirmed in the fixed bed reactor and in a reaction carried out in a bomb. When a bomb was charged with carbon, $Q^{\prime}$ and $\mathrm{NaOMe}$ and heated under argon, gaseous products formed. The gas products were composed of $\mathrm{C} 1$ through $\mathrm{C} 5$ hydrocarbons, MeOMe (major) THF and small amounts of $\mathrm{CO} 2$. Extraction of the solids in the bomb with $\mathrm{MeOH}$ showed the presence of Q' as well as 'T" and $\mathrm{D}^{\prime}$. An attempt to replace carbon with silicon did not result in production of any new products. Replacement of carbon with $\mathrm{CO}$ (bomb experiment) did lead to formation of ' $\mathrm{T}$ ' and $D^{\prime}$. 


\section{Task 3. Economic Analysis}

3.1Re-evaluate the investment cost of a DMC-based process for our step 1 .

3.2 Investment and operating costs of new step 1 and all step 2 processes.

3.3 Determine viability of use of intermediates into industries other than silicones including fiber optics and silane coupling agents.

\section{This analysis is shown in Appendix 5.}

\section{Go No/Go decision at the end of Phase II.}

Using the GE investment criteria based on return on investment, we will go forward into Phase II if the investment targets are met. Also, the new process must achieve $90 \%$ yield of Q' in step 1 based on the silicon dioxide source AND the methyl source (DMC, $\mathrm{MeOH}$ or other cheap source). At least $70 \%$ of the D', silicone intermediate for the process to be viable. GE may decide to go into Phase III using the above processes to produce one or more of the intermediate compounds formed in the course of these investigations.

\section{Timing of Phase II}

We plan to begin Phase $\Pi$ on $9 / 1 / 00$ and complete this phase $8 / 31 / 02$. Both tasks will run simultaneously. A Go/No Go decision is after 1 year (8/31/01) and GE has the right to terminate the work if the technical objectives listed in the SOW are not met.

\section{Phase III}

With the termination of the contract, Phase III will not be executed. Below is the proposed Phase III effort.

$\underline{(\mathbf{G E})}$

Task III-1. In Phase III GE will take the optimized processes of Phase II and perform a 10-15 times scale-up. The scale-up will involve running a 10-15 times bigger reaction from Phase II and running the optimized conditions determined in Phase II.

Task III-2. Comprehensive Assessment of Technology. A GE chemical engineer will carry out Aspen or similar modeling to determine the commercial viability of these processes.

\section{Partner}

When we requested the change in SOW in September we asked to replace OMG as the partner and the DOE management agreed. We attempted to partner with University of California, Berkley (Prof. T/ Don Tilley). Unfortunately, they were not able to identify a student to work on the program. We then visited Clariant, Gainesville, FL in 2/2001. 
They were unable to commit to the program in a timely fashion. Thus at this late date we request that the requirement of a partner in this program be waived.

Original reason for dropping OMG as our partner:

GE proposes to replace OMG with another partner. As stated previously and documented in the quarterly reports, OMG consistently failed to deliver technical results. Their only contribution was in the last of the 8 quarters. GE is currently in negotiation with potential partners. We intend to have the partner participate in ALL tasks in Phase II. There is no partner in Phase III. 


\title{
Spin-off Discosveries
}

\section{Q' as SiO2 Precursor}

The optimized formation of (MeO)4Si (Q') was a key part of our program. We investigated value-added uses for $Q^{\prime}$ other than as a precursor for silicones. Q' is a potential feed source for fiber-optic quartz. We investigated the formation of $\mathrm{SiO} 2$ by burning Q' in a hydrogen flame. A summary of the work using Q' as an $\mathrm{SiO}_{2}$ source is given in Appendix 6.

\section{Q' as Silane Precursor}

The reaction of Q' with hydrides like $\mathrm{NaH}$ was used as a way to prepare (MeO)3SiH ( T'H) and (unexpectedly) MeSi(OMe)3 (T'). Under some conditions over reaction of $\mathrm{NaH}$ with Q' was observed and $\mathrm{SiH} 4$ was formed. The description of the work to intentionally make $\mathrm{SiH} 4$ from $Q^{\prime}$ is described in Appendix 7.

\section{Reaction of Base \& DMC with Metal Oxides $\neq \mathrm{SiO} 2$}

The reaction of base and DMC with $\mathrm{SiO} 2$ has been extensively investigated in this work. A brief attempt was made to see if metal oxides other than $\mathrm{SiO} 2$ were reactive under the conditions used for making Q'. We had previously found that (MeO)4Ti formed when Ticontaining silica sources were reacted with base and DMC. We found that germanium gave exciting results when reacted with DMC in the presence of base catalyst. Other metal oxides explored included stannic and stannous oxide, antimony oxide, gallium oxide and boron oxide. The results of this study are discussed in Appendix 8.

\section{Appendix 1}

\begin{abstract}
This report covers the first nine months of research efforts in the "Direct Production of Silicones from Sand" project (contract DE-FC02-98CH10931). The project is geared towards establishing a low-energy, halogen-free synthetic route to silicones from a commercial source of $\mathrm{SiO}_{2}$. The two major challenges are 1.) synthesis of $\mathrm{Si}(\mathrm{OR})_{4}$ from a commercial $\mathrm{SiO}_{2}$ source and 2.) catalytic $\mathrm{Si}-\mathrm{C}$ bond formation. The base-catalyzed formation of $\mathrm{Q}^{\prime}$ from natural $\mathrm{DE}$, a commercial $\mathrm{SiO}_{2}$ source, and $\mathrm{DMC}$ was found. Using MAIC Six Sigma tools, the process was optimized to $69 \% \mathrm{SiO}_{2}$ utilization towards 'Q'. The unexpected direct formation of $\mathrm{Me}_{2} \mathrm{Si}(\mathrm{OMe})_{2}$ from $\mathrm{KOH}$-treated flux-calcined $\mathrm{DE}$ was observed. The results suggest that the presence of metals is required. So far no catalytic formation of D' has been observed.
\end{abstract}

\section{INTRODUCTION}

Silicon, in form of silica and silicates, is the second most abundant element in the earth's crust. However the synthesis of silicones (Scheme 1) and almost all 
organosilicon chemistry is only accessible through elemental silicon. ${ }^{1}$ Silicon dioxide (sand or quartz) is converted to chemical-grade elemental silicon in an energy intensive reduction process, a result of the exceptional thermodynamic stability of silica. Then, the silicon is reacted with methyl chloride to give a mixture of methylchlorosilanes catalyzed by copper containing a variety of trace metals such as tin, zinc etc. The socalled direct process was first discovered at GE in $1940 .^{1-3}$ The methylchlorosilanes are distilled to purify and separate the major reaction components, the most important of which is dimethyldichlorosilane. Polymerization of dimethyldichlorosilane by controlled hydrolysis results in the formation of silicone polymers. Worldwide, the silicones industry produces about 1.3 billion pounds of the basic silicone polymer, polydimethylsiloxane.

\section{Scheme 1.}

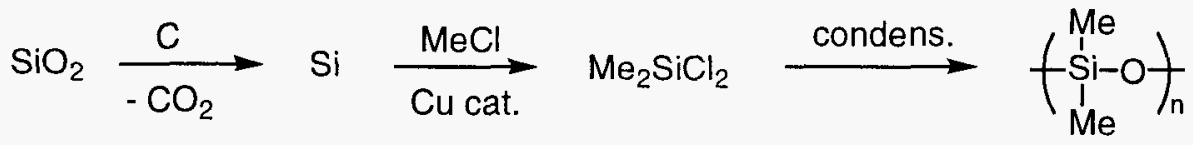

The energy costs associated with the route in Scheme 1are mainly a result of the reduction of $\mathrm{Si}(\mathrm{IV})$ to $\mathrm{Si}(0)$ and subsequent reoxidation to $\mathrm{Si}(\mathrm{IV})$. The conversion of silicon dioxide to elemental silicon in an electrochemical furnace at temperatures $\sim 1500$ ${ }^{\circ} \mathrm{C}$ consumes large amounts of electricity and carbon for reduction. Additionally, the production and separation of the methylchlorosilane mixture is energy intensive, involving several distillation steps.

An alternative synthetic route was proposed ${ }^{4}$ to the Department of Energy to avoid reduction and reoxidation of silicon as well as the use of chlorine containing intermediates. The proposal consists of a three-step route to silicone polymers starting from silicon dioxide (Scheme 2).

\section{Scheme 2.}

$$
\mathrm{SiO}_{2} \stackrel{\text { Step 1 }}{\longrightarrow} \mathrm{Si}(\mathrm{OMe})_{4} \stackrel{\text { Step 2 }}{\longrightarrow} \mathrm{Me}_{2} \mathrm{Si}(\mathrm{OMe})_{2} \stackrel{\text { Step 3 }}{\longrightarrow} \underset{\substack{\mathrm{Me} \\
\left(\begin{array}{c}
1 \\
\mathrm{Me}
\end{array}\right.}}{\stackrel{\mathrm{O}}{\mathrm{O}})_{\mathrm{n}}}
$$

Precedence for Step 1 in Scheme 2 was recently reported by Ono et al. ${ }^{5}$ starting from silica gel and gaseous dimethyl carbonate (DMC) at 500-600 K to yield tetramethoxysilane in the presence of a catalyst supported on the silica. The employed catalysts include $\mathrm{MX}(\mathrm{M}=\mathrm{Na}, \mathrm{K}, \mathrm{Rb}, \mathrm{Cs} ; \mathrm{X}=\mathrm{OH}, \mathrm{F}, \mathrm{Cl})$. Rice hull ash $\left(92 \% \mathrm{SiO}_{2}\right.$ purity) also reacts with DMC when loaded with $5 \mathrm{wt} \%$ of potassium hydroxide at 625 K. ${ }^{6}$

Earlier examples of the base catalyzed activation of $\mathrm{SiO}_{2}$ using alcohol derivatives include the formation of hexacoordinated dianionic complexes from silica (eq 1). ${ }^{7}$ 
<smiles>CC1(C)Oc2ccccc2O1</smiles>

Additionally, Laine and coworkers have shown that silicon dioxide reacts with base and a diol to form a reactive penta-coordinate silicate species (eq 2). ${ }^{8,9}$

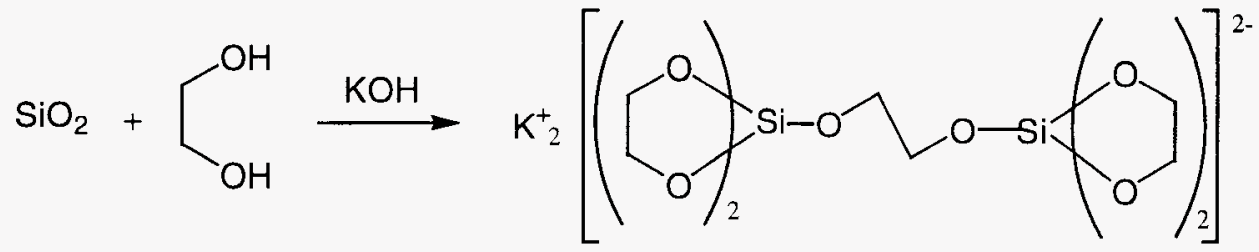

Very few other examples of the conversion of silicon dioxide to silicate-like compounds have been reported. ${ }^{10}$

Currently the only access to dialkyldialkoxysilane from tetraalkoxysilane (Step 2) involves the stoichiometric transformation using Grignard reagents. ${ }^{11,12}$ The hydrolytic polymerization of alkylalkoxysilanes to silicone polymers (Step 3) is a process that is practiced commercially.

The two major challenges connected with this proposed approach to silicones from silicon dioxide are:

- Optimization of the alkoxysilane synthesis from a low-cost silicon dioxide source.

- Innovation of a new process for synthesis of alkylalkoxysilane from alkoxysilane.

This report, the first of a series of progress reports under the title 'Sand to Silicones', describes the synthesis of tetramethoxysilane ( $Q$ ') from a low-cost silicon dioxide source and unexpected results regarding the formation of dimethyldimethoxysilane (D') directly from silicon dioxide.

\section{EXPERIMENTAL}

\section{Fixed-bed lab reactor.}

A schematic representation of the fixed-bed flow reactor used is shown in Figure 1. The reactor is a glass tube $(20 \mathrm{~cm}$ long; $1 \mathrm{~cm}$ inner diameter) with a porous glass grid to hold the $\mathrm{SiO}_{2}$ sample. The reactor is centered vertically in a Nichrome ribbon wound glass tube ( $5 \mathrm{~cm}$ outer diameter). Two pairs of electrodes were fitted to the Nichrome to create two heated zones. The top heating zone is used to preheat the DMC/carrier gas mixture, the bottom section for the reactor itself. The Nichrome wound tube was centered in a quartz glass tube $(6.4 \mathrm{~cm}$ outer diameter) for insulation and safety purposes. The carrier gas stream was regulated using a mass flow controller (MKS Instruments type 1179A) connected to a four channel readout device (MKS Instruments type 247D). The 
DMC was added into the carrier gas stream (typically argon) above the upper heating zone through a septum via motor driven syringe. The reactor downstream was collected using a water-chilled condenser.

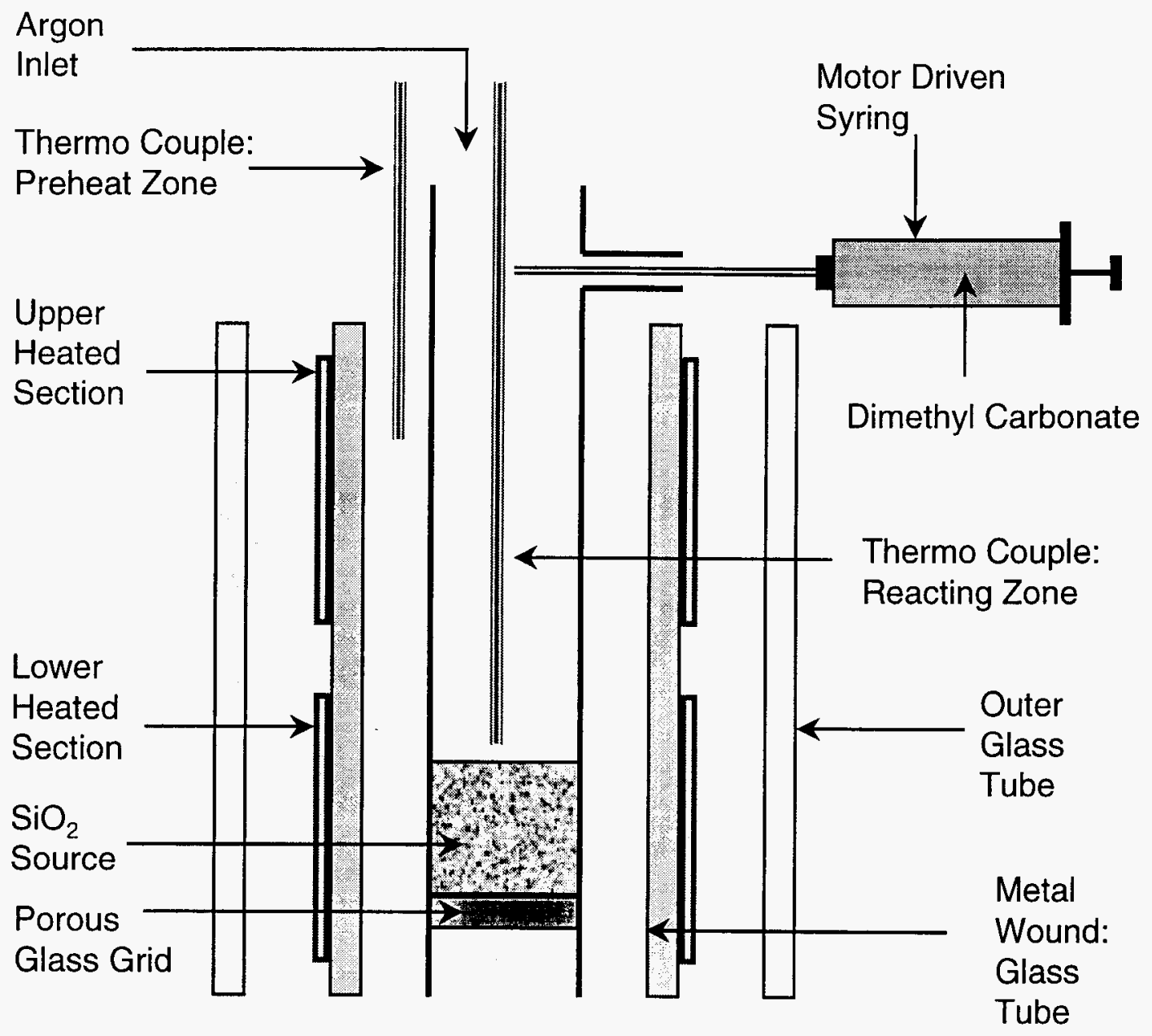

Figure 1. Schematic representation of fixed-bed flow reactor.

\section{Reaction of $\mathrm{SiO}_{2}$ source with DMC.}

Typical procedure. The $\mathrm{SiO}_{2}$ source was stirred in an aqueous solution of $\mathrm{KOH}$. The suspension was heated to dryness and the solid obtained was further dried overnight at $115^{\circ} \mathrm{C}$. The material was ground and charged into the described fixed-bed flow reactor with vertical furnace. The solid (typically $0.8 \mathrm{~g}$ ) was kept at the reaction temperature (typically $320^{\circ} \mathrm{C}$ ) in the argon stream for $1 \mathrm{~h}$. DMC (typically $20 \mathrm{mmol} / \mathrm{h}=1.68 \mathrm{~mL} / \mathrm{h}$; total of $10 \mathrm{~mL}$ ) was fed into the carrier gas stream $(20 \mathrm{~mL} / \mathrm{min})$ using a motor driven syringe. The reactor products downstream were collected in fractions using a water chilled condenser and analyzed by gas chromatography $(\mathrm{GC})$. Formation of $\mathrm{Si}(\mathrm{OMe})_{4}$ 
(Q'), $\mathrm{Me}_{2} \mathrm{Si}(\mathrm{OMe})_{2}$ (D') and traces of $\mathrm{MeSi}(\mathrm{OMe})_{3}\left(\mathrm{~T}^{\prime}\right)$ was confirmed by GC/MS and ${ }^{1} \mathrm{H}$ NMR. The $\mathrm{SiO}_{2}$-utilization values (\%) were calculated from the collected amounts of $\mathrm{Si}(\mathrm{OMe})_{4}$ and $\mathrm{Me}_{2} \mathrm{Si}(\mathrm{OMe})_{2}$ (determined by GC). The weight difference in the $\mathrm{SiO}_{2}$ bed before and after reaction was also determined, however a black carbon-based deposit rendered a precise weight determination impossible. In the experiments using metal doped silica gel and colloidal silica the reaction temperature was changed to $350^{\circ} \mathrm{C}$ from $320^{\circ} \mathrm{C}$ after $3 \mathrm{~h}$.

A water-chilled condenser was used due to the high melting point of DMC (m.p. = 2$4{ }^{\circ} \mathrm{C}$ ). During the course of the work reported, the condensation method was improved by adding a trap immersed in a dry ice/acetone bath in series after the water condenser.

MS Real Time Monitoring. Jim Carnahan proposed and implemented a modification of the current setup consisting of an additional outlet in the glass elbow downstream of the reactor. A capillary inserted through a septum sealing the outlet allows sampling of the downstream by MS. The various amounts of DMC, D' and Q' can be determined by extraction from the total signals. The reactions were carried out as described in the typical procedure.

UV experiments. The experimental setup was identical to the one described above with an UV light source attached to the outer wall of the reactor setup. All glass parts (outer glass tube, metal wound inner tube and the reactor) consisted of UV transparent quartz glass. Two different UV sources were employed: a low power, monochromatic (254 or $366 \mathrm{~nm}$ ) UV lamp and a medium pressure Hg lamp (450 W).

The following $\mathrm{SiO}_{2}$ sources were used in the above described procedure:

- Silica gel: Davison Chemical Division W. R. Grace \& Co (grade 12; $700 \mathrm{~m}^{2} / \mathrm{g}$ surface area).

- Natural diatomaceous earth: Celite Snow Floss ${ }^{\circledR}$; Celite $209^{\circledR}$; Celite FC ${ }^{\circledR}$ and Dicalite SA $-3^{\circledR}$.

- Calcined diatomaceous earth: Celite $270^{\circledR}$.

- Flux-calcined diatomaceous earth: Celite Hyflo ${ }^{(1)}$ and Celite $545^{(1)}$.

- Titanium-containing zeolites TS-1 (1.25\% Ti and 10\% Ti).

\section{RESULTS AND DISCUSSION}

\section{Tetramethoxysilane from Diatomaceous Earth.}

\section{Validation of literature synthesis of Q'.}

The reported base-catalyzed synthesis of Q' starting from silica gel ${ }^{5}$ was investigated serving two purposes, first to test this reaction in our reactor setup and second to use the data as a benchmark for other $\mathrm{SiO}_{2}$ sources. The literature procedure uses a small-scale 
setup ( $2 \mathrm{mmol}, 120 \mathrm{mg}$ of $\mathrm{SiO}_{2}$ ) and the products downstream were directly monitored by $\mathrm{GC}$ without the use of a condenser. Quantitative $\mathrm{SiO}_{2}$ utilization was reported. ${ }^{5}$

In the current work, silica gel ( $200 \mathrm{mg}$ ), loaded with $4.5 \% \mathrm{KOH}$ catalyst, was reacted with DMC at $320^{\circ} \mathrm{C}$. GC analysis of the down stream products showed only two signals, Q' and unreacted $\mathrm{DMC}$. $\mathrm{SiO}_{2}$-utilizations of $93 \%$ and $88 \%$ were found for two independent experiments. The $\mathrm{SiO}_{2}$ beds turned deep black indicating carbon deposit.

\section{Q' from fumed silica.}

In the context of screening available $\mathrm{SiO}_{2}$ sources, fumed silica was used as a reagent. The fumed silica, doped with $4.6 \% \mathrm{KOH}$, reacted almost quantitatively with DMC at 320 ${ }^{\circ} \mathrm{C}$ to give Q'.

\section{Diatomaceous earth, a low-cost $\mathrm{SiO}_{2}$ source.}

The literature synthesis of Q' uses silica gel as the $\mathrm{SiO}_{2}$ form. Silica gel is made from $\mathrm{SiCl}_{4}$ and ultimately from elemental silicon and therefore commercially unattractive. Additionally, silica gel has a very high surface area $\left(>100 \mathrm{~m}^{2} / \mathrm{g}\right)$. The biggest challenge for a potential commercial implementation of the base-catalyzed synthesis of Q' from $\mathrm{SiO}_{2}$ and $\mathrm{DMC}$ represents the discovery of a reaction using a lowcost silicon dioxide source.

Diatomaceous earth (DE), also known as diatomite, is a naturally occurring, porous, high surface area form of hydrous silica. DE consists mainly of accumulated shells of intricately structured amorphous hydrous silica secreted by diatoms, which are microscopic, one celled algae. All diatom species (more than 12,000 species are known) have an elaborately ornamented siliceous skeleton, which results in accumulations of uniquely porous particle of high surface area. Three general types of DE are commercially available, natural, calcined and flux-calcined. The natural product results from mining of the crude DE, careful grinding (to preserve the intricate structure of DE) and drying. The calcined type is produced by subjecting the natural $\mathrm{DE}$ to high temperatures $\left(900-1000^{\circ} \mathrm{C}\right)$. The flux-calcined material is obtained by calcining the natural product in the presence of a fluxing agent, generally sodium carbonate. A selection of relevant properties is listed in Table 1. Annual production in 1990 in the USA totaled 619,000 $\mathrm{t}$ and exceeded 1.8 Mt world wide.

Table 1. Ranges of selected properties of diatomaceous earth products. ${ }^{a}$

\begin{tabular}{llll}
\hline Property & Natural & Calcined & Flux-calcined \\
\hline & & & \\
specific gravity & 2.00 & 2.25 & 2.33 \\
porosity, by volume $(\%)$ & $65-85$ & $65-85$ & $65-85$ \\
surface area $\left(\mathrm{m}^{2} / \mathrm{g}\right)$ & $10-30$ & $4-6$ & $1-4$ \\
Crystalline content $(\%)$ & $<5$ & $5-10$ & $>60$ \\
\hline
\end{tabular}


${ }^{a}$ Values given are typical or estimated values.

As a result of its natural formation, DE contains a wide variety of metals in form of their oxides in addition to $\mathrm{SiO}_{2} . \mathrm{SiO}_{2}$ contents range between $70 \%$ and more than $90 \%$. Most of the samples commercially available in the US contain $85-90 \% \quad \mathrm{SiO}_{2}$. For example Celite $\mathrm{Hyflo}^{\circledR}$ contains $\mathrm{Al}(2.6 \%)$, Fe $(1.0 \%)$, Na $(3.3 \%), \mathrm{K}(0.5 \%)$, Ca $(0.4 \%)$, $\mathrm{Mg}(0.4 \%)$, Ti $(0.1 \%)$ and other elements (50-1000 ppm) such as $\mathrm{Ba}, \mathrm{Mn}, \mathrm{Ni}, \mathrm{Cr}, \mathrm{Zn}, \mathrm{Sr}$.

\section{$\mathrm{SiO}_{2}$ utilization.}

$\mathrm{DE}$, treated with $\mathrm{KOH}$, reacts at temperatures between 300 and $360{ }^{\circ} \mathrm{C}$ to yield Q'. The $\mathrm{SiO}_{2}$-utilization is a function of the commercial grade of the $\mathrm{DE}$. The flux-calcined grade (Celite $\mathrm{Hyflo}^{\circledR}$ ) exhibits the lowest $\mathrm{SiO}_{2}$ utilization $(<5 \%)$. $\mathrm{SiO}_{2}$-utilization for the calcined grade was found to be $10 \%$ (Celite $270^{\circledR}$ ). $\mathrm{SiO}_{2}$-utilization for the natural grade DE (Celite Snow Floss ${ }^{\circledR}$ ) was optimized to $69 \%$. The difference in reactivity between the three commercially available grades can best be explained by the variation in surface area, crystallinity and porosity (Table 1) with the surface area most likely representing the decisive factor (higher surface area equals higher $\mathrm{SiO}_{2}$-utilization).

The $\mathrm{SiO}_{2}$ utilization also depends on a variety of process factors, the most vital being the amount of $\mathrm{KOH}$ loading and the reaction temperature. The dependence of the $\mathrm{SiO}_{2}-$ utilization on reaction conditions was established in the frame work of a Six Sigma project and details of the screening DOE and the subsequent optimization will be communicated in a separate CRD report. ${ }^{13}$

\section{DMC decomposition.}

The decomposition of DMC into dimethylether and carbon dioxide was already reported as a significant side reaction in the work by Ono et al. At $550 \mathrm{~K}$, Ono and coworkers found the DMC consumption and the transformation of DMC into Q' to be about equal, indicating that the gas phase decomposition of DMC was negligible. However at $600 \mathrm{~K}$ they reported significant decomposition.

Mass balance analysis supports DMC decomposition findings from our work. DMC utilization is defined as the ratio of DMC reacted towards Q' and the DMC consumed. DMC consumed is calculated by subtracting the recovered DMC from the added DMC. It is important to note that DMC loss due to inefficient condensing is included. Typically DMC utilization for the commercially viable natural DE is less than $20 \%$.

\section{Mechanistic aspects.}

A plausible mechanism for formation of $\mathrm{Q}^{\prime}$ from $\mathrm{SiO} 2$ and $\mathrm{DMC}$ is depicted in Figure 2. The mechanism is consistent with the data reported by Ono et al., computational data from Molecular Simulations Inc. and our own observations. 


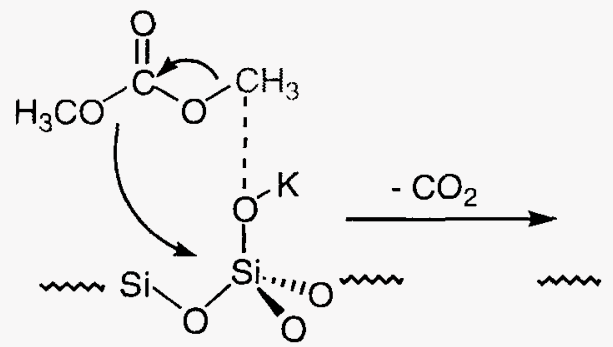<smiles>CO[Si](O)(OC)O[Te]</smiles><smiles>[Y]O[Si][Si](OC)(OC)OC</smiles><smiles>CO[Si](OC)(OC)OC</smiles><smiles>[Y]O[Si](C)(OC)OC</smiles><smiles>[Y]O[Si](OC)(OC)OC</smiles>

Figure 2. Proposed mechanism for the base catalyzed formation of Q' from $\mathrm{SiO}_{2}$.

Consistent with the literature, ${ }^{14}$ the $\mathrm{KOH}$-treated $\mathrm{SiO}_{2}$ surface likely contains $\mathrm{Si}-\mathrm{O}-\mathrm{K}$ linkages as structural units under the typical reaction conditions. Calculations by Molecular Simulations Inc. (MSI) show that Si-O bonds elongate upon interaction with the potassium ion (from 1.63 to $1.67 \mathrm{~A}$ ) suggesting an activation of the $\mathrm{Si}-\mathrm{O}$ bond. Experiments using a modified reactor setup that allowed mass spectrometry detection directly downstream of the reactor, showed the exclusive production of $\mathrm{CO}_{2}$ directly after the start of the DMC addition. Q' formation was observed after an induction period. The computational results are consistent with the proposed mechanism because initially the reaction of DMC with the potassium-containing $\mathrm{SiO}_{2}$ surface results solely in the methylation of the silica surface under formation of $\mathrm{CO}_{2}$ (Figure 2). The formation of Q' requires a second activation of the methylated silica surface by $\mathrm{K}^{+}$followed by reaction with a second molecule of DMC. 


\section{Dimethyldimethoxysilane Directly from $\mathrm{SiO}_{2}$.}

The following section describes the unprecedented direct formation of D' from $\mathrm{SiO}_{2}$. This direct formation has been confirmed in different experimental setups and under a variety of conditions. However, many experiments reported in the following section were analyzed using an early GC setup with significant noise. Also, we found that decomposition of silicone grease produces additional D' in some cases affecting the determined amount of some of the reported results. In one case the D' that apparently formed decreased from $0.9 \%$ to $0.2 \%$; the $0.2 \% \mathrm{D}^{\prime}$ was confirmed by GCMS analysis. Nevertheless, the direct formation of $\mathrm{D}^{\prime}$ from $\mathrm{SiO}_{2}$ has been proven and we are currently running all experiments in a grease-free system using a highly reproducible GC instrumentation

\section{Direct Formation of D' from Diatomaceous Earth.}

Reaction of DMC with KOH-treated, flux-calcined DE (Celite Hyflo ${ }^{\circledR}$ ) at $320{ }^{\circ} \mathrm{C}$ unexpectedly yields D' (Figure 3) in addition to Q' (main product) and T'. The formation of D' was confirmed by GC, GC/MS and ${ }^{~} \mathrm{H}$ NMR. Analogous reactions employing natural $\mathrm{DE}$ do not result in the direct production of D'. Consistent with the literature, no D' formation is observed from $\mathrm{KOH}$-treated silica gel. The proof of concept of the formation of $\mathrm{Si}-\mathrm{C}$ bonds directly from $\mathrm{SiO}_{2}$ represents a fundamental discovery. Most of the research efforts described in the following sections are geared towards understanding this direct formation as well as increasing the yield of D'.

Gas-solid reactions take place at the interface of the two phases. Extensive efforts in surface analysis were carried out in order to link surface properties of flux-calcined $\mathrm{DE}$ with this unusual direct formation of $\mathrm{D}^{\prime}$.

The most obvious difference between flux-calcined $\mathrm{DE}$ and a $\mathrm{SiO}_{2}$ source that does not produce D' directly such as silica gel, is the presence of additional metals $(\sim 10 \%)$. Much of the work reported below is concerned with exploring the effects of metals.

Finally, work will be reported that addresses the mechanistic aspects of the direct formation of D'.

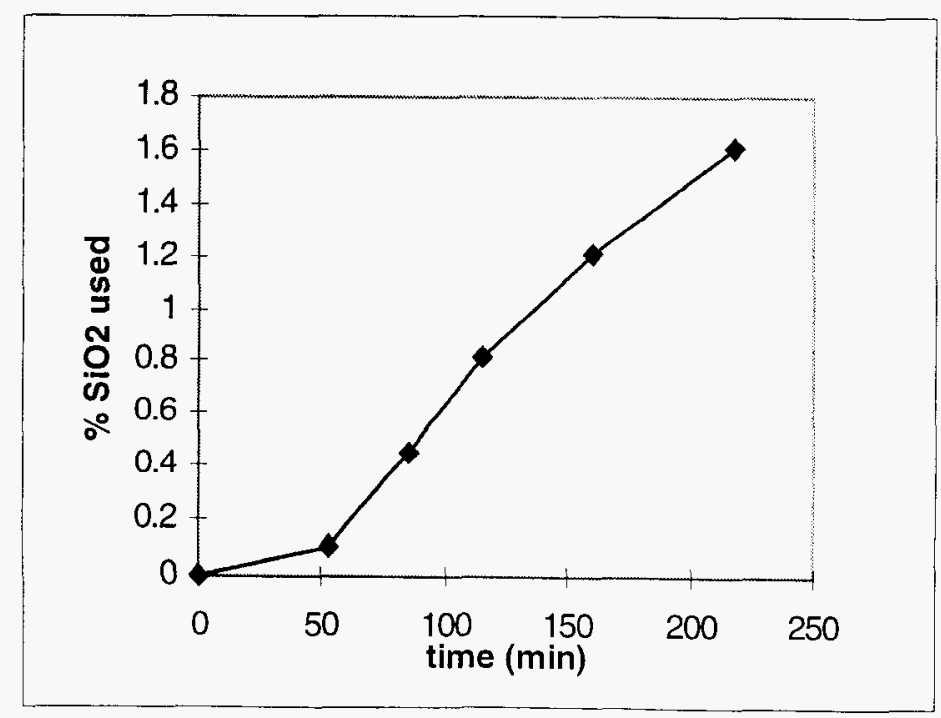


Figure 3. $\mathrm{SiO}_{2}$-utilization towards formation of 'D'.

\section{Surface Analysis of Celite Samples.}

SEM analysis of DE samples. SEM surface analysis was carried out on Celite Snow Floss $^{\circledR}$ (natural DE) with and without KOH catalyst (Figure 4) and on Celite Hyflo ${ }^{\circledR}$ (flux-calcined DE) with and without $\mathrm{KOH}$ catalyst (Figure 5). Figure 4 and 5 show the intricate structures of various DE species. The natural DE sample exhibits a wide distribution of particle size. In comparison, the flux-calcined DE has a lower particle size distribution and also shows some flake type materials. 


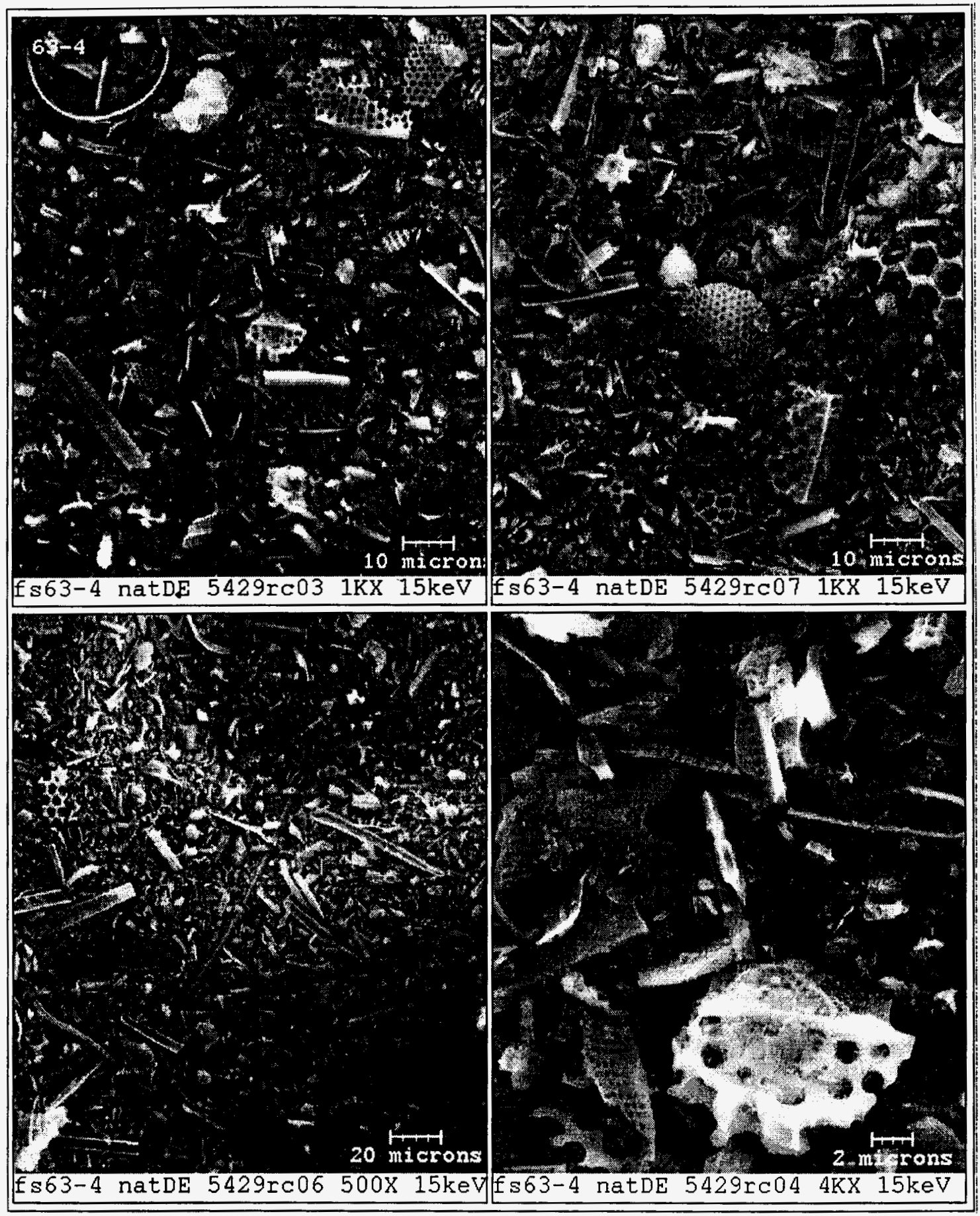

Figure 4. SEM of natural DE (Celite Snow Floss ${ }^{\circledR}$ ). 


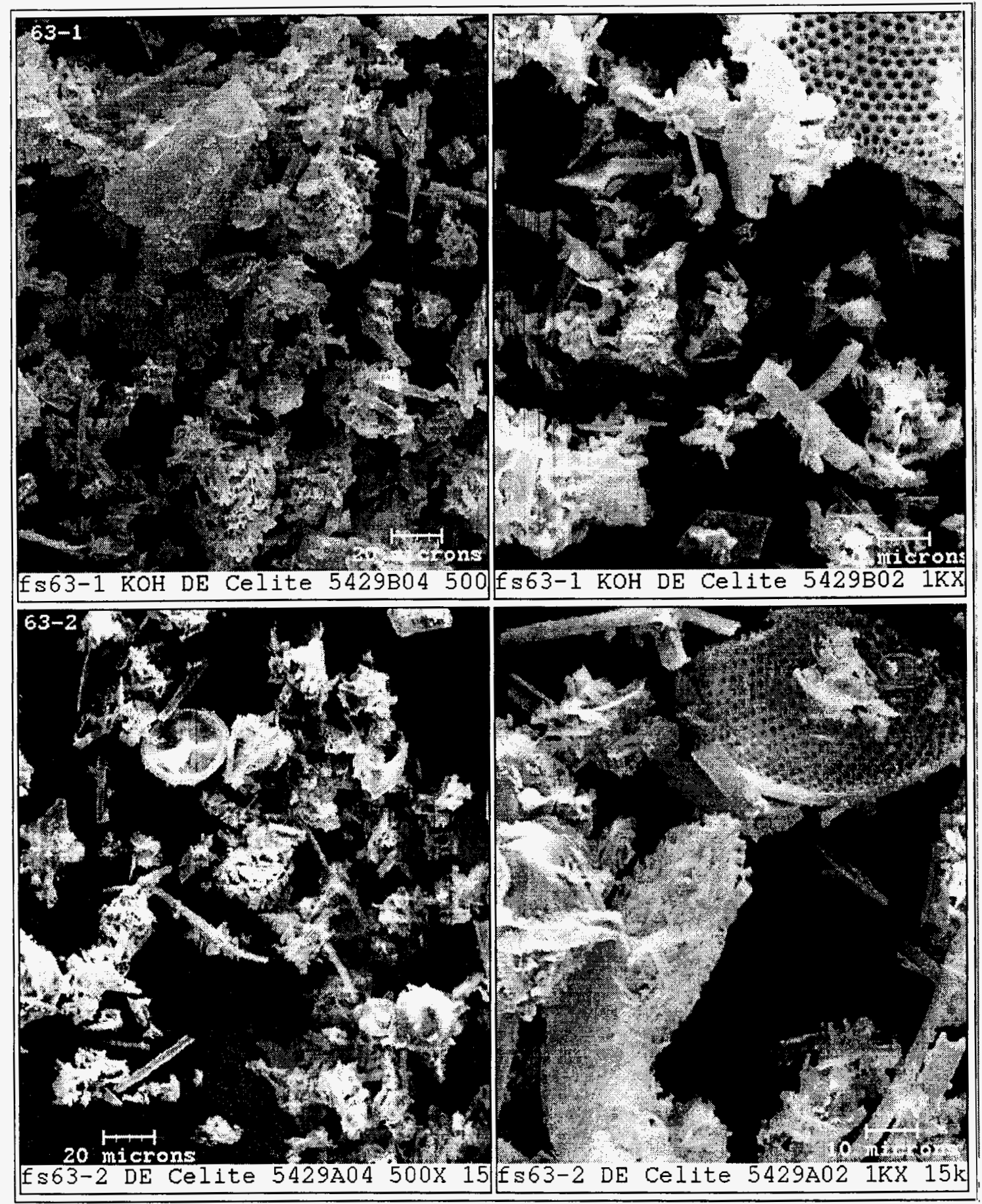

Figure 5. SEM of flux-calcined DE (Celite Hyflo $\left.{ }^{(}\right)$with $\mathrm{KOH}$ (top) and without $\mathrm{KOH}$ (bottom).

XPS surface analysis of Celite samples. XPS surface analysis was performed on Celite $\mathrm{Hyflo}^{\circledR}$ (calcined DE) with and without $\mathrm{KOH}$ catalyst treatment to obtain the average elemental composition on the surface. For comparison Celite Snow Floss ${ }^{(1)}$ (natural DE) was also investigated with and without $\mathrm{KOH}$ catalyst: 
- Surface $\mathrm{Al}, \mathrm{Mg}$ levels correlate well with the bulk elemental analysis (flux-calcined $\mathrm{DE})$.

- Flux-calcined DE shows higher $\mathrm{Na}$ levels (3.3\%) than the natural DE $(0.4 \%)$ as expected.

- Surprisingly Fe was either not detected (flux-calcined DE) or only at low levels (less than $0.2 \%$ for natural DE).

- Interestingly the Si content was found to be higher for the natural DE (31\%) than for the flux-calcined material $(26 \%)$.

Field emission scanning auger nanoprobe surface analysis of Celite samples. Auger nanoprobe surface analysis was employed to detect differences in the elemental composition on the surface between various DE particles. So far only Celite Snow Floss ${ }^{\circledR}$ (natural DE with $\mathrm{KOH}$ catalyst) was investigated.

- The Fe levels (average of $1.3 \%$ above noise level) were too close to the noise level to identify local differences.

- No correlation of the Fe signal with the Al or the Si signal was found.

- Occasionally Mg was detected (1-2\%) barely above noise level.

The metal levels are too close to the detection limit for this surface analysis technique. Therefore the analysis of a flux-calcined DE sample (Celite Hyflo ${ }^{(1)}$ ) was cancelled.

Overall the data obtained from surface analysis have been inconclusive. No significant differences between the elemental composition of the surface and that of the bulk material were observed. The concentration levels of the metals were generally found to be too close to the detection limit.

\section{Effects of Metals on the Direct Formation of D'.}

\section{D' from metal doped silica gel.}

The presence of metals offers a potential explanation for the unusual direct formation of D' from $\mathrm{SiO}_{2}$. Surface doping of silica gel with a variety of metal compounds represents an easily accessible route in exploring the impact of metals on the formation of D'. Two silica gel samples with different amounts of metal compounds (w\%) were prepared in addition to a control sample only containing a potassium source (Table 5). $\mathrm{KOH}$ could not be used for the surface treatment since several of the metal compounds precipitate under basic conditions.

Table 5. Metal content of surface doped silica gel samples.

\begin{tabular}{cccccccc}
\hline \multicolumn{7}{c}{ Sample composition [\%] } \\
Sample & $\mathrm{SiO}_{2}$ & $\mathrm{KF}$ & $\mathrm{FeCl}_{3}\left(\mathrm{H}_{2} \mathrm{O}\right)_{6}$ & $\mathrm{FeCl}_{2}\left(\mathrm{H}_{2} \mathrm{O}\right)_{4}$ & $\mathrm{MgCl}_{2}$ & $\mathrm{CuSO}_{4}$ & $\mathrm{Ca}\left(\mathrm{O}_{2} \mathrm{CMe}_{2}\right.$ \\
\hline A & 81.2 & 3.8 & 4.4 & 2.9 & 1.7 & 3.7 & 2.4 \\
B & 89.2 & 2.4 & 2.4 & 1.6 & 1.0 & 2.1 & 1.3
\end{tabular}


Samples A, B and C were used in the reaction with DMC. As shown in Figures 6-11, an increase in the production of D' can be observed when metal doped silica gel samples (A and B) are used. The effect of metals on D' production was not dramatic. Surprisingly, sample $C$ also showed the production of $\mathrm{D}^{\prime}$, although on a lower level than $\mathrm{A}$ and $\mathrm{B}$. Formation of $\mathrm{D}^{\prime}$ from $\mathrm{SiO} 2$ and $\mathrm{KOH}$ has not been observed. As mentioned before, D' formation also could be attributed to decomposition of the silicone grease. Also surprisingly, sample A with a higher metal content gave lower overall yield in $D^{\prime}$ than sample B. Sample A and $\mathrm{B}$ showed lower $\mathrm{SiO}_{2}$-utilization towards Q' compared to the control sample $\mathrm{C}$. Towards the end of the reaction, the deposited metal compounds may block access to the $\mathrm{SiO}_{2}$ surface.

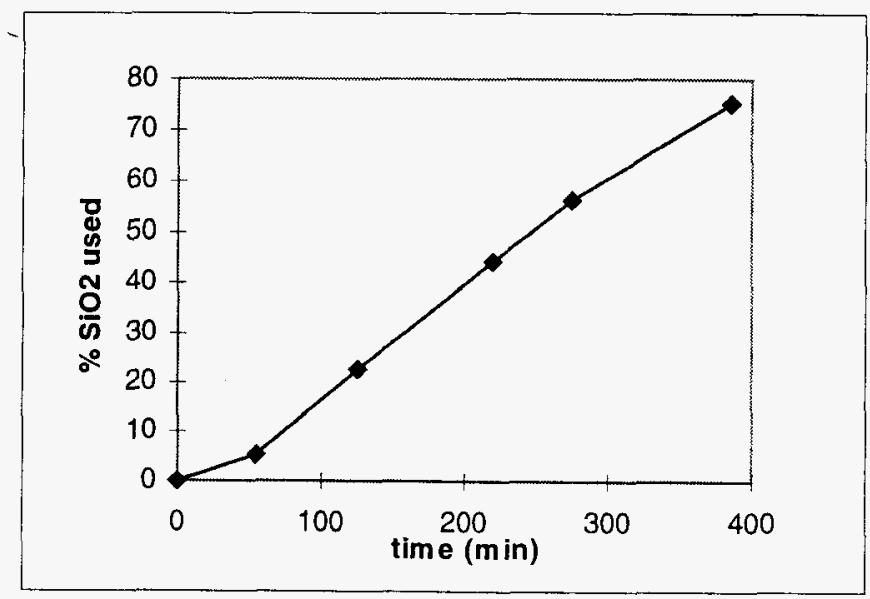

Figure 6. $\mathrm{SiO}_{2}$-utilization towards the formation of Q' using doped silica gel sample A. 


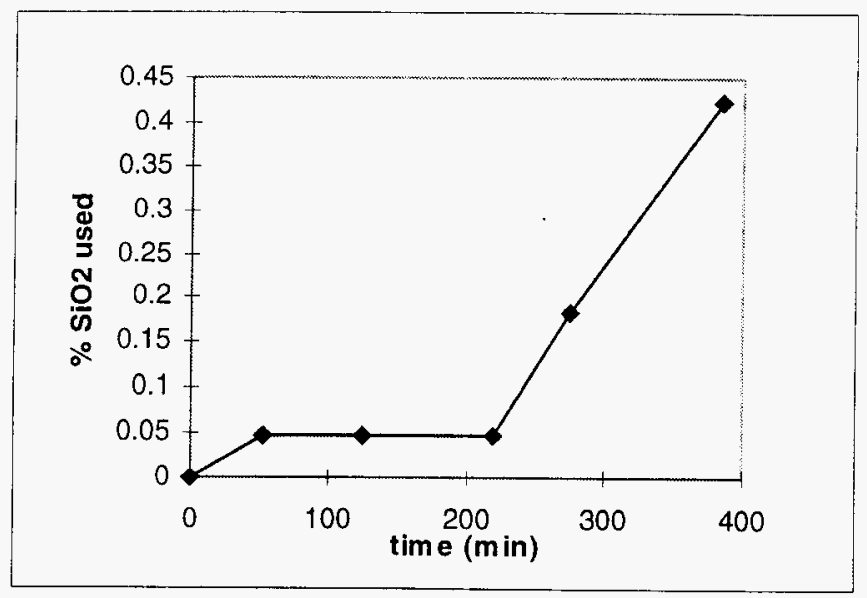

Figure 7. $\mathrm{SiO}_{2}$-utilization towards the formation of D' using doped silica gel sample A.

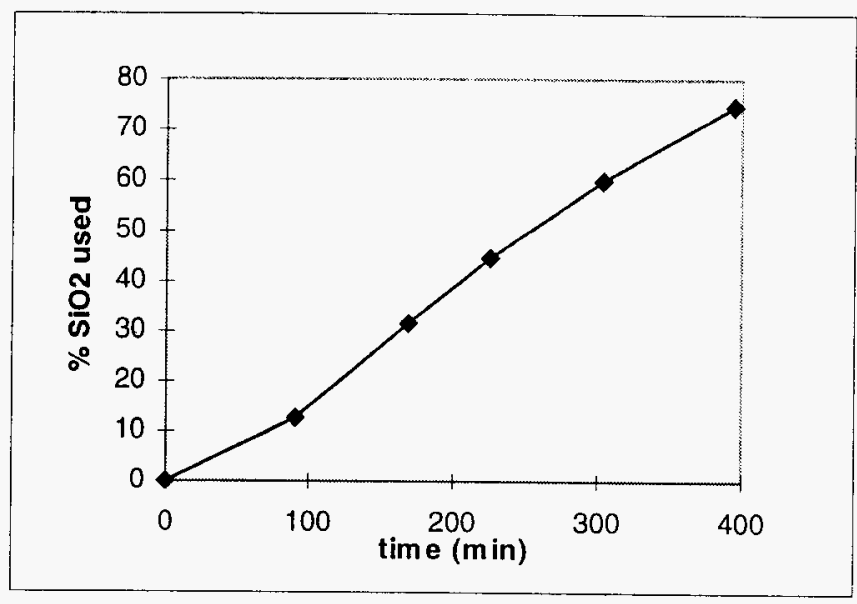

Figure 8. $\mathrm{SiO}_{2}$-utilization towards the formation of Q' using doped silica gel sample $\mathrm{B}$. 


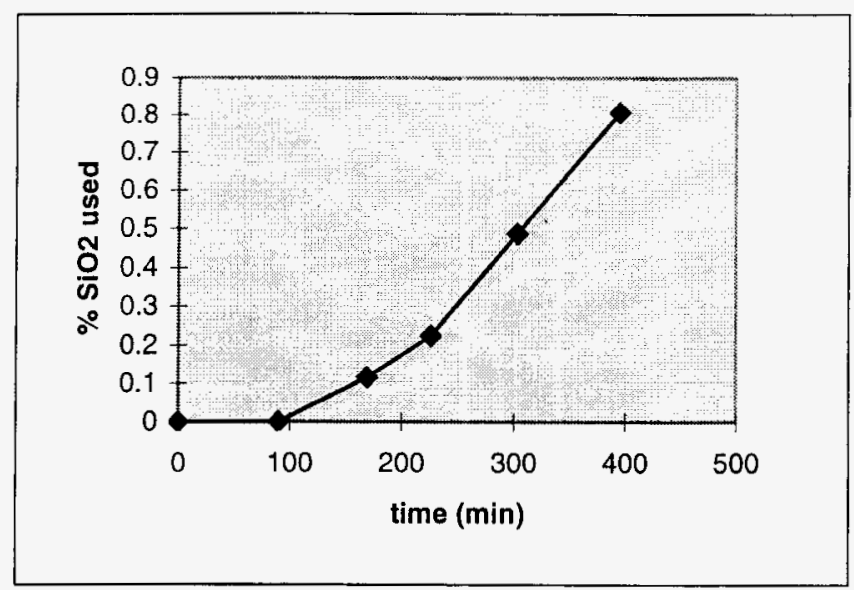

Figure 9. $\mathrm{SiO}_{2}$-utilization towards the formation of $\mathrm{D}^{\prime}$ using doped silica gel sample $\mathrm{B}$.

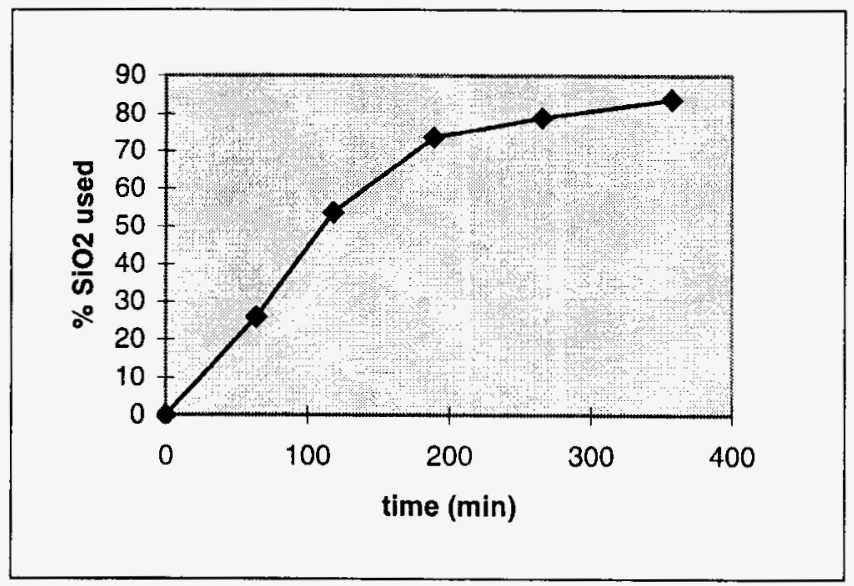

Figure 10. $\mathrm{SiO}_{2}$-utilization towards the formation of Q' using control sample $\mathrm{C}$.

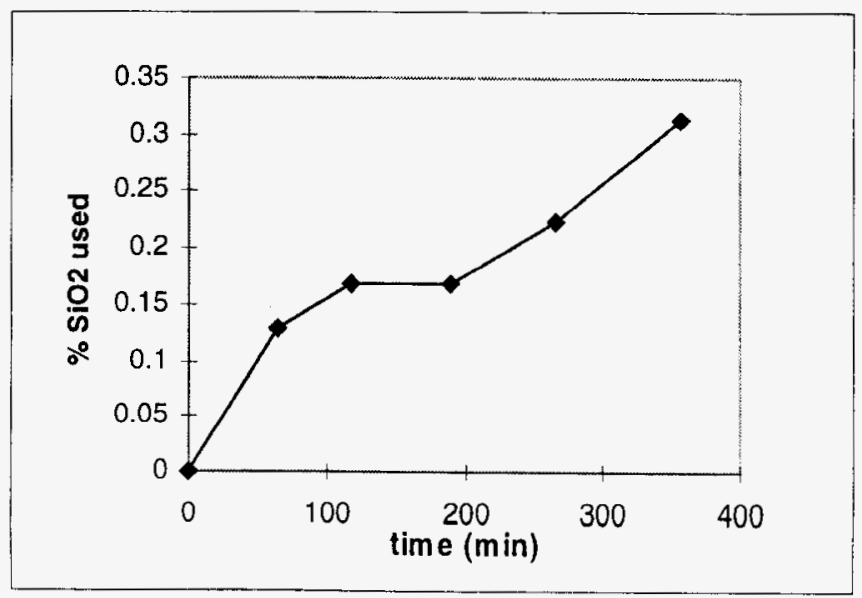


Figure 11. $\mathrm{SiO}_{2}$-utilization towards the formation of $\mathrm{D}^{\prime}$ using control sample $\mathrm{C}$. 


\section{Colloidal silica as silicon dioxide source.}

Deposition of metal compounds on the surface of silica gel results in high concentrations of metals on the surface, but no incorporation into the bulk material. For materials with extremely high surface area such as the silica gel surface deposition is sufficient, however it is still desirable to find a method that allows incorporation of the metal compounds. Co-precipitation of metal compounds with colloidal silica is one viable option to achieve bulk metal incorporation into other forms of silica. Two metal doped colloidal silica samples were prepared (Table 6):

Table 6. Composition of metal containing silica samples prepared by coprecipitation of metal compounds with colloidal silica.

\begin{tabular}{lll}
\hline \multicolumn{1}{c}{ Sample $\mathrm{D}^{\mathrm{a}}$} & \multicolumn{1}{c}{${\text { Sample } \mathrm{E}^{\mathrm{a}}}_{\mathrm{KF}(5 \%)}$} & Sample F $^{\mathrm{a}}$ \\
\hline aluminum acetate $(1 \%)$ & $\mathrm{KF}(5 \%)$ & $\mathrm{KF}(5 \%)$ \\
titanium oxalate $(1 \%)$ & titanium oxalate $(1 \%)$ & \\
magnesium chloride $(1 \%)$ & magnesium chloride $(1 \%)$ & \\
calcium acetate $(1 \%)$ & calcium acetate $(1 \%)$ & \\
ferrous chloride $(1 \%)$ & ferrous chloride $(1 \%)$ & \\
& copper(1) chloride $(1 \%)$ & \\
\hline
\end{tabular}

${ }^{a}$ Remaining balance of total composition is colloidal silica.

$\mathrm{SiO}_{2}$-utilization towards production of D' (based on $\mathrm{GC}$ ):

Sample D: $0.63 \% \mathrm{SiO}_{2}$ used (9.2 mg D' found).

Sample E: $0.54 \% \mathrm{SiO}_{2}$ used (7.7 mg D' found).

Sample F: $0.20 \% \mathrm{SiO}_{2}$ used (3.0 mg D' found).

The metal-treated colloidal silica samples exhibited similar reactivity behavior compared to the metal doped silica gel samples. The D' production triples upon metal doping of the silica sample, however total D' production is still low (sub-stoichiometric based on metal compounds). Colloidal silica with and without metal doping serves as a good model for silica gel in terms of D' and Q' production.

\section{Mechanistic Aspects.}

The following section will cover the approaches we took to shed some light on the mechanism of Q' and D' formation. The direct formation of D' has only been observed at low yields so far $\left(\mathrm{SiO}_{2}\right.$-utilization $\left.<2 \%\right)$. Therefore, efforts have been directed towards changing reaction conditions, feed stock etc. and monitoring effects in the product distribution. 
Alternative reaction pathways. An important question arises from the observed direct formation of D'. Is the D' formation a result of the primary reaction of DMC with a $\mathrm{SiO}_{2}$ fragment on the surface or does it form in a secondary reaction from intermediately formed Q'?
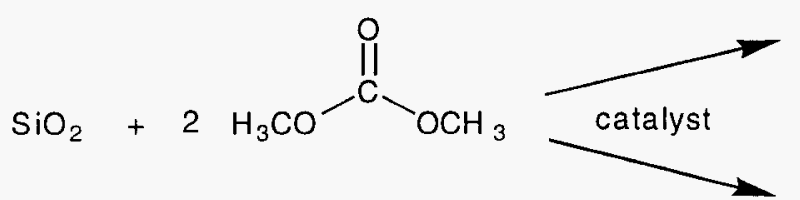
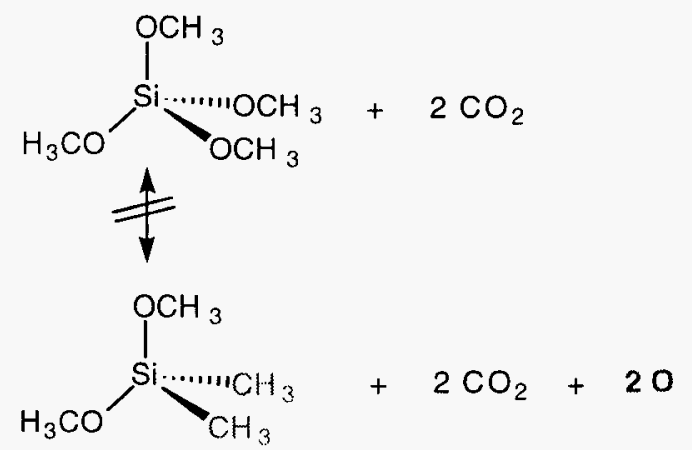

Figure 12. D' and Q' form in alternative reaction pathways.

Reaction of Q' with flux-calcined DE $(5.2 \% \mathrm{KOH})$ at $360^{\circ} \mathrm{C}$ did not show the formation of $D^{\prime}$. Adding a mixture $(1 / 1 \mathrm{w} / \mathrm{w})$ of $\mathrm{DMC}$ and $\mathrm{Q}^{\prime}$ to the reactor loaded with flux-calcined DE only resulted in traces of T'. Similarly, D' was stable under the typical reaction conditions. These results suggest alternative pathways of formation for $Q^{\prime}$ and D’ (Figure 12).

MS Real Time Monitoring. The product stream in the reaction of base treated $\mathrm{SiO}_{2}$ and DMC is condensed using a water chilled condenser and collected in fractions, which are analyzed by GC. Typically 4-6 fractions are collected resulting in only a rough kinetic profile. Material that is not condensed, cannot be tracked with the current setup. Additionally more refined kinetic information, especially during the induction period is unavailable. Figure 13 shows the mass spec traces from the reaction of DMC with KOH treated $(5 \%)$ Celite $\mathrm{Hyflo}^{\circledR}$ :

- Upon addition of DMC, an initial surge in the formation of D' and Q' can be observed, the $D^{\prime} / Q^{\prime}$ formation declines to a steady state almost immediately (less than 1 minute). The $D^{\prime}$ concentration peaks before that of $Q^{\prime}$ and DMC which suggests the presence of reactive centers on the surface that react with DMC to form D'. The almost immediate, subsequent loss of D' formation supports a stoichiometric or substoichiometric reaction (based on metal content).

- Over the first hour the DMC signal remains constant, while the signals corresponding to D' and Q' decline. 
Abundance
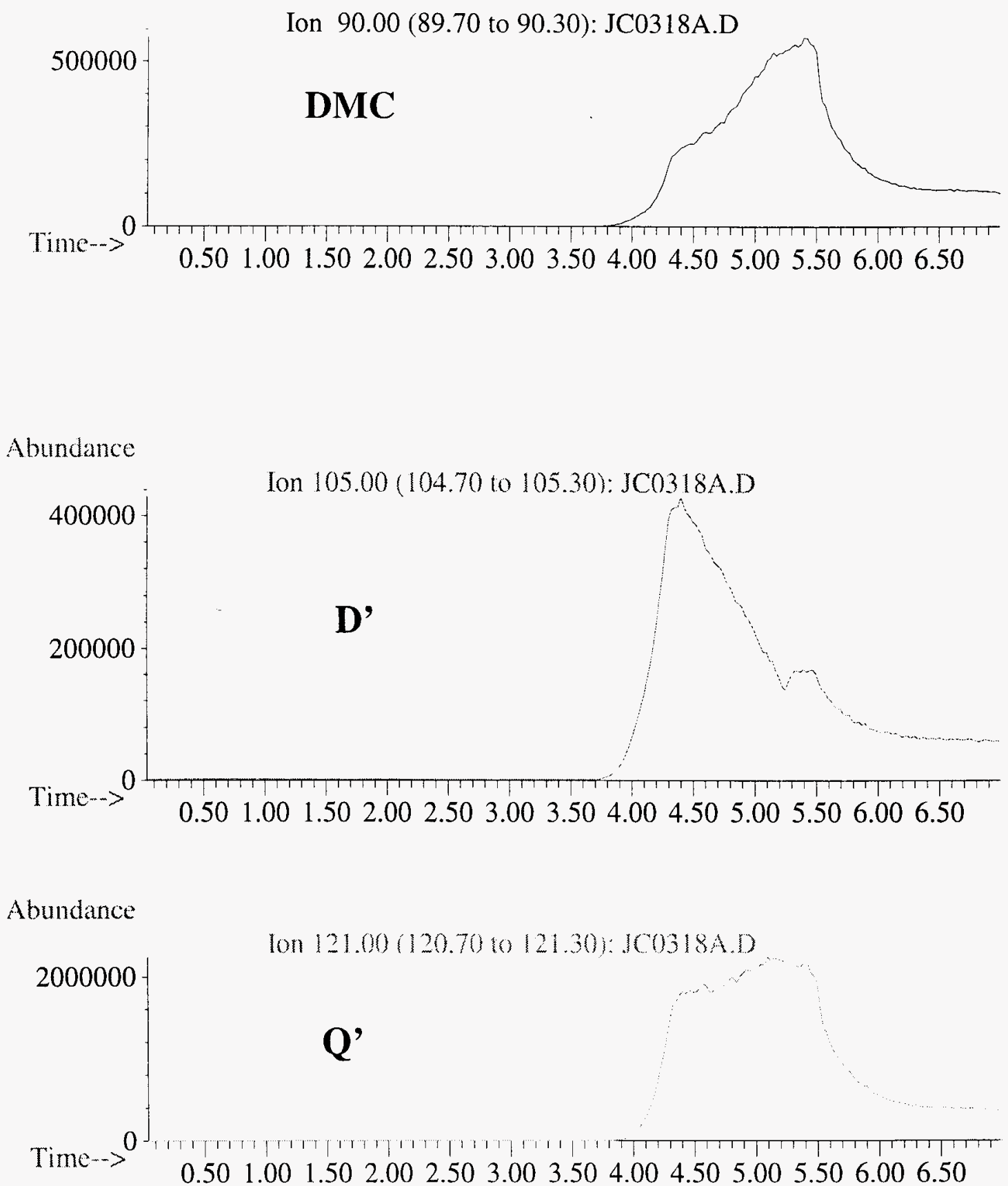

Figure 13. Mass spectrometry traces for DMC, D' and Q' in the reaction of DMC with KOH-treated (5\%) DE. 
Reactions under UV light. Three basic mechanistic pathways can most likely explain the direct formation of D' from metal-containing silica: radical, ionic or silylene. Of these the radical and the silylene pathway are expected to be sensitive to UV light. To explore this hypothesis, reactions of silica with DMC were performed under exposure to UV light.

No change in the production of $\mathrm{D}^{\prime}$ was observed for the reaction of DMC with a metal doped silica gel sample (Sample B in Table 5) and the KF-containing silica gel sample $\mathrm{C}$ under UV irradiation (low power, monochromatic UV lamp at 254 and at 366 $\mathrm{nm})$. At higher temperatures $\left(350^{\circ} \mathrm{C}\right)$ using the medium pressure $\mathrm{Hg}$ lamp an increase in the amount of D' was observed. However, control experiments showed that the D' is formed by the UV-catalyzed reaction of small amounts of silicon grease with DMC.

The UV irradiation results suggest that pathways involving radicals or silylene species are unlikely. The highly polar nature of $\mathrm{KOH}$ activated silica presumably favor an ionic reaction pathway.

Reactions in the presence of a hydrogen source. Thermodynamic considerations on model reactions suggested that co-feeding of a hydrogen source should favor D' production relative to Q' production. A possible choice for the hydrogen source is methanol. A mixture of DMC (83.3 w\%) and methanol (16.7 w\%) was added via motor driven syringe to surface treated silica gel (Sample B, Table 5). No significant change in the production of D' was observed when methanol was added.

Elemental hydrogen is more reducing than methanol. Activation of $\mathrm{H}_{2}$ under the reaction conditions could promote the formation of D'. Additionally, $\mathrm{Si}-\mathrm{H}$ containing compounds are of great value. One could imagine the formation of $\mathrm{Si}-\mathrm{H}$ containing compounds if hydrogen is used as carrier gas during the reaction of $\mathrm{DMC}$ and a $\mathrm{SiO}_{2}$ source. $\mathrm{KOH}$ treated natural DE (Celite Snow Floss ${ }^{\mathrm{B}}$ ) was reacted with DMC at $320^{\circ} \mathrm{C}$ with 3\% hydrogen in argon as carrier gas and with pure hydrogen as carrier gas. In both cases neither formation of D' nor new peaks were detected. In an attempt to provoke reactivity by activation of hydrogen, the natural $\mathrm{DE}$ was surface-treated with $\mathrm{KOH}$ and $10 \%$ of $\mathrm{Na}_{2} \mathrm{PdCl}_{4}$. Again neither $\mathrm{D}^{\prime}$ and nor any new products were observed as confirmed by GC/MS.

Other alkyl sources. The reaction of $\mathrm{DMC}$ with $\mathrm{SiO}_{2}$ to form $\mathrm{D}^{\prime}$ formally requires oxygen in some form as a byproduct (eq 3).

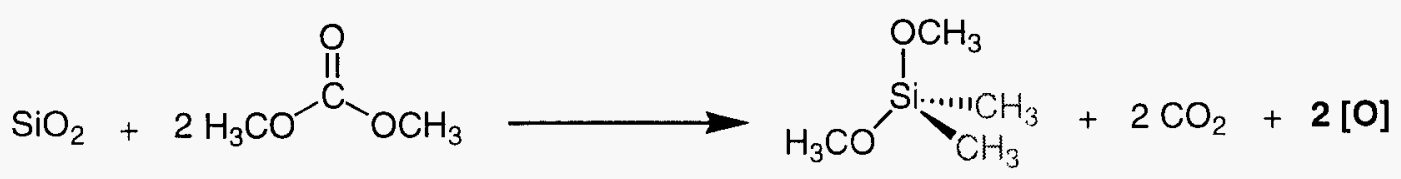

Methyl oxalate possesses one additional $\mathrm{CO}$ unit when compared to DMC, which could capture oxygen to form additional $\mathrm{CO}_{2}$ (eq 4). 


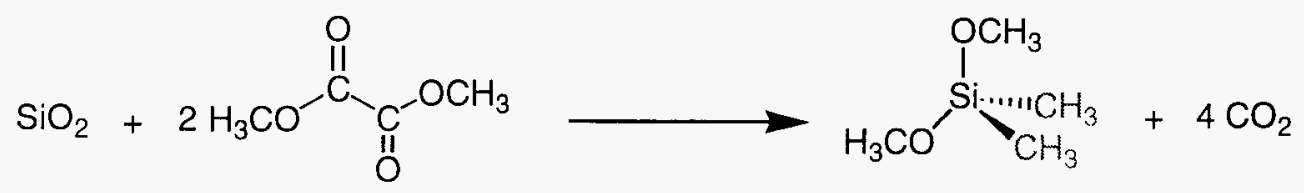

Methyl oxalate is a solid and cannot be added as a pure compound using the current setup. Instead a mixture of methyl oxalate in DMC $(1 / 3 \mathrm{w} / \mathrm{w})$ was used. Ethyl oxalate is a liquid and can easily be introduced using the motor driven syringe. Metal-treated silica gel (Sample B; Table 5) as well as KOH-treated natural DE were used.

Unfortunately neither oxalates appeared to react and no product formation was observed.

\section{D' from Titanium-Containing Zeolites and Sol-Gel Materials.}

The Ti-containing materials covered in the following section are treated separately from the other metal-containing $\mathrm{SiO}_{2}$ materials for two main reasons. First, so far D' formation has only been observed in the presence of combinations of metal compounds. The results presented in this section are the only examples of significant D' formation in the presence of only one metal (besides potassium). Second, the Ti-containing materials are unique, because they represent homogenous $\mathrm{SiO}_{2}$ sources where a certain number of the tetra-valent silicon atoms are replaced by the iso-electronic titanium atoms. In other words, the titanium and the silicon atoms are part of the same lattice.

\section{High surface area titanium zeolites as $\mathrm{SiO}_{2}$ source.}

Titanium zeolites, prepared hydro-thermally by National Chemistry Laboratories (NCL, India) as a potential heterogeneous catalyst, were used as $\mathrm{SiO}_{2}$ sources in the reaction with DMC.

In Figures 14 and 15 the $\mathrm{SiO}_{2}$-utilizations towards $\mathrm{Q}^{\prime}$ and $\mathrm{D}^{\prime}$ respectively are shown for a $\mathrm{KOH}$-treated $(5.4 \%)$ titanium zeolite $(10 \% \mathrm{Ti}, 90 \% \mathrm{Si})$. Similar profiles were obtained when the reaction was repeated. 


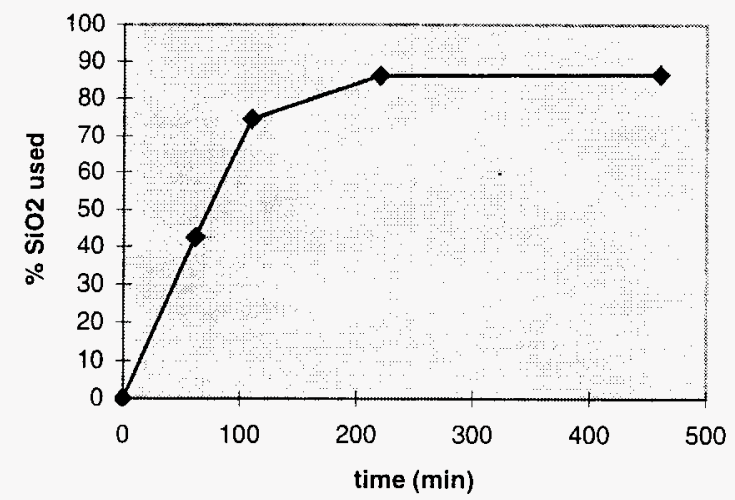

Figure 14. $\mathrm{SiO}_{2}$-utilization towards $\mathrm{Q}^{\prime}$ using titanium-containing zeolite TS-1 (10\% Ti).

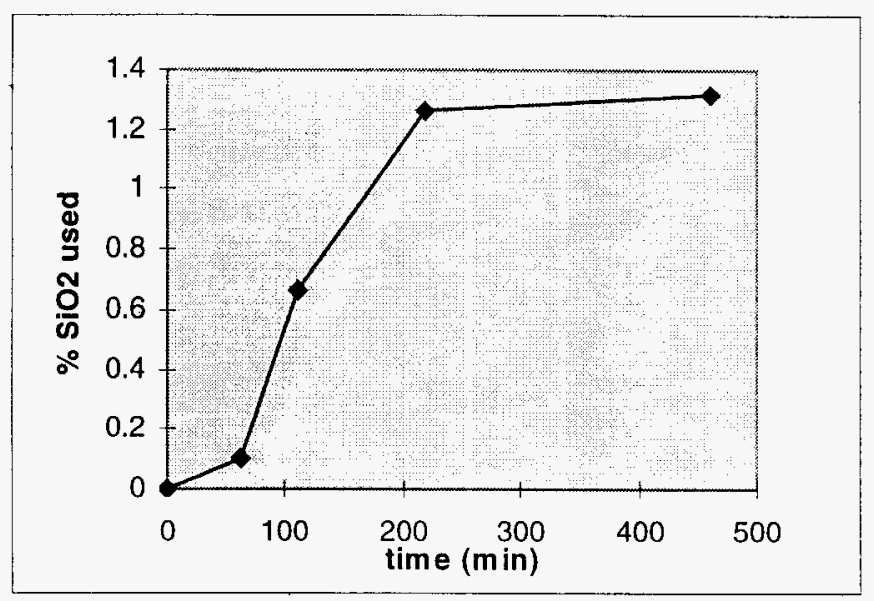

Figure 15. $\mathrm{SiO}_{2}$-utilization towards $\mathrm{D}^{\prime}$ using titanium-containing zeolite TS-1 (10\%Ti).

Figures 16 and 17 show the $\mathrm{SiO}_{2}$-utilizations towards Q' and $\mathrm{D}^{\prime}$ for a different $\mathrm{KOH}$-treated $(5.2 \%)$ titanium zeolite $(1.25 \% \mathrm{Ti}, 98.75 \% \mathrm{Si})$. Similar profiles were obtained when repeated. The fact that the amount of titanium (10\% vs. $1.25 \%)$ in the sample has no significant effect on $D^{\prime}$ formation, can be explained by the limitation of incorporation of $\mathrm{Ti}$ into the $\mathrm{SiO}_{2}$ lattice. X-ray diffraction analysis techniques revealed that at $\mathrm{Ti}$ levels higher than $2.25 \%, \mathrm{TiO}_{2}$ forms as a separate phase. 


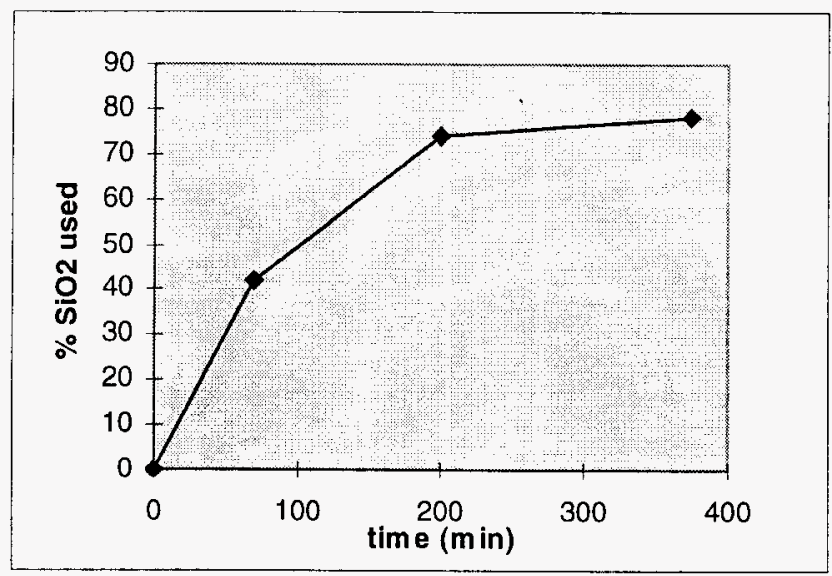

Figure 16. $\mathrm{SiO}_{2}$-utilization towards Q' using titanium-containing zeolite TS-1 (1.25\% Ti).

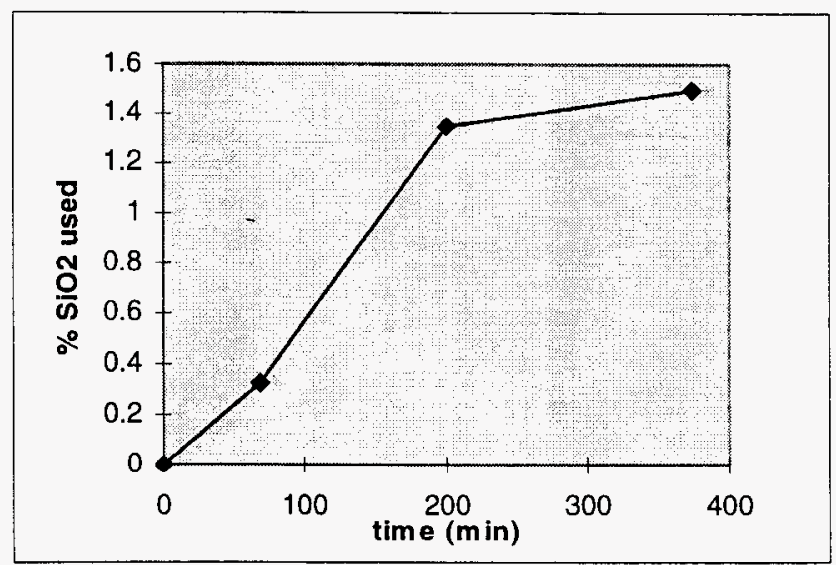

Figure 17. $\mathrm{SiO}_{2}$-utilization towards $\mathrm{D}^{\prime}$ using titanium-containing zeolite TS-1 (1.25\% Ti).

\section{Reactivity of metal-containing $\mathrm{SiO}_{2}$ samples prepared by sol-gel process.}

The base-catalyzed direct formation of D' from titanium-containing zeolites, where the $\mathrm{Ti}$ atoms are part of the $\mathrm{SiO}_{2}$ structure, was described in the previous section. Sol-gel chemistry offers an attractive pathway into metal containing silica structures, especially in view of sample preparation for efforts using combinatorial chemistry. Several metalcontaining $\mathrm{SiO}_{2}$ samples were prepared by Stan Stoklosa and Ted Sun. The glass like materials were ground by hand, treated with $\mathrm{KOH}$ catalyst and reacted with $\mathrm{DMC}$ under typical conditions $\left(10 \mathrm{~mL} \mathrm{DMC} ; 320^{\circ} \mathrm{C} ; \mathrm{DMC}\right.$ addition rate $=20 \mathrm{mmol} / \mathrm{h} ; \mathrm{Ar}$ gas flow $=$ $20 \mathrm{~mL} / \mathrm{min}$ ). The $\mathrm{SiO}_{2}$-utilization results towards Q' and D' are listed in Table 7. Figure 18 and 19 show the $\mathrm{SiO}_{2}$-utilization towards Q' and $\mathrm{D}^{\prime}$ respectively vs. reaction time for the sol-gel material containing $1 \% \mathrm{Ti}$. Figures 20 and 21 show the analogous plots for the 
sample containing $2 \%$ Ti. Figures 18-21 do not include D' collected in the on-line -78 ${ }^{\circ} \mathrm{C}$ trap. In contrast the $\mathrm{SiO}_{2}$-utilization towards $\mathrm{D}$ ' values that are listed in Table 7, reflect the total amount of $\mathrm{D}^{\prime}$ collected (sum of $\mathrm{D}^{\prime}$ collected using the water-chilled condenser and $\mathrm{D}^{\prime}$ found in the $-78^{\circ} \mathrm{C}$ trap). The amounts of $\mathrm{D}^{\prime}$ collected in the $-78{ }^{\circ} \mathrm{C}$ trap were excluded in the $\mathrm{SiO}_{2}$-utilization plots (Figures 18-21) to avoid distortion of the kinetic profile. 
Table 7. $\mathrm{SiO}_{2}$-utilization towards Q' and D' using sol-gel materials.

\begin{tabular}{lcc}
\hline & \multicolumn{2}{c}{$\mathrm{SiO}_{2}$ utilization (\%) } \\
Metal content (w\%) & $\mathrm{Q}^{\prime}$ & $\mathrm{D}$ \\
\hline $\mathrm{KOH}(5.4), \mathrm{Ti}(1)$ & 42 & 1.2 \\
$\mathrm{KOH}(5.4), \mathrm{Ti}(2)$ & 52 & 0.8 \\
$\mathrm{KOH}(5.4), \mathrm{Ti}(2), \mathrm{Zr}(2)$ & $-{ }^{\mathrm{a}}$ & $-{ }^{\mathrm{a}}$ \\
$\mathrm{KOH}(5.4), \mathrm{Ti}(2), \mathrm{Al}(2)$ & $-{ }^{\mathrm{a}}$ & $-{ }^{\mathrm{a}}$ \\
$\mathrm{KOH}(5.4), \mathrm{Ti}(2), \mathrm{Y}(2)$ & 10 & 0.4 \\
\hline
\end{tabular}

${ }^{a}$ Only DMC collected.

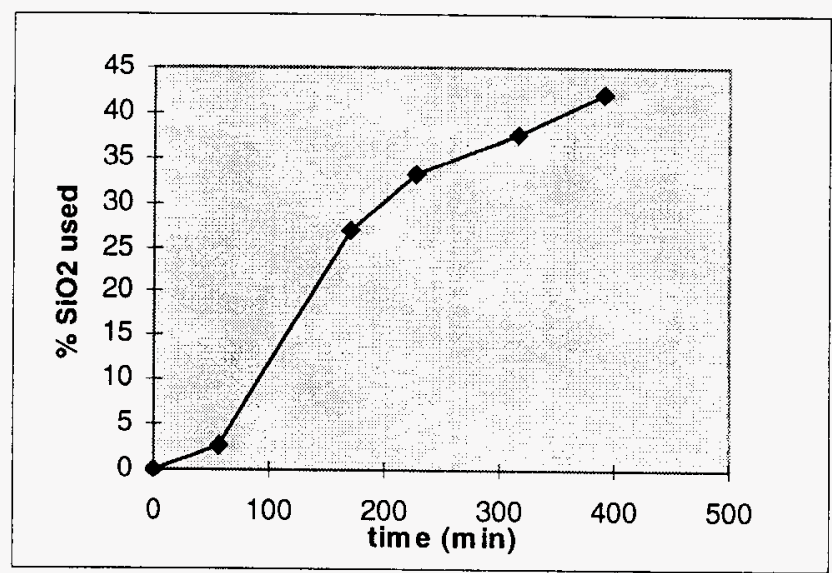

Figure 18. $\mathrm{SiO}_{2}$-utilization towards $\mathrm{Q}$ ' using Ti-containing (1\%) sol-gel.

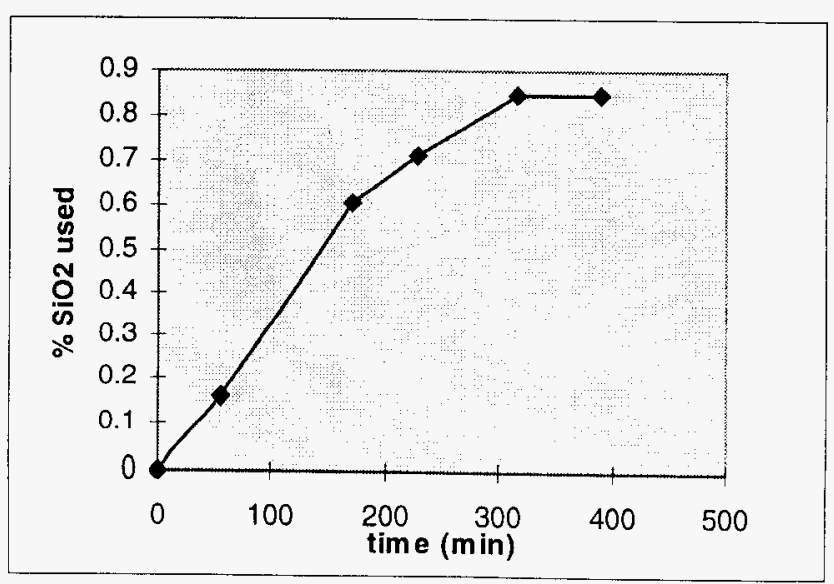


Figure 19. $\mathrm{SiO}_{2}$-utilization towards $\mathrm{D}^{\prime}$ using Ti-containing (1\%) sol-gel.

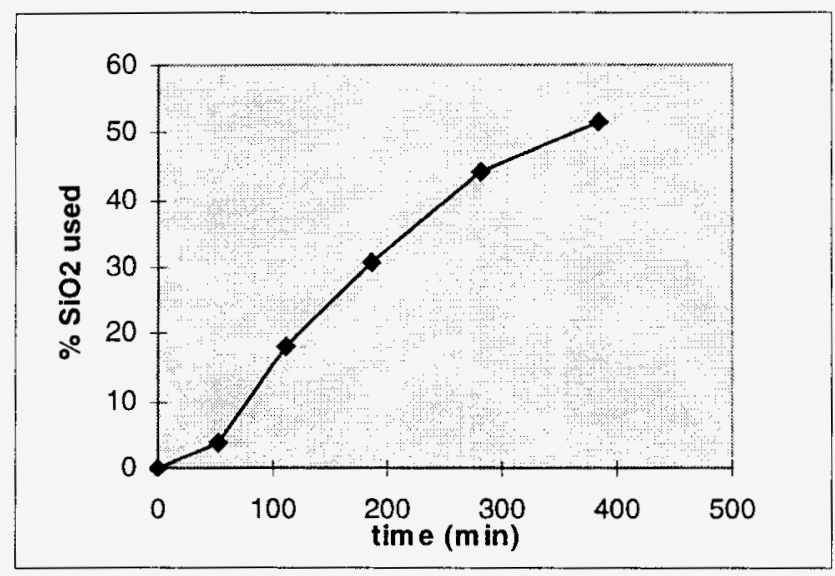

Figure 20. $\mathrm{SiO}_{2}$-utilization towards Q' using Ti-containing (2\%) sol-gel.

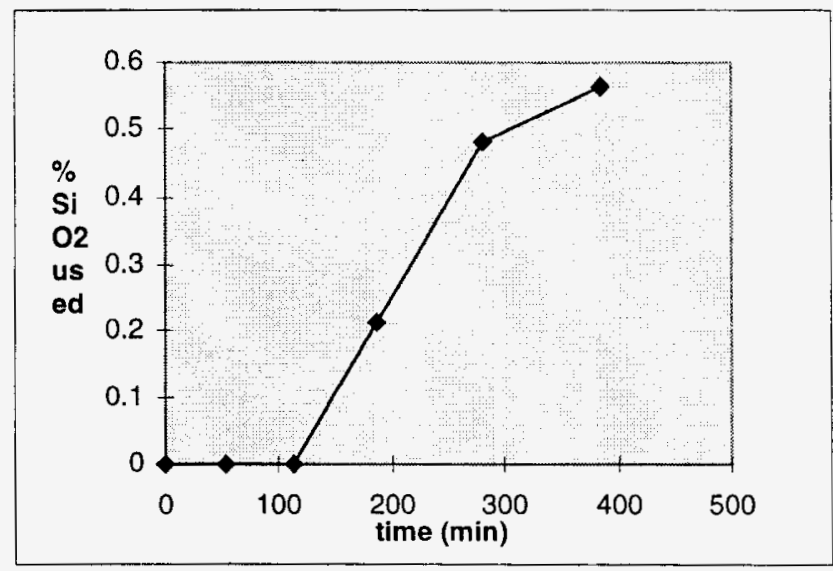

Figure 21. $\mathrm{SiO}_{2}$-utilization towards D' using Ti-containing (2\%) sol-gel.

In the case of the samples containing $\mathrm{Ti} / \mathrm{Al}(2 \% / 2 \%)$ and $\mathrm{Ti} / \mathrm{Zr}(2 \% / 2 \%)$ no product was formed, only unreacted DMC was collected. The Ti/Y $(2 \% / 2 \%)$ sample resulted in low yields of Q' and D' (Table 7). Recently prepared sol-gel materials with $2 \% \mathrm{Ti}$ or $2 \%$ each $\mathrm{Ti}$ and $\mathrm{Al}$ showed high conversion to $\mathrm{Q}^{\prime}(75-95 \%)$ and detectable $\mathrm{D}^{\prime}(0.2-0.3 \%)$. 
Generally this class of metal-containing sol-gel materials exhibits lower reactivity than typical synthesized $\mathrm{SiO}_{2}$ sources (silica gel, titanium zeolites, colloidal silica). Low surface area offers the most likely explanation for the lower reactivity.

\section{Fate of titanium in titanium-containing $\mathrm{SiO}_{2}$ samples.}

Generation of $\mathrm{Ti}(\mathrm{OMe})_{4}$. Yellow crystals are typically found in the out-flow of the fixed-bed reactor in reactions involving titanium-containing $\mathrm{SiO}_{2}$ sources. Mass spectrometry analysis of these yellow crystals using EI direct insertion probe showed a mixture of compounds. Major component is a compound with $\mathrm{m} / \mathrm{z}=171$ exhibiting the isotope pattern typical for $\mathrm{Ti}$ (molecular weight of $\mathrm{Ti}(\mathrm{OMe})_{4}$ is 172). Peaks with the highest intensity $(\mathrm{m} / \mathrm{z}=142$ and 141 ; also showing the characteristic Ti pattern) can be explained as $\mathrm{Ti}(\mathrm{OMe})_{3} \mathrm{H}^{+}$and $\mathrm{Ti}(\mathrm{OMe})_{3}{ }^{+}$respectively. The remaining peaks of the spectrum are also consistent with fragments from $\mathrm{Ti}(\mathrm{OMe})_{4}$. The other components of the mixture can be interpreted as partially hydrolyzed products of tetramethoxy titanium.

Elemental analysis (Varian Liberty II ICP-AES) of the crystals yielded a titanium content of $29.7 \%$ ( $\pm 1.74 \%$; represents $95 \%$ confidence interval). The expected value for $\mathrm{Ti}(\mathrm{OMe})_{4}$ is $27.9 \%$ : The determined value (although still within the confidence interval) is somewhat higher than the expected value, which is also consistent with a partially hydrolyzed titanium methoxide sample. Also the sample weight was very low introducing considerable weighing error.

The results are consistent with the generation of $\mathrm{Ti}(\mathrm{OMe})_{4}$, which quickly partially hydrolyzes upon exposure to the atmosphere. The total amount collected represents $50 \%$ of the total expected amount of $\mathrm{Ti}(\mathrm{OMe})_{4}$. Considering the insufficient way of collecting, presumably most of the Ti leaves the reactor in the course of the reaction.

Titanium depletion of the reactor bed. The formation of volatile titanium species was confirmed by determining the Ti content of the reactor bed before and after reaction.

$\mathrm{KOH}$-treated reactor beds based on titanium-containing zeolites were submitted for elemental analysis. One sample was taken from the bed before, the other after reaction with DMC.

Table 1 shows the Ti results, expressed in micrograms Ti per gram (ppm) $+/$ - the $95 \%$ confidence interval. The confidence intervals reported reflect variability in the data due to the instrument calibration regression line and the instrument repeatability.

Table 8. Ti content of reactor bed before and after reaction with DMC.

\begin{tabular}{|c|c|c|c|}
\hline SAMPLE ID & EA LAB \# & Ti, ppm & 95\% CI, ppm \\
\hline Run \#15 before & 9905244 & 9083 & 295 \\
\hline & & 9180 & 294 \\
\hline Run \#15 after & 9905245 & 1204 & 407 \\
\hline & & 1605 & 456 \\
\hline
\end{tabular}


The two wavelengths were examined to check for spectral interference; the results agreed, therefore only the results for the $336.121 \mathrm{~nm}$ line are reported. A sample was spiked to check for matrix interference and recovery was $95 \%$.

After digestion there was a residue remaining in the reactor bed collected after reaction. This residue was examined by qualitative XRF and found to contain no detectable Ti. The following elements were also found: $\mathrm{Zn}, \mathrm{Cr}, \mathrm{Ca}, \mathrm{K}, \mathrm{Zr}, \mathrm{Ba}$, and $\mathrm{S}$.

These results are consistent with the previously established generation of $\mathrm{Ti}(\mathrm{OMe})_{4}$ from the $\mathrm{Ti}$ containing reactor beds and confirm that $\mathrm{Ti}$ leaves the reactor during the course of the reaction. In a few cases the silica gel with $5 \% \mathrm{KOH}$ was reacted with DMC and a co-feed of volatile $\mathrm{Ti}$ sources such as $(\mathrm{MeO}) 4 \mathrm{Ti}$ or $(\mathrm{BuO}) 4 \mathrm{Ti}$. In neither case was there a significant increase in D' formation.

\section{Silicate Minerals}

Given the exciting lead provided by diatomaceous earth, a screen of silicate minerals was suggested. The silicates can be divided into the structural forms shown in figure 22 .

Figure 22. Silicate Structural Types and Specimens to be Examined 


\begin{tabular}{|c|c|c|}
\hline \multirow{4}{*}{ Nesosilicate } & Topaz & \\
\hline & Datolite & Almandine \\
\hline & $\begin{array}{l}\text { Perridot } \\
\text { Sphene }\end{array}$ & Andradite \\
\hline & Cyrtolite & $\begin{array}{l}\text { Grossular } \\
\text { Olivine }\end{array}$ \\
\hline$\left(\mathrm{SiO}_{4}\right)^{4-}$ & Kyanite & Forsterite \\
\hline
\end{tabular}
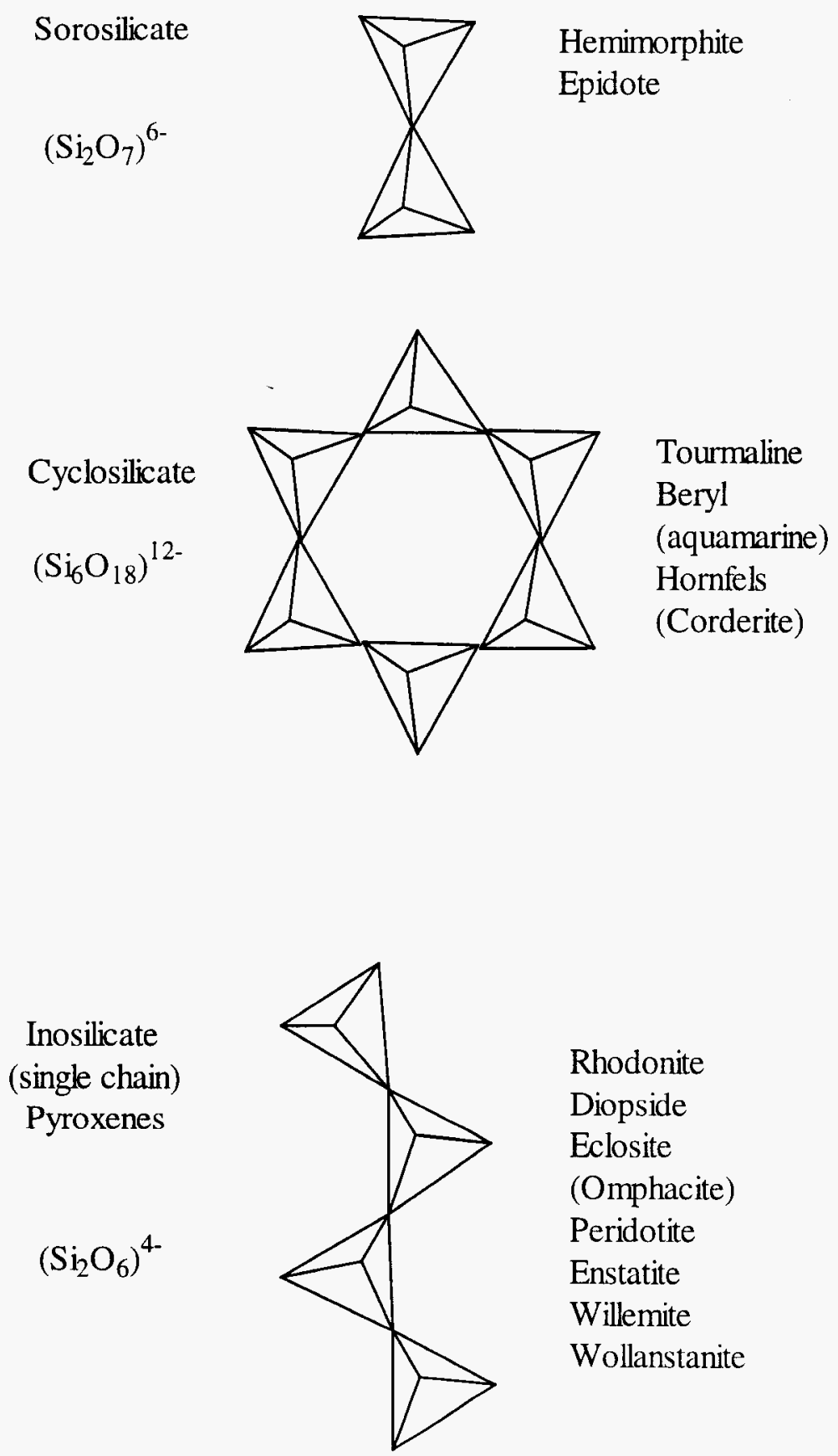
Inosilicate

(double chain)

Amphiboles

$\left(\mathrm{Si}_{4} \mathrm{O}_{11}\right) 6-$

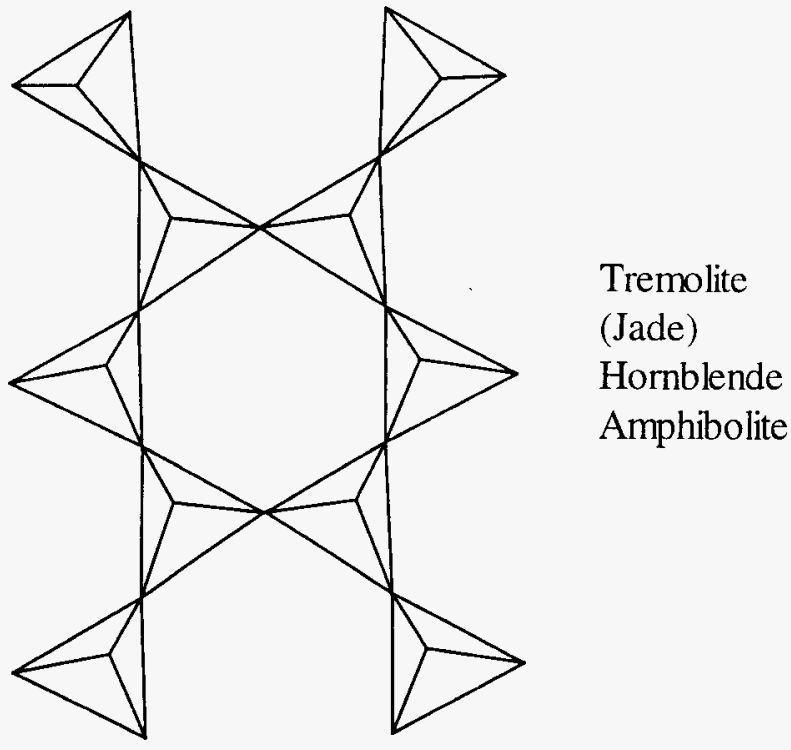

Phyllosillicate

$\left(\mathrm{Si}_{2} \mathrm{O}_{5}\right)^{2-}$

Tectosilicate
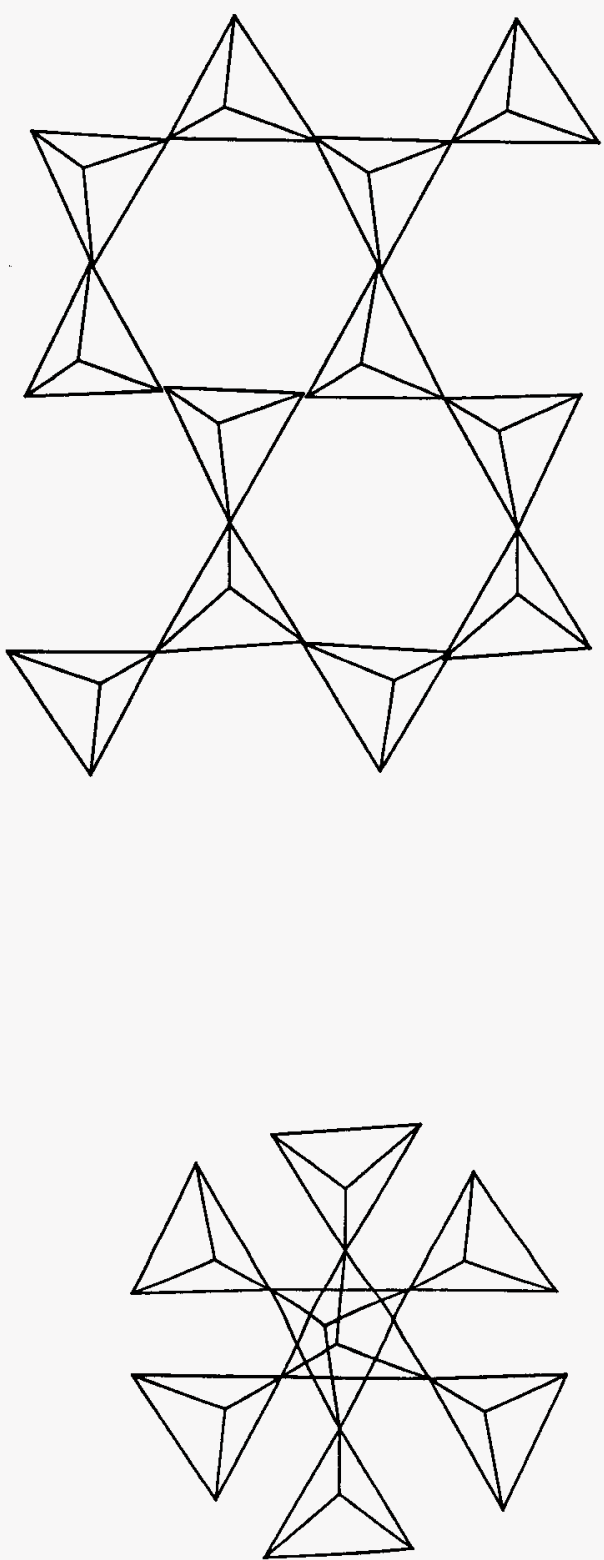

Rubellite

Chysocolla

Serpentine

Fuchsite

Mica

Vermiculite

Kaolin

Montmorillonite

Talc

Chrysotile

Feldspar

Amazonite

Labradorite

Stilbite

(zeolite)

Jasper

Sodalite

Columbite

Flint Clay

Sea Sand 
Rocks

Shale

Clays

Tuff

Trachyte

Syenite

Obsidian

Pumice

Granodiorite

Gabbro

Basalt

Shale

\section{Synthetics}

Fume silica

Sodium silicate (glass)

Zirconium silicate

Titanium zeolite

Cobalt silicate

Calcium silicate

Lithium silicate

Some of the silicate materials have been examined in the fixed bed reactor. However due to the large number of materials, most will be screened in the recently constructed combinatorial reactor. The overall strategy is to find a natural combination of $\mathrm{SiO} 2$ and metal (or metals) that facilitates conversion of the $\mathrm{SiO} 2$ of the silicate into D' from reaction with DMC. This screen will hopefully provide hints about what metals mediate silicon methylation. With a very limited number of minerals screened in the lab reactor, only hemimorphite, a zinc-containing sorosilicate, showed formation of D' (Q' formation was low, results similar to that for flux-calcined DE). Sphene, rhodonite, zircon, chysocolla, flint clay, topaz and perridot have been screened and failed to give detectable D'. 


\section{CONCLUSIONS}

This progress report covers the first nine months of research efforts in the "Direct Production of Silicones from Sand" project (contract DE-FC02-98CH10931). The project is geared towards establishing a low-energy, halogen-free synthetic route to silicones from a commercial source of $\mathrm{SiO}_{2}$. The two most critical barriers for success are 1.) the synthesis of $\mathrm{Si}(\mathrm{OR})_{4}$ from a commercial $\mathrm{SiO}_{2}$ source and 2.) catalytic formation of alkylalkoxysilanes from $\mathrm{Si}(\mathrm{OR})_{4}$.

Building on a literature synthesis of Q' from silica gel, the base-catalyzed formation of Q' from natural $\mathrm{DE}$, a commercial $\mathrm{SiO}_{2}$ source, and DMC was found. Using MAIC Six Sigma tools, the process was optimized to $69 \% \mathrm{SiO}_{2}$ utilization towards Q'. At this point the DMC utilization is still low $(<20 \%)$.

While exploring reactivity for the Q' formation from various $\mathrm{SiO}_{2}$ starting materials, the unexpected formation of $\mathrm{Me}_{2} \mathrm{Si}(\mathrm{OMe})_{2}$ in low yield directly from flux-calcined $\mathrm{DE}$ was observed. Low yields of D' were also obtained from silica gel that was surfacetreated with metal compounds and from a material prepared by coprecipitation of a variety of metal compounds with colloidal silica. D' formation from Ti-containing materials indicate that titanium (and potentially other electropositive transition metals) is an active promoter.

The following points summarize the current status of understanding of the D' formation:

- Metals appear to play a vital role in the production of D'.

- Titanium was identified as promoter.

- The formation of D' is substoichiometric in the metals present in the $\mathrm{SiO}_{2}$ materials.

- Mechanistically, the D' formation can best be explained by the initial presence of reactive sites containing oxygen-deficient, electropositive metal centers.

- The low yields make it very difficult to pick up trends.

Focus is currently shifting towards $\mathrm{Si}-\mathrm{C}$ bond formation from Q' rather than the direct formation of D' from $\mathrm{SiO}_{2}$, since no signs of catalytic behavior could be observed in the direct formation.

\section{ACKNOWLEDGEMENTS}

All the work described in this report would have not been possible without the help of many people. We thank Jim Carnahan for the real time monitoring setup and the data evaluation, Ted Sun and Stan Stoklosa for the preparation of the sol-gel materials and Molecular Solutions Inc. for the calculations. John Leman has been an invaluable pool of information. We thank Woody Ligon and Hans Grade for the GC/MS work and the fast turnaround times and June W. Klimash and Nancy Marotta for the elemental analysis. 


\section{REFERENCES}

13. Kirk-Othmer Encyclopedia of Chemical Technology, $3^{\text {rd }}$ ed.; Wiley-Interscience, New York, 1979; Vol. 20, 750-880.

14. Liebhafsky, H. A. Silicones Under the Monogram, John Wiley and Sons, New York, 1978.

15. Warwick, E. L. Forty Years of Firsts, McGraw Hill, New York, 1990.

16. Department of Energy contract DE-FC02-98CH10931, "Direct Production of Silicones from Sand."

17. Ono, Y.; Akiyama, M.; Suzuki, E. Chem. Mater. 1993, 5, 442.

18. Akiyama, M.; Suzuki, E.; Ono Y. Inorg. Chim. Acta 1993, 207, 259.

19. Rosenheim, A.; Raibmann, B.; Schendel, G. Z. Anorg. Allg. Chem. 1931, 196, 160.

20. Laine, R. M.; Blohowiak, K. Y.; Robinson, T. R.; Hoppe, M. L.; Nardi, P.; Kampf, J.; Uhm, J. Nature 1991, 353, 642.

21. Blohowiak, K. Y.; Treadwell, D. R.; Mueller, B. L.; Hoppe, M. L.; Jouppi, S.; Kansal, P.; Chew, K. W.; Scotto, C. L. S.; Babonneau, F.; Kampf, J.; Laine, R. M. Chem. Mater. 1994, 6, 2177.

22. Goodwin, G. B.; Kenney, M. E. Polym. Prep. 1986, 27, 107.

23. Graefe, J.; Uzick, W.; Weinberg, U. Ger. Offen. DE 3821483 Chem Abstr 112:217263.

24. Goodwin, G. B.; Kenney, M. E. Adv. Chem. Ser. 1990, 224, 251.

25. Schattenmann, F. J. 1999 Sand to Silicones Six Sigma Project, General Electric Company Report in print.

26. Mler R. K. The Chemistry of Silica, John Wiley and Sons, New York, 1979.

Appendix 2

\section{OMG Contribution to Phase I, Mark Barr}

Note: OMG has resigned as our partner for PhaseII.

$$
(\mathrm{MeO})_{4} \mathrm{Si}+2 \mathrm{MeCl} \stackrel{\mathrm{H}_{2}}{\longrightarrow} \mathrm{Me}_{2} \mathrm{Si}(\mathrm{MeO})_{2}
$$

In the gas phase and over relatively unreactive materials such as fibrous fused silica, borosilicate glass beads, and $\alpha$-alumina tetramethoxysilane is unreactive with methyl chloride and with a $4 \% \mathrm{H}_{2} / \mathrm{MeCl}$ blend at temperatures up to at least $400 \mathrm{C}$. On the other hand, methyl chloride cracks and forms coke on relatively unreactive materials such as fused silica wool, and $\alpha$-alumina at temperatures above $350 \mathrm{C}$. More reactive materials, such as activated acidic $\gamma$-alumina and high purity copper, further increase methyl chloride cracking and coke deposition at temperatures above $350 \mathrm{C}$. Hence, it is necessary to identify materials that will promote reaction of tetramethoxysilane without 
excessive cracking of methyl chloride. We are trying to identify materials that will facilitate reaction of tetramethoxysilane with methyl chloride to produce methylmethoxysilanes at temperatures below 350C in order to avoid methyl chloride cracking and excessive coke deposition.

\section{High Purity Copper}

High purity tetramethoxysilane does not react with high purity copper under nitrogen, methyl chloride, or $4 \% \mathrm{H}_{2} / \mathrm{MeCl}$ feed streams in the temperature range $150 \mathrm{C}$ to $400 \mathrm{C}$. Methyl chloride and $\mathrm{H}_{2} / \mathrm{MeCl}$ showed some coking at the top of the fixed bed at $400 \mathrm{C}$. No reaction products in the condensed TMOS were detected.

A lower purity tetramethoxysilane produced a pale straw yellow condensate when reacted with a $150 \mathrm{C}$ to $400 \mathrm{C}$ temperature ramp, but the source of the color was not detected in the GC analysis and was not pursued further.

\section{$\underline{\alpha-A l u m i n a}$}

Tetramethoxysilane with methyl chloride and with $4 \% \mathrm{H}_{2}$ in methyl chloride did not react over $\alpha$-alumina, other than methyl chloride cracking above $350 \mathrm{C}$.

GC analysis of the condensed downstream gases did not show any condensable reaction products in the condensed tetramethoxysilane. No reaction exotherm was measured as the reactor bed temperature was increased linearly from $250 \mathrm{C}$ to $400 \mathrm{C}$. The reaction bed did not show a weight increase after the tests were completed.

\section{Copper/ $\alpha$-Alumina}

No reaction of tetramethoxysilane occurred in a $4 \% \mathrm{H}_{2}$ in methyl chloride stream over $25 \%$ high purity, high surface area copper with an $\alpha$-alumina reaction bed. No exotherm was recorded and no reaction products were observed, but the copper increased methyl chloride cracking and coking in the bed at temperatures greater than $350 \mathrm{C}$. Within experimental error, no weight increase in the bed was observed after reaction.

\section{-Alumina}

In contrast to $\alpha$-alumina, acidic $\gamma$-alumina does react with tetramethoxysilane in a $4 \%$ hydrogen in methyl chloride feed stream. A variety of conditions were tested to identify conditions to encourage TMOS reaction with $\mathrm{MeCl}$.

When $\gamma$-alumina is activated at $400 \mathrm{C}$ and cooled to $150 \mathrm{C}$ under high purity nitrogen the alumina surface is very reactive. When the $\mathrm{TMOS} / \mathrm{H}_{2} / \mathrm{MeCl}$ gas contacts the activated $\gamma$ alumina at $150 \mathrm{C}$, a reaction exotherm is observed. As the temperature is further increased, a second exotherm is observed at $320 \mathrm{C}$.

The low temperature exotherm is believed to be adsorption on the activated alumina surface. When the $\gamma$-alumina bed is held at $160 \mathrm{C}$ and exposed to the TMOS/ $/ \mathrm{H}_{2} / \mathrm{MeCl}$ stream, no reaction products are detected in the condensed TMOS. 
When $\gamma$-alumina was activated as described and the temperature was raised to 320C under nitrogen before switching the gas flow to a $\mathrm{TMOS} / \mathrm{H}_{2} / \mathrm{MeCl}$ stream, a reaction exotherm is detected and GC analysis of the condensed TMOS shows reaction products.

The reaction products in the condensed TMOS are not methylmethoxysilanes. Two unidentified peaks with a $20 \mathrm{~min}$. and $28 \mathrm{~min}$. retention time were detected. The peaks are detected by both gas phase sampling and by sampling the condensed TMOS. The high retention time peaks may be siloxanes, but additional analysis is necessary to identify this material. We plan to use ${ }^{29} \mathrm{Si}$ NMR and/or GC-MS to identify the peaks. We looked for, but did not detect methanol, methylmethoxysilanes, or water in the gas phase or in the condensed TMOS after the reaction at 320C. This is perhaps surprising. Dimethylether is also a possible reaction product from TMOS reacting over a Lewis acid such as $\gamma-$ alumina, but this species has a retention time very close to $\mathrm{MeCl}$ on our column and can not be detected with the current GC configuration. The reaction bed was weighed after reaction and showed nearly a $25 \%$ increase in weight.

\section{Copper/ $\gamma$-alumina}

Copper is effective below $350 \mathrm{C}$ for cleaving the $\mathrm{C}-\mathrm{Cl}$ bond without breaking the $\mathrm{C}-\mathrm{H}$ bond. High surface area copper was investigated as a source of methyl groups to react with the chemisorbed tetramethoxysilane on acidic $\gamma$-alumina. The goal is to provide an active methyl group to react with the adsorbed tetramethoxysilane to produce methylmethoxysilanes. In the temperature range $250 \mathrm{C}-350 \mathrm{C}$, no methylmethoxysilanes were detected. The weight of the reaction bed increased $20-25 \%$, very similar to the weight increase measured without copper in the reactor bed.

Based on these results, it appears that tetramethoxysilane is so strongly bound to the acidic $\gamma$-alumina surface that it is unavailable to react with methyl groups made available from the methyl chloride. Future experiments will focus on identifying materials that react with tetramethoxysilane, but form less tightly bound surface species.

\section{Basic $\gamma$-Alumina}

GC analysis of both the gas phase product stream and condensed TMOS show two new peaks when $\mathrm{TMOS} / \mathrm{H}_{2} / \mathrm{MeCl}$ are reacted over basic $\gamma$-alumina at 320C. GC retention times at 20 and $28 \mathrm{~min}$. are observed. These peaks are not methylmethoxysilanes and additional analyses are required to identify the source of the peaks.

\section{Future Plans :}

\section{Note: after these plans were suggested, OMG resigned as our partner and further work below was not done.}

Aluminum oxide appears more promising for activating tetramethoxysilane (TMOS) than bulk metals; however, it is still likely that metals are needed to produce active methyl groups from methyl-containing molecules for reacting with the activated TMOS.

Our experimental plan is to continue evaluation of a range of metal oxides to identify materials that react with TMOS. 
We plan to test acidic, neutral, and basic $\gamma$-alumina to determine the role of acid-base surface properties in the reaction of tetramethoxysilane and an $\mathrm{H}_{2} / \mathrm{MeCl}$ gas stream. We will support copper oxide and reduced copper on these supports and evaluate reactivity.

Non-reducible metal oxides with a range of varying basicity ranges may also show improved reactivity with tetramethoxysilane. We plan to evaluate amphoteric and basic nonreducible metal oxides to activate tetramethoxysilane for further reaction with reactive methyl groups. We will investigate co-precipitated $\mathrm{SiO}_{2}-\mathrm{Al}_{2} \mathrm{O}_{3}, \mathrm{ZrO}_{2}, \mathrm{MgO}$, $\mathrm{CaO}, \mathrm{BaO}, \mathrm{Y}_{2} \mathrm{O}_{3}$, and $\mathrm{La}_{2} \mathrm{O}_{3}$ for reactivity with TMOS. Promising metal oxides will also be evaluated with copper to assist in activating methyl chloride to produce a reactive methyl group.

Modified aluminum oxides will be further investigated to improve reactivity with tetramethoxysilane. Alumina sols co-precipitated with basic metal oxides or with silica sols can create a range of Lewis acid, Lewis base, and Bronsted acid sites which may improve tetramethoxysilane reactivity with the alumina surface. Aluminum oxide is reactive toward TMOS, but silica is not. We plan to test co-precipitated silica-modified alumina to determine reactivity with tetramethoxysilane. These same materials will be evaluated with metallic copper for catalytic activity between methyl chloride and tetramethoxysilane. If we determine acidity on these modified materials is deleterious because tetramethoxysilane chemisorbs too strongly to the surface, we will further modify the surface with mono- and di-valent metal oxides to remove the Lewis and Bronsted acid sites.

\title{
Appendix 3
}

Note: this manuscript was submitted to Inorg. Chem. 8/01

\section{The Reaction of Silicate Minerals to Form Tetramethoxysilane*}

\author{
Larry N. Lewis*, Florian J. Schattenmann*, Tracey M. Jordan, \\ James C. Carnahan, William P. Flanagan, Ronald J. Wroczynski, John P. Lemmon, \\ Joseph M. Anostario, Michelle A. Othon
}

\section{GE Corporate Research \& Development Center Niskayuna, NY, 12309, USA}

\begin{abstract}
Several silicon dioxide sources were used as reagents in the base-mediated reaction with dimethylcarbonate (DMC) to make tetramethoxysilane (Q'). Several commercially available diatomaceous earth materials were investigated. High throughput screening was employed to explore over 200 silicate rocks and minerals as alternative silicon dioxide sources for formation of Q' from DMC and base. Amorphous silicon dioxide materials
\end{abstract}


are effective reagents for the Q' forming reaction. Effective silicon dioxide sources in addition to the diatomaceous earth materials include opal and various synthetic silicates ( $\mathrm{Li}, \mathrm{Co}$ and $\mathrm{Ca}$ ).

* This work was supported by Department of Energy Contract DE-FC02-98CH10931 


\section{INTRODUCTION}

Silicon, in the form of silica and silicates, is the second most abundant element in the earth's crust. However the synthesis of silicones (Scheme 1) and almost all organosilicon chemistry is only accessible through elemental silicon. ${ }^{1}$ Silicon dioxide (sand or quartz) is converted to chemical-grade elemental silicon in an energy intensive reduction process, a result of the exceptional thermodynamic stability of silica. Silicon is reacted with methyl chloride to give a mixture of methylchlorosilanes catalyzed by copper containing a variety of trace metals such as tin, zinc etc. The so-called direct process for making methyl chlorosilanes was first discovered at GE in 1940, Scheme 1. ${ }^{1-}$ 3 . The

\section{Scheme 1.}

Industrial Process for Production of Silicones
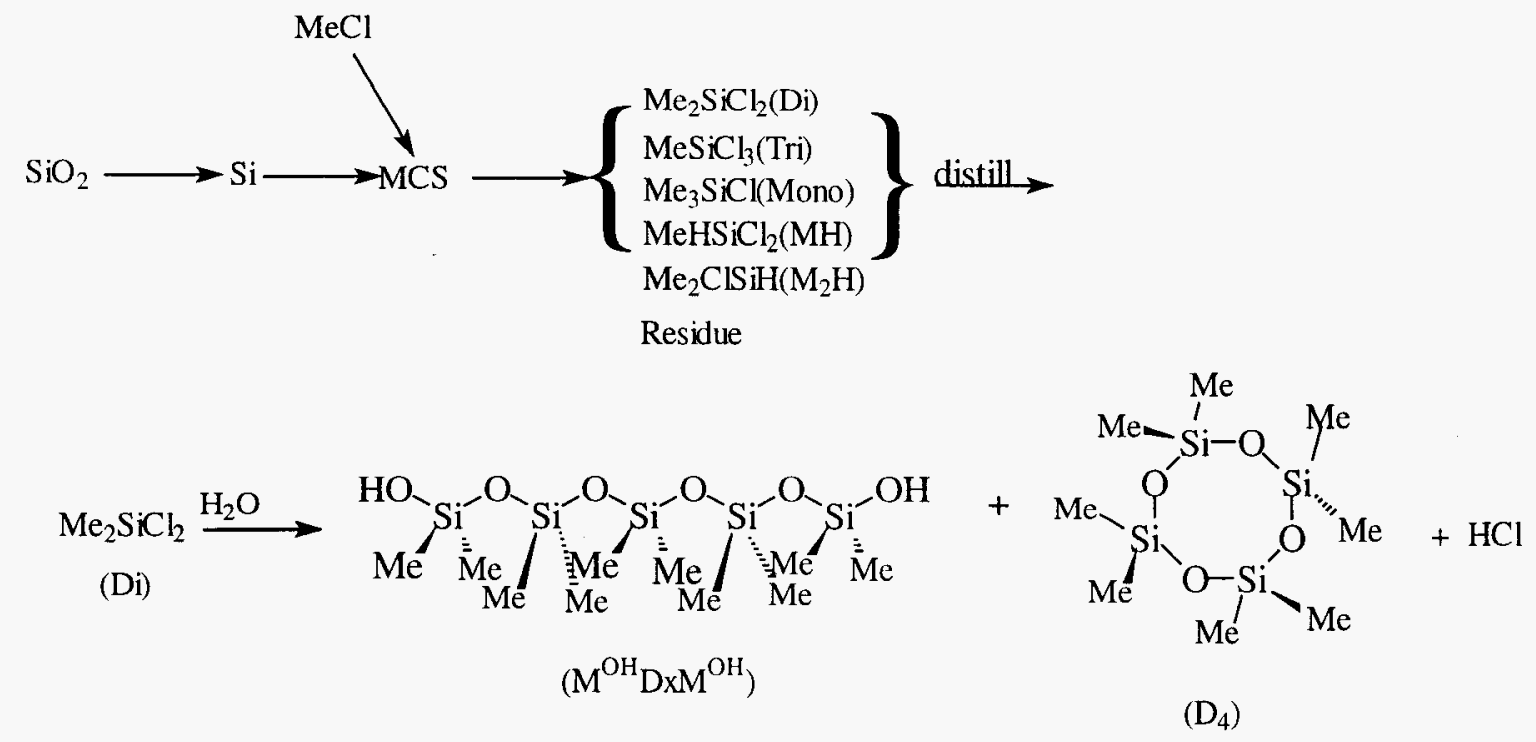
methylchlorosilanes are distilled to purify and separate the major reaction components, the most important of which is dimethyldichlorosilane. Polymerization of dimethyldichlorosilane by controlled hydrolysis results in the formation of silicone polymers. Worldwide, the silicones industry produces about 1.3 billion pounds of the basic silicone polymer, polydimethylsiloxane.

The energy costs associated with the process in Scheme 1, are mainly a result of the reduction of $\mathrm{Si}(\mathrm{IV})$ to $\mathrm{Si}(0)$ and subsequent re-oxidation to $\mathrm{Si}(\mathrm{IV})$. The conversion of silicon dioxide to elemental silicon in an electrochemical furnace at temperatures $\sim 1500^{\circ} \mathrm{C}$ consumes large amounts of electricity and carbon for reduction. Additionally, the production and separation of the methylchlorosilane mixture is energy intensive, involving several distillation steps. The difference in boiling points between the two main products from the direct process, dimethyldichlorosilane and methyltrichlorosilane is $4^{\circ} \mathrm{C}$.

An alternative synthetic route to the direct process is shown in Scheme 2 where the reduction and re-oxidation of silicon is avoided. The process in Scheme 2 makes alkoxy silanes instead of chlorosilanes. An alkoxysilane process has the advantage of avoiding chlorine use and the products are formed with a larger difference in boiling point than the conventional direct process; the difference in boiling point between dimethyldimethoxysilane and methyltrimethoxysilane is $20^{\circ} \mathrm{C}^{4}$.

\section{Scheme 2.}

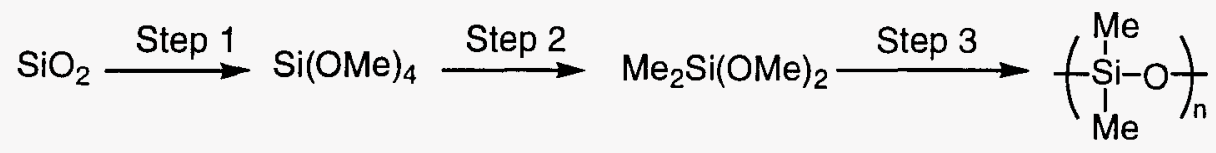

Precedence for Step 1 in Scheme 2 was recently reported by Ono et al. ${ }^{5}$ starting from silica gel and gaseous dimethyl carbonate (DMC) at $500-600 \mathrm{~K}$ to yield tetramethoxysilane in the presence of a catalyst supported on the silica. The employed catalysts include $\mathrm{MOH}(\mathrm{M}=\mathrm{Na}, \mathrm{K}, \mathrm{Rb}, \mathrm{Cs}), \mathrm{CsF}, \mathrm{KF}, \mathrm{KCl}, \mathrm{NaCl}$. Rice hull ash $(92 \%$ $\mathrm{SiO}_{2}$ purity) also reacts with $\mathrm{DMC}$ when loaded with $5 \mathrm{wt} . \%$ of potassium hydroxide at $625^{\circ} \mathrm{K} .{ }^{6}$

Earlier examples of the base catalyzed activation of $\mathrm{SiO}_{2}$ using alcohol derivatives include the formation of hexacoordinated dianionic complexes from silica (eq 1). ${ }^{7}$

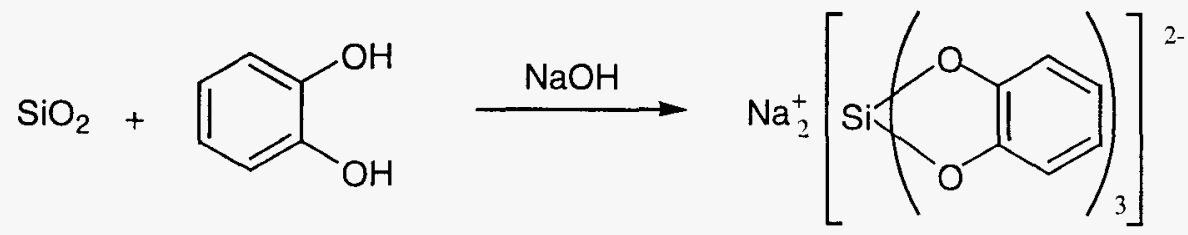

Additionally, Laine and coworkers have shown that silicon dioxide reacts with base and a diol to form a reactive penta-coordinate silicate species (eq 2). ${ }^{8,9}$ 


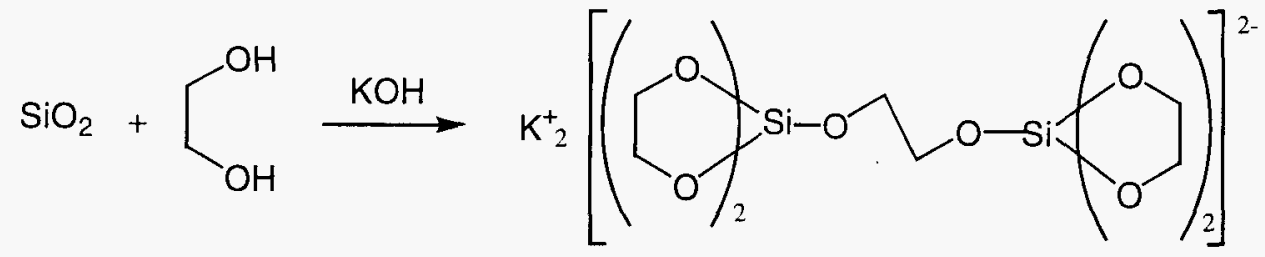

Very few other examples of the conversion of silicon dioxide to silicate-like compounds have been reported. ${ }^{10}$

Currently the only access to dialkyldialkoxysilane from tetraalkoxysilane (Step 2) involves the stoichiometric transformation using Grignard reagents. ${ }^{11,12}$ The hydrolytic polymerization of alkylalkoxysilanes to silicone polymers (Step 3 ) is a process that is practiced commercially.

The two major challenges connected with this proposed approach to silicones from silicon dioxide are: ptimization of the alkoxysilane synthesis from a low-cost silicon dioxide source and innovation of a new process for synthesis of alkylalkoxysilane from alkoxysilane.

This report describes the synthesis of tetramethoxysilane (Q') from a low-cost silicon dioxide source. High throughput screening was used to find suitable silicate sources for formation of Q'.

\section{EXPERIMENTAL}

\section{Fixed-bed lab reactor.}

A schematic representation of the fixed-bed flow reactor used is shown in Figure 1. The reactor was a glass tube $(20 \mathrm{~cm}$ long; $1 \mathrm{~cm}$ inner diameter) with a porous glass grid to hold the $\mathrm{SiO}_{2}$ sample. The reactor was centered vertically in a Nichrome ribbon wound glass tube ( $5 \mathrm{~cm}$ outer diameter). Two pairs of electrodes were fitted to the Nichrome to create two heated zones. The top heating zone was used to preheat the $\mathrm{DMC} /$ carrier gas mixture, the bottom section for the reactor itself. The Nichrome wound tube was centered in a quartz glass tube $(6.4 \mathrm{~cm}$ outer diameter) for insulation and safety purposes. The carrier gas stream was regulated using a mass flow controller (MKS Instruments type 1179A) connected to a four channel readout device (MKS Instruments type 247D). The DMC was added into the carrier gas stream (typically argon) above the upper heating zone through a septum via motor driven syringe. The reactor downstream was collected using a water-chilled condenser. 


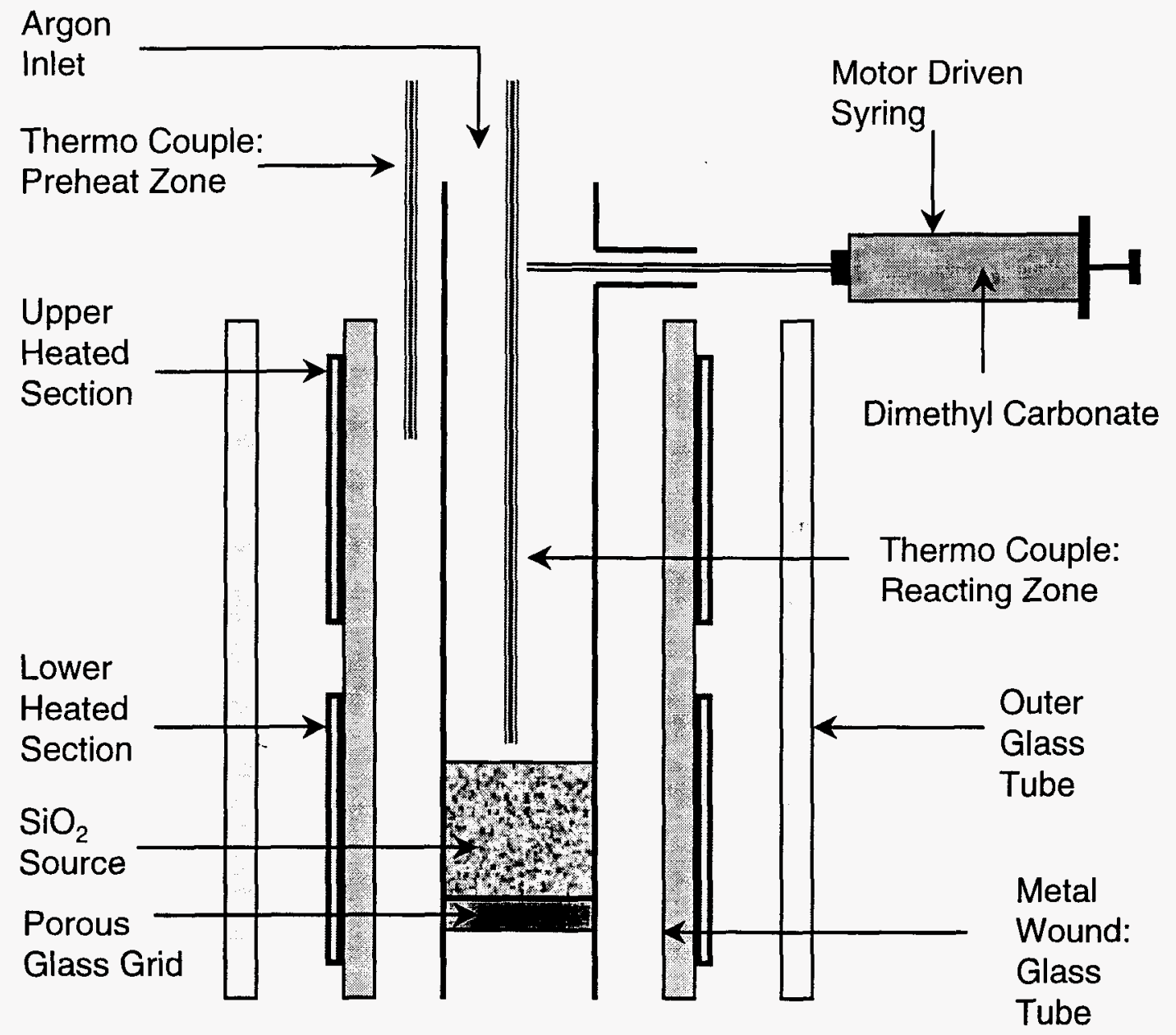

Figure 1. Schematic representation of fixed-bed flow reactor.

\section{Reaction of $\mathrm{SiO}_{2}$ source with DMC.}

Typical procedure. The $\mathrm{SiO}_{2}$ source was stirred in an aqueous solution of $\mathrm{KOH}$. The suspension was heated to dryness and the solid obtained was further dried overnight at $115^{\circ} \mathrm{C}$. The material was ground and charged into the described fixed-bed flow reactor with vertical furnace. The solid (typically $0.8 \mathrm{~g}$ ) was kept at the reaction temperature (typically $320^{\circ} \mathrm{C}$ ) in the argon stream for $1 \mathrm{~h}$. DMC (typically $20 \mathrm{mmol} / \mathrm{h}=1.68 \mathrm{~mL} / \mathrm{h}$; a total of $10 \mathrm{~mL}$ ) was fed into the carrier gas stream $(20 \mathrm{~mL} / \mathrm{min})$ using a motor driven syringe. The reactor downstream was collected in fractions using a water chilled condenser and analyzed by gas chromatography. Formation of $\mathrm{Si}(\mathrm{OMe})_{4}$ was confirmed by $\mathrm{GC} / \mathrm{MS}$. The $\mathrm{SiO}_{2}$-utilization values (\%) were calculated from the collected amounts of $\mathrm{Si}(\mathrm{OMe})_{4}$. The weight difference in the $\mathrm{SiO}_{2}$ bed before and after reaction was also determined, however a black carbon-based deposit rendered a precise weight determination impossible. 
The following $\mathrm{SiO}_{2}$ sources were used initially in the above described procedure:

- Silica gel: Davison Chemical Division W. R. Grace \& Co (grade 12; $700 \mathrm{~m}^{2} / \mathrm{g}$ surface area).

- Natural diatomaceous earth: Celite Snow Floss ${ }^{\circledR}$; Celite $209^{\circledR}$; Celite FC ${ }^{\circledR}$ and Dicalite SA $-3^{\circledR}$.

- Calcined diatomaceous earth: Celite $270^{\circledR}$.

- Flux-calcined diatomaceous earth: Celite Hyflo ${ }^{\circledR}$ and Celite $545^{\circledR}$. 
A large number of mineral and rock sources were obtained as described in the body of the text. Minerals were crushed in a Denver Equipment Co. jaw crusher and then ground in a SPEX Industries shatterbox. The list of all materials investigated and their origin can be found in the supplementary material.

\section{High Throughput Screening}

A 32-tube reactor system was employed. The reactor had a region to supply or generate a reacting vapor, gas flow control to a parallel array of replaceable reactor tubes, temperature control of the reactor tubes and a region where the reacted streams flowed from the reactor tubes to collecting vials for later analysis. A block diagram of the reactor is shown in Figure 2.

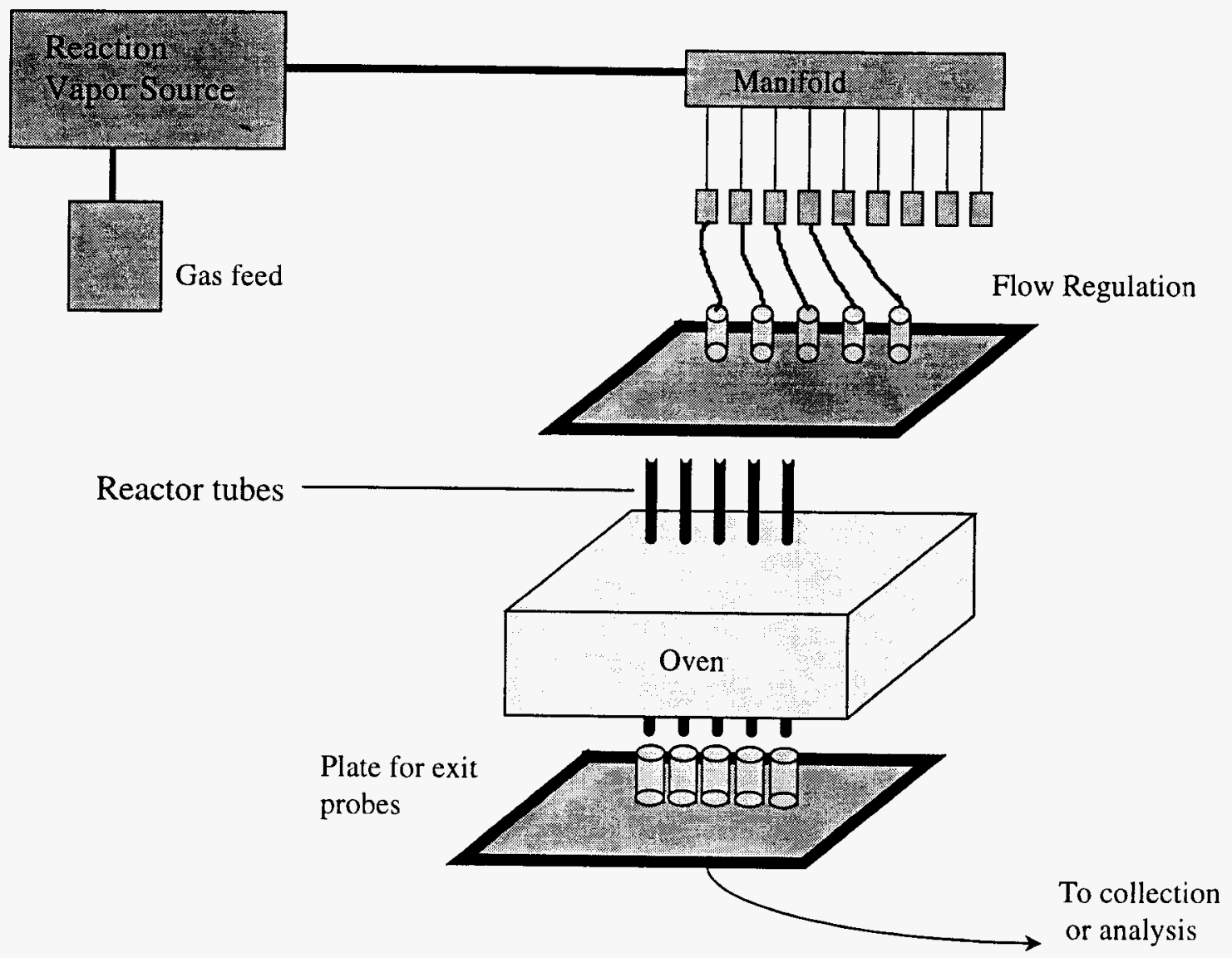

Figure 2. 32-tube High Throughput Screening Reactor Block Diagram. 


\section{Vaporizer Module}

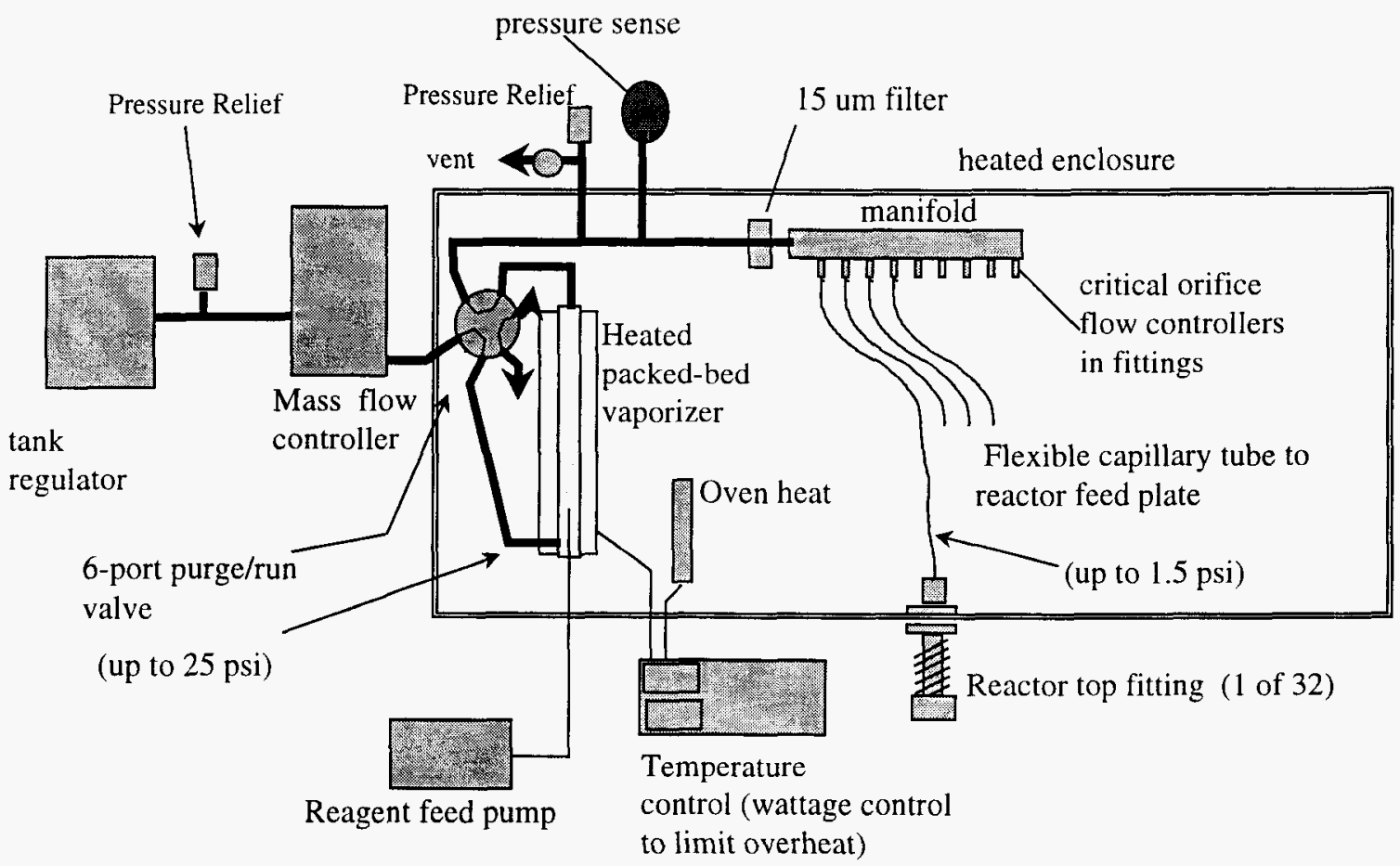

Figure 3. Vaporizer Module.

As shown in Figure 3, the mixing chamber was heated and purged with a controlled flow of carrier gas while DMC was added at a controlled rate to give a reactant gas mixture of known composition.

The reactant gas mixture generated by the vaporizer was then fed to a manifold to distribute the reactants to the array of reaction tubes. The manifold and flow lines were maintained at elevated temperature to avoid condensation of DMC from the gas stream. In order to obtain meaningful comparisons of activity of the condensed phase reagent with the DMC, the flow rate of the vapor was controlled to provide similar gas flow rates through each reaction tube. Capillary tube restrictors were employed as passive flow control devices for distribution to the array of reaction tubes. 
We utilized elastomer or inert thermally stable polymer seals to provide a gas-tight seal at the entrance and exit of the reactor tubes (Figure 4). The reactor tube length was substantially longer than the heater block to permit cooling of the exposed portions of the tubes and thus reduced thermal effects on the elastomer seals. The seals at the bottom end of the reaction tube are spring loaded and allowed to move in the reaction tube axis while mounted on a locating plate.

\section{Reactor Top Tube Seal}
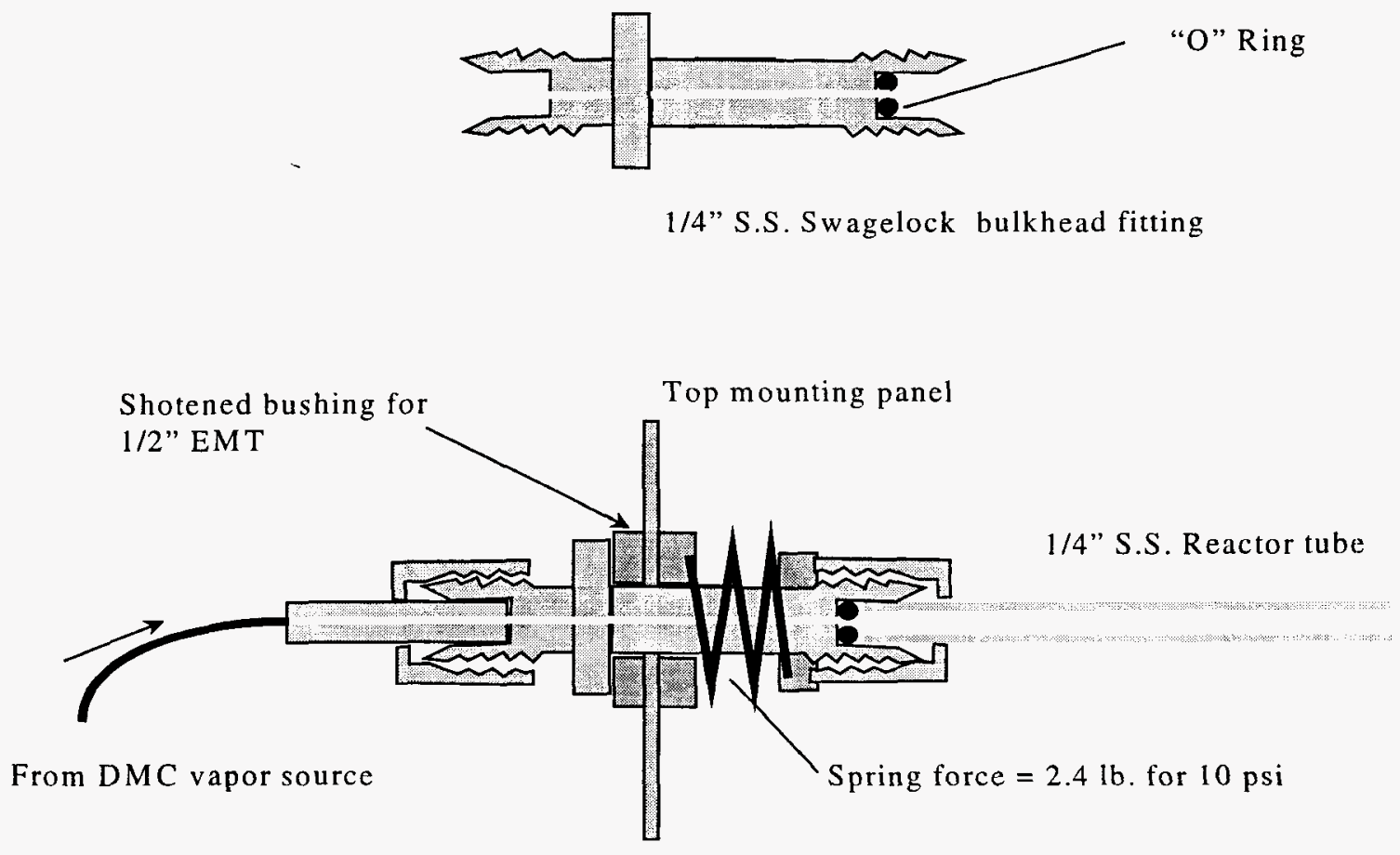

Figure 4. Example of Spring-Loaded Reactor End Seals

The exit gases from the reactor tubes were passed through a bundle of 32 heated capillary tubes to an array of 32 culture tubes containing dichlorobenzene in a cooled block.

\section{High Speed gas Chromatography}

Gas chromatographic analysis was carried out using the EZ-Flash ${ }^{\circledR}$ GC accessory from Thermedics. The EZ-Flash is an accessory for conventional gas chromatographs that directly heats the capillary column permitting very high heating rates and temperature 
uniformity. The fundamental separating capability of the column was maintained while dramatically shortening analysis time without a decrease in peak resolution.

The column used for the HTS reactor products was a silicone coated capillary from Restek (RTX-5). The column was a 5 meter $0.25 \mathrm{~mm}$ diameter capillary coated with 0.5 microns of a cross-linked dimethylsiloxane. The EZ-flash temperature program consisted of a hold for 30 seconds at $40^{\circ} \mathrm{C}$ followed by a ramp to $280^{\circ} \mathrm{C}$ at 60 seconds $\left(480^{\circ} \mathrm{C} / \mathrm{min}\right)$ and a 15 second hold at $280^{\circ} \mathrm{C}$. The carrier gas was helium at 15 psi head pressure, the injector and flame detector temperatures were $290^{\circ} \mathrm{C}$ and a $1 \mu \mathrm{l}$ injection was used in split mode with a split ratio of $120: 1$. The oven program on the host HP5890-II GC was as follows: A 30 second hold at $40^{\circ} \mathrm{C}$ then a ramp at $10^{\circ} \mathrm{C} / \mathrm{min}$ to $41^{\circ} \mathrm{C}$ followed by a ramp at $-40^{\circ} \mathrm{C} / \mathrm{min}$ to $40^{\circ} \mathrm{C}$ and a hold for 22 seconds. The short temperature program avoided HP fault shutdown due to oven temperature excursions and permits rapid cooling of the EZ-Flash column to the start condition.

$\underline{\mathrm{XRD}}$

X-Ray Diffraction was performed on thirty-seven mineral samples in an effort to identify individual phases in each of the samples. The majority of the samples (twenty-nine samples) were measured on a Siemans D500 diffractometer, which utilizes a BraggBrentano vertical $\Theta: 2 \Theta$ goniometer geometry, while the remainders (eight samples) were measured on a Scintag XDS 2000 diffractometer, utilizing a Bragg-Brentano vertical $\Theta: \Theta$ goniometer geometry.

Both instruments used a $\mathrm{Cu}$ anode tube, (wavelength for CuKalphal $=1.54056 \AA$ ), and samples were typically measured at the following parameters:

Power Generation
$\mathrm{kV}=45$
$\mathrm{~mA}=40$

Siemans D500 $=1^{\circ}$

\author{
Instrument Setup \\ 2 theta range $=10-90^{\circ}$ \\ Stepsize $=0.05^{\circ}$ \\ Dwell time $=2$ seconds \\ Slit sizes:
}

\section{Scintag XDS $2000=0.5 / 0.3$}

Variations in the above listed setup were typically due to analyses specific to a certain sample, (ex: placing tape over the surface of certain samples in an effort to maintain optimal measuring surface, extending the 2 theta range to explore additional peaks in a sample, etc.). All samples were top-loaded into an Al cavity mount sample holder.

Upon the completion of each measurement, the spectra were then analyzed with Materials Data, Inc. (MDI) Jade XRD pattern processing software package (version 5.0.24). Using information such as chemical composition, 2theta/d-space position, and peak intensity, all phases were referenced to the International Centre for Diffraction Data (release 1999) database $^{13}$ for the closest reasonable match. Determination of mineral phases was 
sometimes supported by knowing the likely appearances of certain minerals with each other $^{14}$.

Procedure for analyzing powder using image analysis

Small samplings of powder were removed from the vial and placed on a glass slide. A small droplet of dispersion fluid with a refractive index that provided good contrast between the powder and background was applied to a glass cover slip. The cover slip was placed on the powder sample and dispersed using mechanical agitation. The slide was then placed on a transmitted light microscope (Zeiss Photomicroscope III) and observed at sufficient magnification to distinguish the size and shape of the power. The microscope was outfitted with a high-resolution camera (Kodak ES1) which was interfaced to a computer in order to provide a digital image for further analysis. Image analysis software (Clemex Vision) was used to quantify the particle sizes as seen from the microscope.

Three samplings of powder were taken from each vial and analyzed. Three areas were imaged from each slide for a total of at least 9 areas measured for analysis. This procedure provided good statistical sampling of the true particle size distribution of the powder.

The size distribution was displayed in two forms: number and volume. The size distribution based on number was created by determining the number of particles that fell between size ranges determined by the user. The size distribution based on volume was made with the assumption that each particle approximated a sphere. In this way, each particle diameter was transformed into a volume using standard formulas and the distribution was based on the number of particles that fall between volume ranges (expressed as diameter). The importance of these two distributions lie in the fact that very often a plethora of very small particles were present that did not account for all of the volume. Using both forms illuminated the true distribution character of the powder.

\section{RESULTS AND DISCUSSION}

\section{Validation of literature synthesis of Q'.}

The reported base-catalyzed synthesis of Q' starting from silica gel ${ }^{5}$ was investigated serving two purposes, first to test this reaction in our reactor setup and second to use the data as a benchmark for other $\mathrm{SiO}_{2}$ sources. The literature procedure used a small-scale setup ( $2 \mathrm{mmol}, 120 \mathrm{mg}$ of $\mathrm{SiO}_{2}$ ) and the reactor downstream was directly monitored by GC without the use of a condenser. Quantitative $\mathrm{SiO}_{2}$ utilization was reported. ${ }^{5}$

Silica gel $(200 \mathrm{mg})$, loaded with $4.5 \% \mathrm{KOH}$ catalyst, was reacted with DMC at $320^{\circ} \mathrm{C}$. GC analysis of the down stream showed only two signals, Q' and unreacted DMC. $\mathrm{SiO}_{2}$-utilizations of $93 \%$ and $88 \%$ were found for two independent experiments. The $\mathrm{SiO}_{2}$ beds turned deep black indicating carbon deposition.

\section{Q' from fumed silica.}


In the context of screening available $\mathrm{SiO}_{2}$ sources, fumed silica was used as a reagent. The fumed silica, doped with $4.6 \% \mathrm{KOH}$, reacted almost quantitatively with DMC at $320^{\circ} \mathrm{C}$.

\section{Diatomaceous earth, a low-cost $\mathrm{SiO}_{2}$ source.}

The literature synthesis of Q' used silica gel as the $\mathrm{SiO}_{2}$ form. Silica gel is made from $\mathrm{SiCl}_{4}$ and ultimately from elemental silicon and therefore commercially unattractive. Additionally, silica gel has a very high surface area $\left(>100 \mathrm{~m}^{2} / \mathrm{g}\right)$. The biggest challenge for potential commercial implementation of the base-catalyzed synthesis of Q' from $\mathrm{SiO}_{2}$ and $\mathrm{DMC}$ represented the discovery of reactivity using a lowcost silicon dioxide source.

Diatomaceous earth (DE), also known as diatomite, is a naturally occurring, porous, high surface area form of hydrous silica. DE consists mainly of accumulated shells of intricately structured amorphous hydrous silica secreted by diatoms, which are microscopic, single-celled algae. All diatom species (more than 12,000 species are known) have an elaborately ornamented siliceous skeleton, which results in accumulations of uniquely porous particle of high surface area. Three general types of $\mathrm{DE}$ are commercially available, natural, calcined and flux-calcined. The natural product results from mining of the crude $\mathrm{DE}$, careful grinding (to preserve the intricate structure of DE) and drying. The calcined type is produced by subjecting the natural DE to high temperatures $\left(900-1000^{\circ} \mathrm{C}\right)$. The flux-calcined material is obtained by calcining the natural product in the presence of a fluxing agent, generally sodium carbonate. A selection of relevant properties is listed in Table 1. Annual production in 1990 in the USA totaled $619,000 \mathrm{t}$ and exceeded 1.8 Mt world wide.

SEM analysis of DE samples. SEM surface analysis was carried out on Celite Snow Floss $^{\circledR}$ (natural DE) with and without KOH catalyst (Figure 5) and on Celite Hyflo ${ }^{(1)}$ (flux-calcined DE) with and without KOH catalyst (Figure 6). Figure 5 and 6 showed the intricate structures of various DE species. The natural DE sample exhibited a wide distribution of particle sizes. In comparison, the flux-calcined DE had a lower particle size distribution and also showed some flake type materials. 


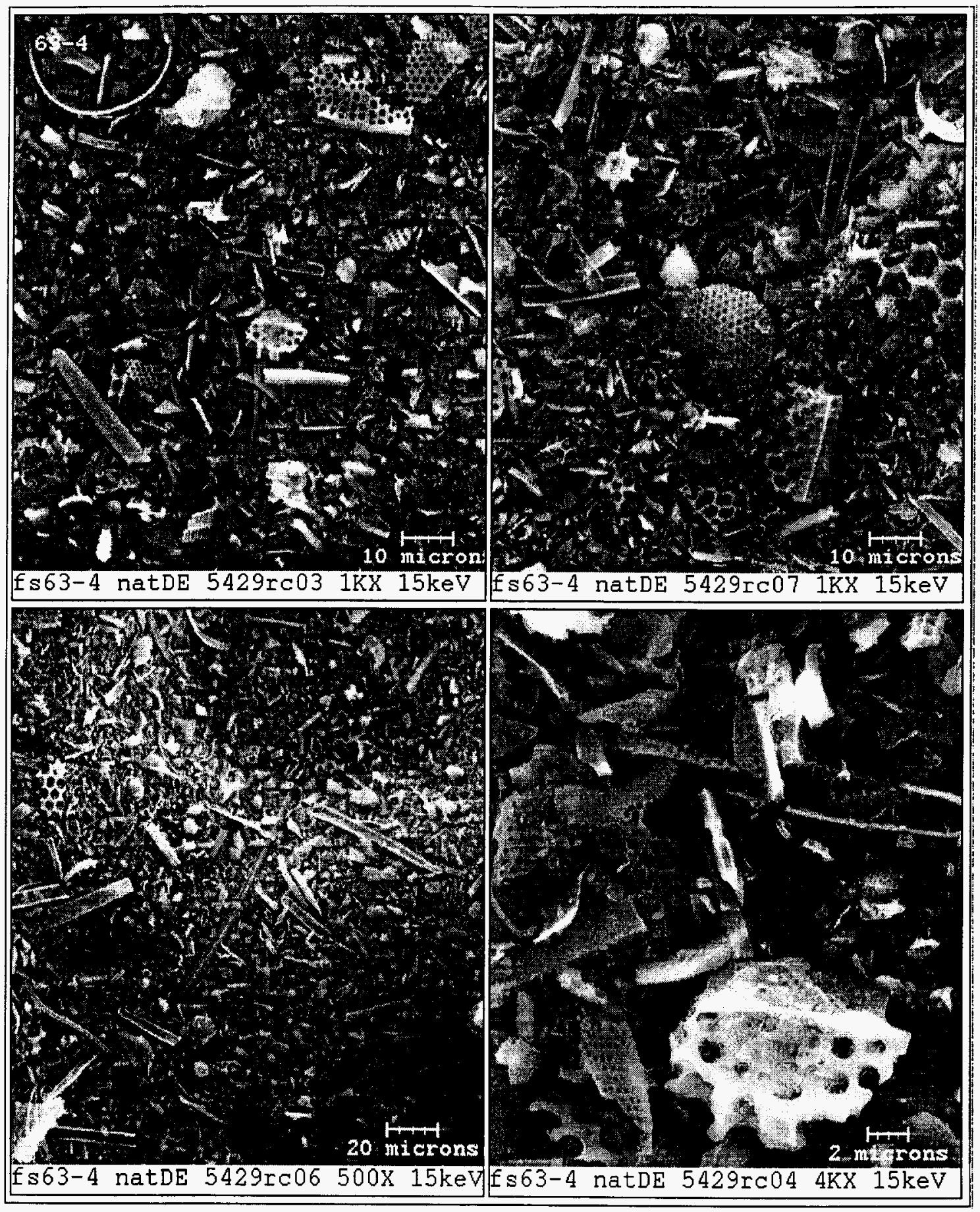

Figure 5. SEM of natural DE (Celite Snow Floss $\left.{ }^{\circledR}\right)$. 


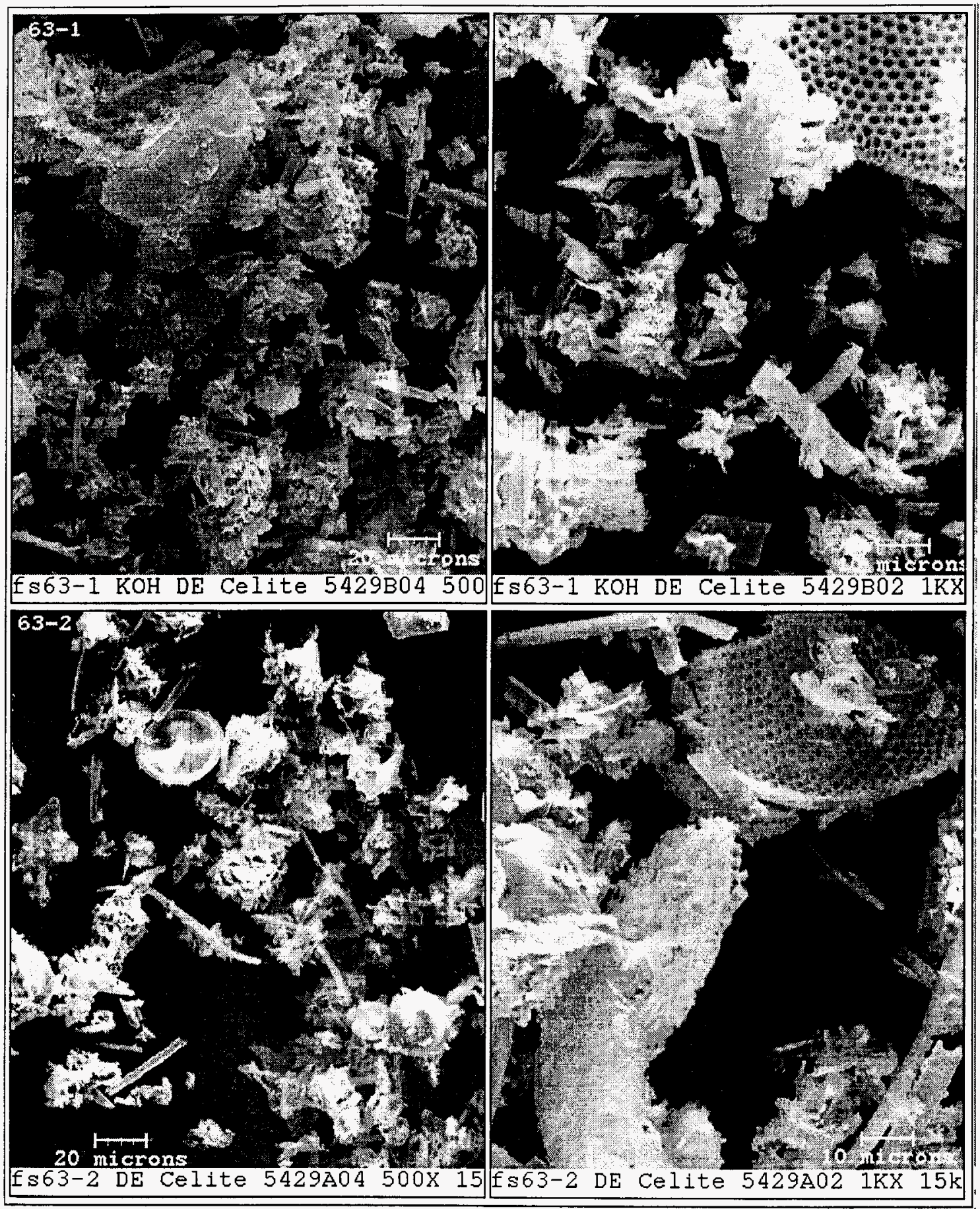

Figure 6. SEM of flux-calcined DE (Celite $\mathrm{Hyflo}^{\circledR}$ ) with $\mathrm{KOH}$ (top) and without $\mathrm{KOH}$ (bottom).

Table 1. Ranges of selected properties of diatomaceous earth products. ${ }^{a}$ 


\begin{tabular}{llll}
\hline Property & Natural & Calcined & Flux-calcined \\
\hline & & & \\
specific gravity & 2.00 & 2.25 & 2.33 \\
porosity, by volume $(\%)$ & $65-85$ & $65-85$ & $65-85$ \\
surface area $\left(\mathrm{m}^{2} / \mathrm{g}\right)$ & $10-30$ & $4-6$ & $1-4$ \\
Crystalline content $(\%)$ & $<5$ & $5-10$ & $>60$ \\
\hline
\end{tabular}

${ }^{a}$ Values given are typical or estimated values.

As a result of its natural formation, $\mathrm{DE}$ contains a wide variety of metals in form of their oxides in addition to $\mathrm{SiO}_{2} . \mathrm{SiO}_{2}$ contents range between $70 \%$ and more than $90 \%$. Most of the samples commercially available in the US contain $85-90 \% \mathrm{SiO}_{2}$. For example Celite $\mathrm{Hyflo}^{\circledR}$ contained $\mathrm{Al}(2.6 \%)$, Fe $(1.0 \%)$, $\mathrm{Na}(3.3 \%), \mathrm{K}(0.5 \%)$, $\mathrm{Ca}(0.4 \%)$, $\mathrm{Mg}(0.4 \%)$, $\mathrm{Ti}(0.1 \%)$ and other elements (50-1000 ppm) such as $\mathrm{Ba}, \mathrm{Mn}, \mathrm{Ni}, \mathrm{Cr}, \mathrm{Zn}, \mathrm{Sr}$.

\section{$\mathrm{SiO}_{2}$ utilization.}

$\mathrm{DE}$, treated with $\mathrm{KOH}$, reacted at temperatures between 300 and $360^{\circ} \mathrm{C}$ to yield Q'. The $\mathrm{SiO}_{2}$-utilization was a function of the commercial grade of the DE. The fluxcalcined grade $\left(\right.$ Celite $\mathrm{Hyflo}^{\circledR}$ ) exhibited the lowest $\mathrm{SiO}_{2}$ utilization $(<5 \%)$. $\mathrm{SiO}_{2}$ utilization for the calcined grade was $10 \%$ (Celite $270^{\circledR}$ ). $\mathrm{SiO}_{2}$-utilization for the natural grade DE (Celite Snow Floss $^{(\mathbb{B})}$ ) was optimized to $>60 \%$. The difference in reactivity between the three commercially available grades could best be explained by the variation in surface area, crystallinity and porosity (Table 1) with the surface area most likely representing the decisive factor (higher surface area equals higher $\mathrm{SiO}_{2}$-utilization).

The $\mathrm{SiO}_{2}$-utilization also depended on a variety of process factors, the most vital were the amount of $\mathrm{KOH}$ loading and the reaction temperature.

\section{DMC decomposition.}

The decomposition of DMC into dimethylether and carbon dioxide was already reported as a significant side reaction in the work by Ono et al. At $550 \mathrm{~K}$, Ono and coworkers found the DMC consumption and the transformation of DMC into Q' to be about equal, indicating that the gas phase decomposition of DMC was negligible. However at $600 \mathrm{~K}$ they reported significant decomposition.

Our mass balance analysis supported the Ono findings. DMC-utilization is defined as the ratio of DMC reacted towards Q' and the DMC consumed. DMC consumed was calculated by subtracting the recovered DMC from the added DMC. It was important to note that DMC loss due to inefficient condensing was included. Typically DMC utilization for the commercially viable natural DE was less than $20 \%$.

\section{Mechanistic aspects.}

A plausible mechanism is depicted in Figure 7. The mechanism is consistent with the data reported by Ono et al., computational data from Molecular Simulations Inc. and our own observations. 


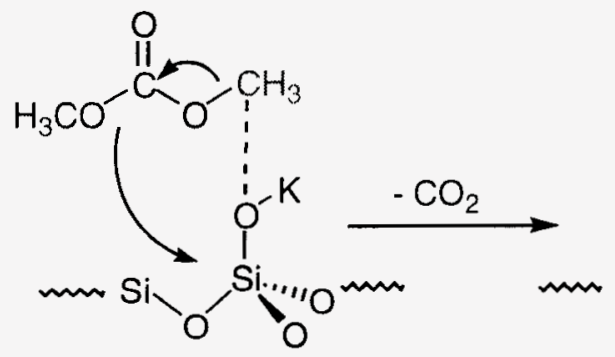<smiles>[3H]O[Si]([O])(OC)OC</smiles><smiles>[R]O[Si](OC)(OC)O[Si](C)(O)OC</smiles>

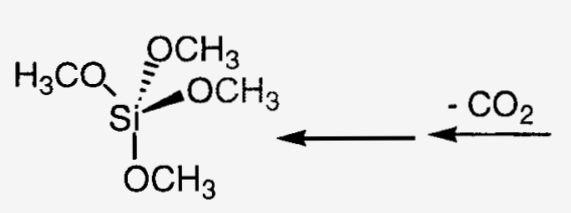<smiles>[X]O[Si](C)(OC)OC</smiles><smiles>[X]O[Si](OC)(OC)OC</smiles>

Figure 7. Proposed mechanism for the base catalyzed formation of $Q^{\prime}$ from $\mathrm{SiO}_{2}$.

Consistent with the literature, ${ }^{15}$ the $\mathrm{KOH}$-treated $\mathrm{SiO}_{2}$ surface likely contains $\mathrm{Si}-\mathrm{O}-\mathrm{K}$ linkages as structural units under the typical reaction conditions. Calculations by Molecular Simulations Inc. (MSI) showed that Si-O bonds elongate upon interaction with the potassium ion (from 1.63 to $1.67 \mathrm{~A}$ ) suggesting an activation of the Si-O bond. Experiments using a modified reactor setup that allowed mass spectrometry detection directly downstream of the reactor, showed the exclusive production of $\mathrm{CO}_{2}$ directly after the start of the DMC addition. Q' formation was observed after a delay consistent with the proposed mechanism because initially the reaction of DMC with the potassiumcontaining $\mathrm{SiO}_{2}$ surface resulted solely in the methoxylation of the silica surface under formation of $\mathrm{CO}_{2}$ (Figure 7). The formation of Q' requires a second activation of the methylated silica surface by $\mathrm{K}^{+}$followed by reaction with a second molecule of DMC. 


\section{Silicate Minerals}

Given the exciting lead provided by diatomaceous earth, a screen of silicate minerals was suggested. Well over 200 silicate minerals were screened for their reactivity with DMC and base. All of these minerals were crushed, ground, sieved, pre-mixed with aqueous base, dried and then reacted with DMC. High-speed gas chromatographic (GC) analysis (EZ-Flash) permitted rapid analysis of the products. The amount of Q' formation was compared to a reaction internal standard for each experiment. Not all of the minerals gave silicon containing volatile products, however the only product ever observed was Q'. The most promising silicate candidates in terms of Q' yield, were reacted in the traditional "one-at-a-time" mode using the fixed bed reactor with a larger bed volume. Attempts were also made to analyze and determine the precise nature of the promising minerals found in the screen.

The HTS reactor permitted 32 simultaneous fixed bed experiments to be performed. An LC pump was used to pass liquid reagent (DMC) through a vaporizer so that the reagent could be delivered to the reactor as a gas. Each tube was loaded with a previously ground mineral, pre-mixed with $5-10 \%$ base (usually $\mathrm{KOH}$ ). Un-reacted DMC, other by-products and product (if any) passed through heated transfer lines and condensed into tubes containing o-dichlorobenzene with cyclooctane as an internal standard. The mixtures were analyzed by high-speed gas chromatography. It was well established in the single tube reactor that silica gel and 5\% $\mathrm{KOH}$ reacted with DMC at $350 \mathrm{C}$ to give $\mathrm{Q}^{\prime}$ (vide supra). In a series of reactor runs, up to 32 tubes were loaded with silica gel containing $5 \% \mathrm{KOH}$ from a masterbatch. The reproducibility of formation of $\mathrm{Q}^{\prime}$ within and between runs is shown in figure 8, where $\mathrm{m}=$ the initial charge of $\mathrm{SiO}_{2}$. These experiments showed that a $\mathrm{Q}^{\prime} / \mathrm{m}$ difference of ca. 30 can be determined with $95 \%$ confidence. 


\section{Dot Plot}

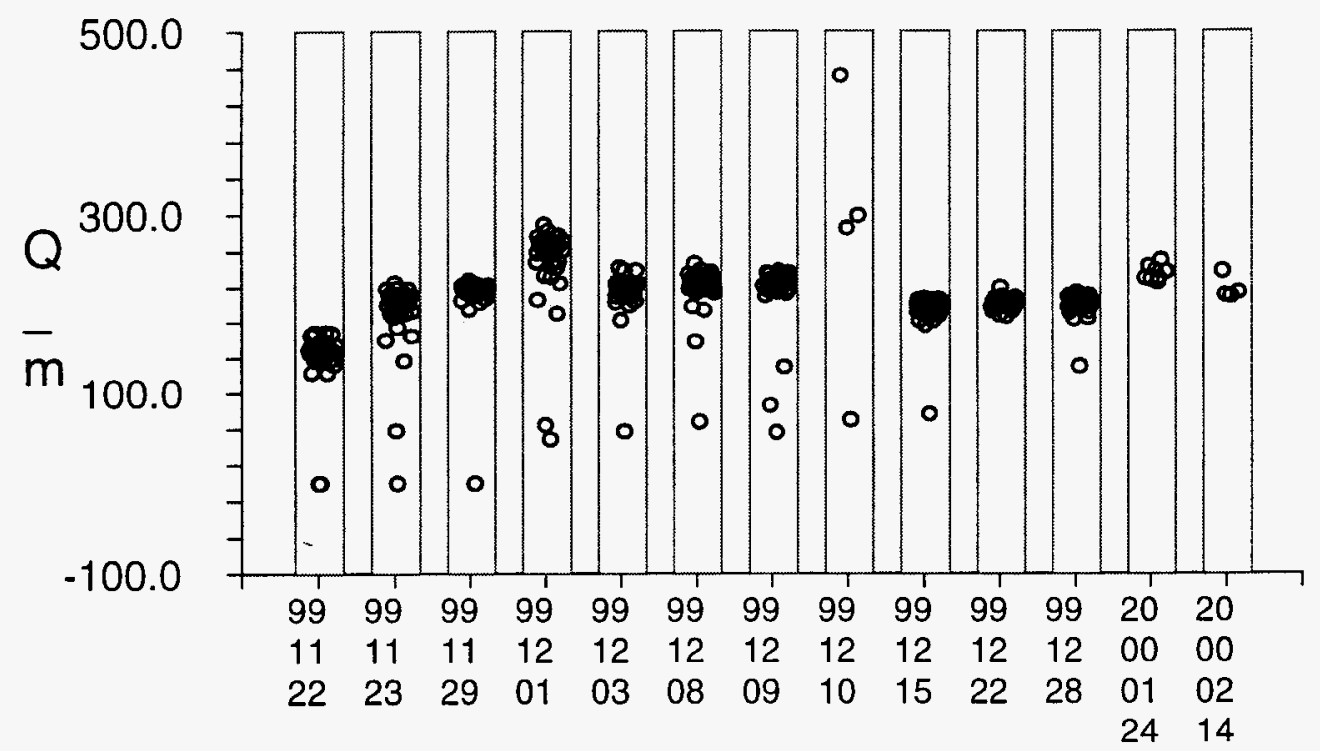

Figure 8

Reproducibility Study of Formation of Q' from Silica Gel $(5 \% \mathrm{KOH})$ in the 32-Column Reactor 
Mineral samples for study were obtained from a variety of sources. The silicates are classified into seven structural forms ${ }^{16}$. As shown below, there was no clear correlation between a particular mineral class and the propensity to form Q'.

Over 200 different minerals were screened for reactivity with DMC in the presence of base. In every 32column block of samples reacted, quadruplicates of the silicate were run as well as quadruplicates of silica gel and quadruplicates of sea sand. The sea sand (despite the fact that we call this project "Sand to Silicones") was nominally a "zero" in our experiments. Thus in every 32column run we had an internal check to insure that $Q^{\prime}$ was produced and that "zero" was really zero. Figure 9 shows the major "hits" from the screen. The amount (in $\mathrm{mg}$ ) of $\mathrm{Q}$ ' formed was compared to that produced from sand from each 32-column run. Figure 9 gives a graphical representation of the activity of all the minerals used in the combinatorial screen.

\section{Data 1}

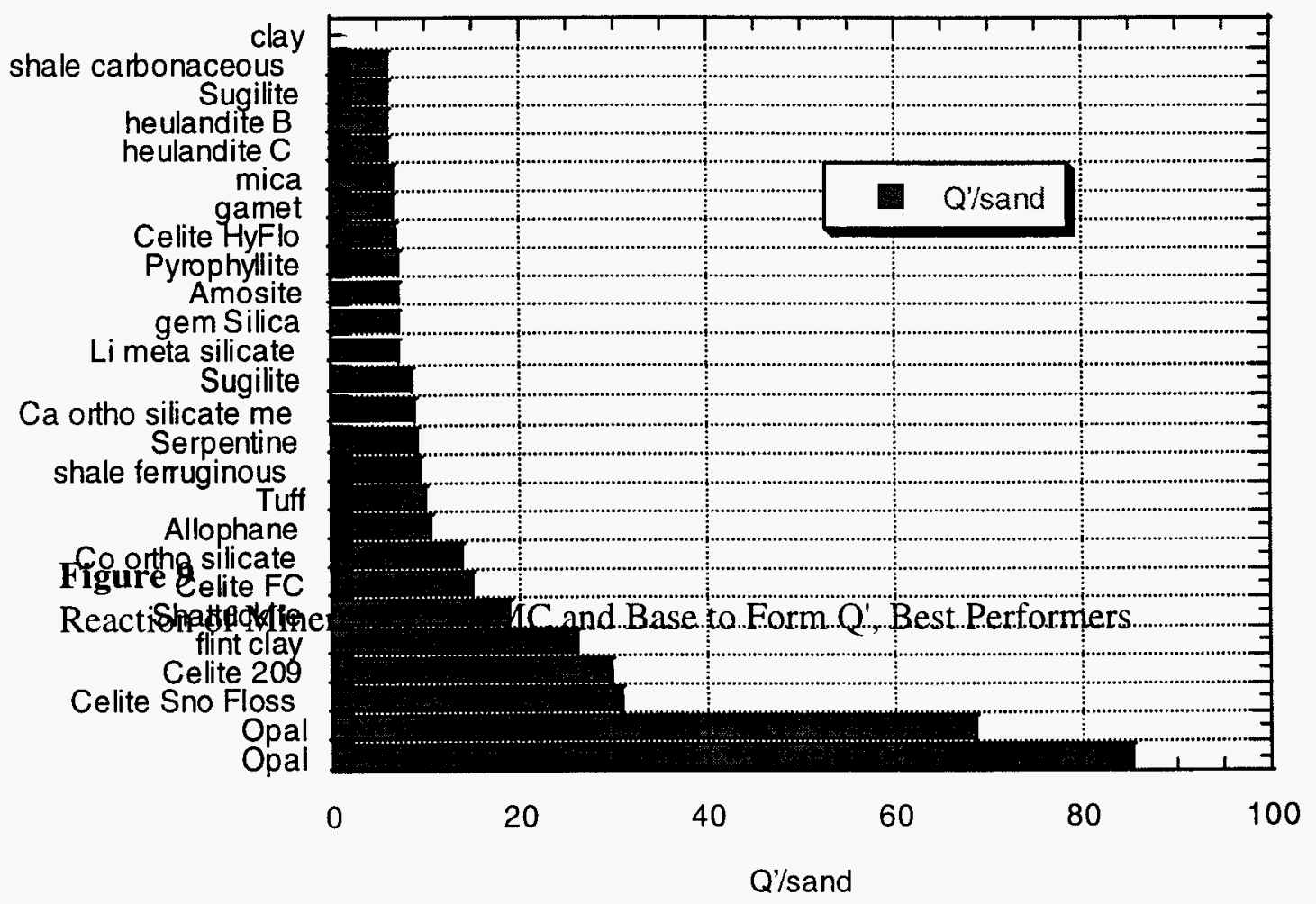


As was found previously, the diatomaceous earth materials were quite reactive with DMC in the presence of base to form Q'. Other amorphous materials were reactive as well, most notably Opal. Three synthetic silicates of $\mathrm{Co}, \mathrm{Li}$ and $\mathrm{Ca}$ were also found to be reactive with base and DMC to form Q'. We initially anticipated that the presence (or absence) of certain metals would be important and further, we wondered if the particle size of the ground mineral powders would also be important. No correlation could be found between particle size or elemental composition in terms of the propensity of a mineral to react with base and DMC to give Q'. The most important attribute for the reactivity of interest was crystalinity of the silica phase; namely amorphous materials had the highest reactivity.

\section{Single Reactor Experiments}

Preliminary work showed that the amorphous diatomaceous earth materials were the most active for formation of Q'. Additionally the flux-calcined diatomaceous earth powders had significant crystalline component. Flux-calcined Celites reacted poorly with base and DMC to give Q'. Using the results from the high throughput screen, we ran the "hits" in a larger scale, one-at-a-time reactor. The results of the single experiment runs are shown in Table 2. This table also shows the number average and volume average particle size for each material in the table. The particle size data was obtained by image analysis.

Table 2 Most Active Minerals for Formation of Q' from reaction with DMC and Base 


\begin{tabular}{|c|c|c|c|c|c|}
\hline Mineral & Formula & Structure & Q'sand & Size (vol) & Size (\#) \\
\hline Opal & $\mathrm{SiO} 2$ & tectosilicate & 102.7632 & 15 & $6.1 E$ \\
\hline Opal & $\mathrm{SiO} 2$ & tectosilicate & 85.39744 & 1.5 & $1.1 \varepsilon$ \\
\hline Celite Sno Floss & $\mathrm{SiO} 2$ & tectosilicate & 68.48718 & 1.74 & 1.4 \\
\hline Celite 209 & $\mathrm{SiO} 2$ & tectosilicate & 30.87379 & 23.4 & 12.37 \\
\hline flint clay & $\mathrm{Al} 2 \mathrm{O} 3-\mathrm{SiO} 2$ & tectosilicate & 29.67213 & 26.2 & 16.5 \\
\hline Shattuckite & $\mathrm{Cu} 5(\mathrm{SiO} 3) 4(\mathrm{OH}) 2$ & Inosilicate & 26 & & \\
\hline Celite FC & $\mathrm{SiO} 2$ & tectosilicate & 18.96117 & 5 & 3.25 \\
\hline Co ortho silicate & $\mathrm{Co} 2 \mathrm{SiO} 4$ & & 15.1203 & 4.4 & $3.0 \varsigma$ \\
\hline Allophane & $\mathrm{Al} 2 \mathrm{O} 3 \cdot(\mathrm{SiO} 2) 1 \cdot 3-2 \cdot((\mathrm{H} 2 \mathrm{O})) 2$ & 2 Phyllosilicate & 14 & 9.8 & 5.91 \\
\hline Tuff & $\mathrm{SiO} 2$ & Tectosilicate & 10.5 & 14.6 & 6.37 \\
\hline shale ferruginous & & & 9.928571 & 12.8 & $7.4 €$ \\
\hline Serpentine & $\mathrm{Mg} 3 \mathrm{Si} 2 \mathrm{O} 5(\mathrm{OH}) 4$ & Phyllosilicate & 9.571429 & 9.2 & $4 . \subseteq$ \\
\hline Ca ortho silicate meta Wollastonite & $\mathrm{CaOSiO} 2$ & & 9.045455 & 10.1 & $78 . €$ \\
\hline Sugilite & $(\mathrm{Na}, \mathrm{K}) \mathrm{AlSiO} 4$ & Tectosilicate & 8.882353 & 24.3 & 10.5 \\
\hline Li meta silicate & $\mathrm{Li2SiO} 3$ & & 8.714286 & 14.3 & 7.4 \\
\hline gem Silica & $\mathrm{SiO} 2$ & & 7.352941 & 22.8 & 10.1 \\
\hline Amosite & $\mathrm{FeC} 2 \mathrm{Mg}) 6 \cdot \mathrm{Si} 8 \mathrm{O} 22(\mathrm{OH}) 2$ & Inosilicate & 7.319672 & & \\
\hline Pyrophyllite & Al2Si4O $10(\mathrm{OH}) 2$ & Phyllosilicate & 7.277778 & 49 & 41.6 \\
\hline Celite HyFlo & $\mathrm{SiO} 2$ & tectosilicate & 7.128205 & 15 & $\varepsilon$ \\
\hline garnet & $33 \% \mathrm{SiO} 2$ & neosilicate & 7 & 4.7 & 2.95 \\
\hline mica & $\mathrm{K} 2 \mathrm{O}(\mathrm{Al} 2 \mathrm{O} 3) x(\mathrm{SiO} 2) y$ & phyllosilicate & 6.772727 & 8.8 & $3 . \varepsilon$ \\
\hline heulandite C & CaAl2Si7O18 6H2O & tectosilicate & 6.571429 & 14.1 & 7.85 \\
\hline heulandite B & $\mathrm{CaAl} 2 \mathrm{Si} 7 \mathrm{O} 186 \mathrm{H} 2 \mathrm{O}$ & tectosilicate & 6.214286 & 23.7 & $9 . \varsigma$ \\
\hline Sugilite & $(\mathrm{Na}, \mathrm{K}) \mathrm{AlSiO} 4$ & Tectosilicate & 6.111111 & 314 & 59.6 \\
\hline shale carbonaceous & & & 6.111111 & 10.9 & 6.6 \\
\hline clay & MV, North Shore & & 6.090909 & 3.5 & $2 . E$ \\
\hline Schist Albite & (NaAlSi3O8)x(CaAl2Si2O8)! & Tectosilicate & 6.055556 & 44.1 & 21.1 \\
\hline Andalusite & Al2SiO5 & neosilicate & 6 & 36.1 & 15.1 \\
\hline Celite 545 & $\mathrm{SiO} 2$ & tectosilicate & 5.948718 & 12.1 & $9 . c$ \\
\hline Shattuckite & $\mathrm{Cu} 5(\mathrm{SiO} 3) 4(\mathrm{OH}) 2$ & Inosilicate & 4.947368 & 13.8 & $5 . \varepsilon$ \\
\hline Orthoclase & KAISi3O8 & Tectosilicate & 4.789474 & 86.2 & 53.5 \\
\hline Ilvaite & $\mathrm{Ca}(\mathrm{Fe} 2+) 3(\mathrm{Fe} 3+) \mathrm{O}(\mathrm{Si} 2 \mathrm{O} 7)($ & sorosilicate & 4.529412 & 59 & $1 \subseteq$ \\
\hline Zircon & $\mathrm{ZrSiO} 4$ & neosilicate & 4.230769 & 1.8 & 1.36 \\
\hline Jade & Ca2Mg5Si8O22(OH)2 & inosilicate & 4.222222 & 14.1 & $5.8 \varepsilon$ \\
\hline slate & & & 3.954545 & 8 & $4.3 \varepsilon$ \\
\hline Lazurite & $(\mathrm{Na}, \mathrm{Ca}) 8(\mathrm{AlSiO} 4) 6(\mathrm{SO} 4, \mathrm{~S}, \mathrm{C}$ & tectosilicate & 3.827586 & 10.9 & 6.35 \\
\hline
\end{tabular}


The results from the high throughput screen showed that reaction of opal and base with DMC gave the highest yields of Q'. Thus the opal reaction was used to determine the repeatability of using the fixed bed reaction. Six replicate experiments were run in the fixed bed where opal with $5 \% \mathrm{KOH}$ was reacted with DMC at $350 \mathrm{C}$. About $20 \%$ yield of Q' was obtained with a standard deviation of $3 \%$.

DMC decomposition also occurred in the course of the reaction of silicate/base with DMC. DMC utilization was $58 \%$ with a standard deviation of $20 \%$ for six replicate runs. Obviously the utilization of DMC was neither highly optimized not very reproducible.

\section{Mineral Analysis}

Unlike a traditional chemistry experiment, experiments performed with rocks or minerals have the problem that the "reagent" may not be pure or may be poorly characterized (caveat emptor!). A selection of minerals used in the combinatorial screen, were analyzed by X-Ray Diffraction (XRD) and by X-Ray Fluorescence (XRF). The diffraction pattern for most common minerals is well known and so XRD patterns for pure materials should match literature patterns. In many cases two or more components were present in our samples and so the observed patterns were composed of components of the mixture. As a result of our screening experiments we found that our best performing materials were amorphous silicates. XRD measurement on amorphous materials will usually give just broad patterns. Table 3 gives the results of the XRD screen. Figures 10, gives a representative example of the observed XRD pattern for a material and the match of that pattern to a known material. Additional patterns are provided in the supplementary material section.

Table 3

XRD Analysis of Some Minerals Investigated in Combinatorial Screen

\begin{tabular}{|c|c|c|c|c|}
\hline Rock/Mineral & Source & Major (PDF file ${ }^{13}$ ) & Minor (PDF file ${ }^{13}$ ) & Comments \\
\hline Slate & $\begin{array}{l}\text { GE CRD, } \\
\text { Hansen Trail }\end{array}$ & Quartz (85-1094) & $\begin{array}{l}\text { Albite (80-1094 } \\
\text { Clinoclore }(7-78) \\
\text { Muscovite (46- } \\
1311)\end{array}$ & \\
\hline Clay & $\begin{array}{l}\text { Martha's } \\
\text { Vineyard, N. } \\
\text { Shore }\end{array}$ & Quartz (85-1094) & $\begin{array}{l}\text { Albite }(80-1094 \\
\text { Clinoclore }(7-78) \\
\text { Muscovite (46- } \\
1311)\end{array}$ & $\begin{array}{l}\text { Identical to } \\
\text { Slate sample }\end{array}$ \\
\hline Zircon & $\begin{array}{l}\text { Curumbin, } \\
\text { Queensland, } \\
\text { Aust. }\end{array}$ & $\mathrm{ZrSiO} 4(6-266)$ & & \\
\hline
\end{tabular}




\begin{tabular}{|c|c|c|c|c|}
\hline Flint Clay & $\begin{array}{l}\text { Christy, } 200 \\
\text { mesh, calcined }\end{array}$ & $\begin{array}{l}\text { Mullite (83-1881) } \\
\text { Quartz (85-504) } \\
\text { Cristobalite (82- } \\
512 \text { ) }\end{array}$ & & \\
\hline $\begin{array}{l}\text { Shale } \\
\text { Carbonaceous }\end{array}$ & $\begin{array}{l}\text { Ward's, } \\
\text { Luzerne, PA }\end{array}$ & $\begin{array}{l}\text { Quartz }(85-1054) \\
\text { Muscovite }(6-263)\end{array}$ & & \\
\hline Mica & $\begin{array}{l}\text { Bombay } \\
\text { Minerals, India }\end{array}$ & Muscovite (6-263) & & $\begin{array}{l}\text { Preferential } \\
\text { orientation, } \\
(002)\end{array}$ \\
\hline Andalusite & $\begin{array}{l}\text { Ward's, Sanat } \\
\text { Theresa, Minas } \\
\text { Gerais, Brazil }\end{array}$ & Andalusite (39-376) & & \\
\hline Orthoclase & Ward's, India & $\begin{array}{l}\text { Microlcline (19- } \\
\text { 932) }\end{array}$ & Albite (9-466) & $\begin{array}{l}\text { Large unknown } \\
\text { peak }\end{array}$ \\
\hline Serpentine & $\begin{array}{l}\text { Ward's, } \\
\text { Roxbury, VT }\end{array}$ & Greenalite $(72-177)$ & $\begin{array}{l}\text { Magnetite (86- } \\
\text { 1334) }\end{array}$ & $\begin{array}{l}3 \text { unknown } \\
\text { peaks, high Fe } \\
\text { by XRF }\end{array}$ \\
\hline Garnet & $\begin{array}{l}\text { Barton Mines, } \\
\text { N. Creek, NY }\end{array}$ & $\begin{array}{l}\text { Almandine (33- } \\
658 \text { ) }\end{array}$ & & \\
\hline Schist Albite & $\begin{array}{l}\text { Ward's, San } \\
\text { Bernadino, CA }\end{array}$ & $\begin{array}{l}\text { Muscovite (46- } \\
1409 \text { ) }\end{array}$ & $\begin{array}{l}\text { Quartz (85-797) } \\
\text { Albite (10-393) }\end{array}$ & $\begin{array}{l}\text { Light \& dark } \\
\text { sections of rock }\end{array}$ \\
\hline $\begin{array}{l}\text { Co } \\
\text { orthosilicate }\end{array}$ & Pfaltz \& Bauer & $\begin{array}{l}\text { Completely } \\
\text { amorphous }\end{array}$ & & \\
\hline $\begin{array}{l}\mathrm{Li} \\
\text { metasilicate }\end{array}$ & $\begin{array}{l}\text { Rocky Mt. } \\
\text { Research }\end{array}$ & Amorphous & $\begin{array}{l}\mathrm{LiNaSO} 4(71-2172) \\
\text { (trace) }\end{array}$ & \\
\hline $\begin{array}{l}\mathrm{Ca} \\
\text { orthosilicate }\end{array}$ & Alfa & $\begin{array}{l}\text { Wollastonite (43- } \\
1460)\end{array}$ & & $\begin{array}{l}\text { Preferential } \\
\text { orientation } 002\end{array}$ \\
\hline
\end{tabular}




\begin{tabular}{|c|c|c|c|c|}
\hline Tuff & $\begin{array}{l}\text { Ward's, Ennis, } \\
\text { MT }\end{array}$ & Quartz (78-2315) & $\begin{array}{l}\text { Cristobalite }(39- \\
1425) \\
\text { Tridymite }(14-260) \\
\text { Sanidine }(80-2106)\end{array}$ & \\
\hline $\begin{array}{l}\text { Shale } \\
\text { ferruginous }\end{array}$ & $\begin{array}{l}\text { Ward's, } \\
\text { Williamsport, } \\
\text { PA }\end{array}$ & Quartz (86-1629) & $\begin{array}{l}\text { Cronstedite (72- } \\
1673) \text { Gismondine } \\
(20-452) \\
\text { Muscovite }(6-263)\end{array}$ & Smaller peaks \\
\hline Jade & $\begin{array}{l}\text { Ward's, British } \\
\text { Columbia }\end{array}$ & $\begin{array}{l}\text { Actinolite (41- } \\
1366)\end{array}$ & & $\begin{array}{l}\text { High Fe by } \\
\text { XRF }\end{array}$ \\
\hline $\begin{array}{l}\text { Diatom- } \\
\text { aceous earth }\end{array}$ & $\begin{array}{l}\text { Celite, Sno } \\
\text { Floss }\end{array}$ & Amorphous & $\begin{array}{l}\text { Tridymite (77- } \\
1060)\end{array}$ & Natural \\
\hline $\begin{array}{l}\text { Diatom- } \\
\text { aceous earth }\end{array}$ & Celite, Hy Flo & $\begin{array}{l}\text { Partially amorphous } \\
\text { Cristobalite (76- } \\
938 \text { ) }\end{array}$ & $\begin{array}{l}\mathrm{SiO} 2(77-1060) \\
\text { (triclinic) }\end{array}$ & Flux calcined \\
\hline $\begin{array}{l}\text { Diatom- } \\
\text { aceous earth }\end{array}$ & Celite 545 & $\begin{array}{l}\text { Amorphous } \\
\text { Cristobalite (76- } \\
938 \text { ) }\end{array}$ & $\begin{array}{l}\mathrm{SiO} 2(77-1060) \\
\text { (triclinic) }\end{array}$ & $\begin{array}{l}\text { Flux calcined, } \\
\text { identical to Hy } \\
\text { Flo }\end{array}$ \\
\hline Shattuckite & Multistone Int'1 & Quartz (79-1906) & & $\begin{array}{l}\text { High } \mathrm{Cu} \text { by } \\
\text { XRF }\end{array}$ \\
\hline Shattuckite & $\begin{array}{l}\text { Ward's, Ajo, } \\
\text { AZ }\end{array}$ & $\begin{array}{l}\text { Shattuckite (83- } \\
1240)\end{array}$ & & $\begin{array}{l}\text { Pattern } \\
\text { different from } \\
\text { Multistone } \\
\text { "Shattuckite" }\end{array}$ \\
\hline Gem Silica & Multistone Int'l & $\begin{array}{l}\text { Alpha quartz (85- } \\
1054)\end{array}$ & & \\
\hline Sugilite & Multistone Int'1 & Quartz (85-504) & Sugilite $(47-1840)$ & \\
\hline Sugilite & Ward's, VA & & & $\begin{array}{l}\text { No match } \\
\text { found } \\
\text { ( } \neq \text { Sugilite) }\end{array}$ \\
\hline Opal & $\begin{array}{l}\text { Ward's, Virgin } \\
\text { Valley, } \\
\text { Humbolt } \\
\text { County, NV } \\
\end{array}$ & $\begin{array}{l}\text { Amorphous opal } \\
(38-448)\end{array}$ & Tridymite (77-126) & 2 samples \\
\hline Lazurite & $\begin{array}{l}\text { Ward's, Andes } \\
\text { of Ovalle, Chile }\end{array}$ & $\begin{array}{l}\text { Lazurite (17-749) } \\
\text { Azurite (11-682) } \\
\text { Wollastonite (27- } \\
88 \text { ) } \\
\end{array}$ & & $\begin{array}{l}\text { High Cu by } \\
\text { XRF }\end{array}$ \\
\hline Ilvaite & $\begin{array}{l}\text { Ward's, Laxey } \\
\text { Mine, S. Mt., } \\
\text { ID }\end{array}$ & $\begin{array}{l}\text { Quartz (85-796) } \\
\text { Ilvaite (70-1863) }\end{array}$ & & \\
\hline Pyrophyllite & $\begin{array}{l}\text { Ward's, } \\
\text { Hillsboro, NC }\end{array}$ & $\begin{array}{l}\text { Pyrophyllite (71- } \\
1051)\end{array}$ & Unknown & \\
\hline Heulandite & Adam's & Quartz (77-1060) & Heulandite (41- & White \\
\hline
\end{tabular}




\begin{tabular}{|l|l|l|l|l|}
\hline & $\begin{array}{l}\text { Minerals, } \\
\text { Nakik, India }\end{array}$ & 1357) & $\begin{array}{l}\text { background of } \\
\text { rock }\end{array}$ \\
\hline Heulandite & $\begin{array}{l}\text { Adam's } \\
\text { Minerals, } \\
\text { Nakik, India }\end{array}$ & Quartz (77-1060) & $\begin{array}{l}\text { Dark base of } \\
\text { rock }\end{array}$ \\
\hline Allophane & $\begin{array}{l}\text { Ward's, Maid of } \\
\text { Sunshine Mine, } \\
\text { Cochise } \\
\text { County, AZ }\end{array}$ & $\begin{array}{l}\text { Unknown } \\
\text { Bard's, }\end{array}$ & $\begin{array}{l}\text { Anthophyllite } \\
\text { (45-1343) }\end{array}$ & $\begin{array}{l}\text { No match to } \\
\text { allophane }\end{array}$ \\
\hline Amosite & \begin{tabular}{llll} 
\\
\hline
\end{tabular} & & & \\
\hline
\end{tabular}




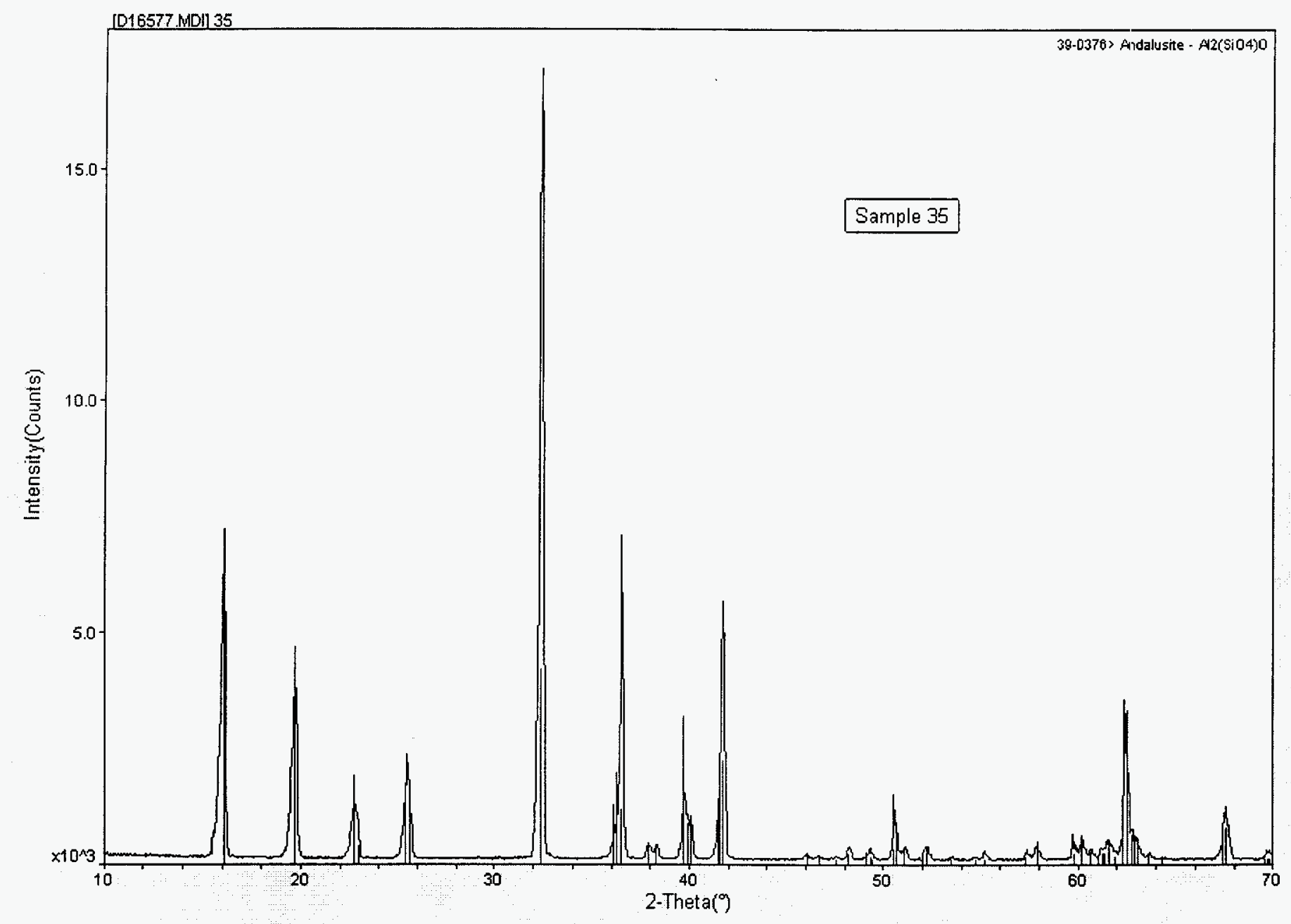

E CRD

[OTHON1CRDJothon] 〈f:10500> Friday, Nay 26, 2000 (MDISJADES)

Figure 10

XRD pattern for Andalusite; $\left(\mathrm{Al}_{2} \mathrm{SiO}_{5}\right)$. Excellent match with PDF No. 39-376 


\section{CONCLUSIONS}

Crystalline samples for the most part were un-reactive toward formation of Q'. The amorphous materials like the natural Celite, opal and $\mathrm{Co}, \mathrm{Li}$ and $\mathrm{Ca}$ silicate gave the best results. Note that the flux calcined Celite had a significant crystalline component. Some materials were not at all what we thought they were such as most of the heulandite, one of the sugilites and the allophane. Surprisingly, shale found on the GE CRD grounds and a clay sample from Martha's Vineyard's north shore had nearly identical XRD patterns.

\section{ACKNOWLEDGEMENTS}

All the work described in this report would have not been possible without the help of many people. We thank Ted Sun and Stan Stoklosa for the preparation of the sol-gel materials and Molecular Solutions Inc. for the calculations. John Leman has been an invaluable pool of information. We thank Woody Ligon and Hans Grade for the GC/MS work and the fast turnaround times and June W. Klimash and Nancy Marotta for the elemental analysis.

\section{REFERENCES}

27. Kirk-Othmer Encyclopedia of Chemical Technology, $3^{\text {rd }}$ ed.; Wiley-Interscience, New York, 1979; Vol. 20, 750-880.

28. Liebhafsky, H. A. Silicones Under the Monogram, John Wiley and Sons, New York, 1978.

29. Warwick, E. L. Forty Years of Firsts, McGraw Hill, New York, 1990.

30. Source: Gelest Catalogue.

31. Ono, Y.; Akiyama, M.; Suzuki, E. Chem. Mater. 1993, 5, 442.

32. Akiyama, M.; Suzuki, E.; Ono Y.Inorg. Chim. Acta 1993, 207, 259.

33. Rosenheim, A.; Raibmann, B.; Schendel, G. Z. Anorg. Allg. Chem. 1931, 196, 160.

34. Laine, R. M.; Blohowiak, K. Y.; Robinson, T. R.; Hoppe, M. L.; Nardi, P.; Kampf, J.; Uhm, J. Nature 1991, 353, 642.

35. Blohowiak, K. Y.; Treadwell, D. R.; Mueller, B. L.; Hoppe, M. L.; Jouppi, S.; Kansal, P.; Chew, K. W.; Scotto, C. L. S.; Babonneau, F.; Kampf, J.; Laine, R. M. Chem. Mater. 1994, 6, 2177.

36. Goodwin, G. B.; Kenney, M. E. Polym. Prep. 1986, 27, 107.

37. Graefe, J.; Uzick, W.; Weinberg, U. Ger. Offen. DE 3821483 Chem Abstr $112: 217263$.

38. Goodwin, G. B.; Kenney, M. E. Adv. Chem. Ser. 1990, 224, 251.

13. Powder Diffraction File, Release 1999, Data Sets 1-49 plus 70-86

PDF, ISSN 1084-3116, International Centre for Diffraction Data 
12 Campus Boulevard, Newtown Square, Pennsylvania 19073-3273 U.S.A. Internet: information@icdd.com, www.icdd.com

14. The Audubon Society Field Guide to North American Rocks and Mineral, $\left(10^{\text {th }}\right.$ printing) New York: Alfred A. Knopf, Inc., 1990.

15. Iler R. K. The Chemistry of Silica, John Wiley and Sons, New York, 1979.

16. Klein, C.; Hurlbut, C.S., Manual of Mineralogy, $2 I^{s t} E d$., John Wiley \& Sons, Inc.: New York, 1993, pp 442-3. 
Supplementary Table 1

\begin{tabular}{|c|c|c|}
\hline $\begin{array}{l}\text { Name } \\
\text { Kaolin }\end{array}$ & $\begin{array}{l}\text { Origin/description } \\
\text { Gift of Prof Barry Pavelitz, U. } \\
\text { Ga./white powder }\end{array}$ & $\begin{array}{l}\text { Location } \\
\text { Georgia }\end{array}$ \\
\hline Slate & Larny Lewis/grey & $\begin{array}{l}\text { GE, CRD, Hansen trail, } \\
\text { Niskayuna, NY }\end{array}$ \\
\hline Clay & $\begin{array}{l}\text { Larry Lewis/soft white, oven- } \\
\text { dried }\end{array}$ & $\begin{array}{l}\text { Martha's Vineyard, } \\
\text { North Shore }\end{array}$ \\
\hline Vermicullite & Larry Lewis/brown, spongy & $\begin{array}{l}\text { Commercial Packing } \\
\text { material }\end{array}$ \\
\hline Sea Sand & Larry Lewis/granules & $\begin{array}{l}\text { Martha's Vineyard, } \\
\text { South beach }\end{array}$ \\
\hline gabbro & $\begin{array}{l}\text { Ward's Scientific } \\
47 \mathrm{H} 3308 / \text { black with } \\
\text { colorless crystals }\end{array}$ & Duluth, MN \\
\hline Datolite & $\begin{array}{l}\text { Many Facets/off white } \\
\text { crystal }\end{array}$ & Woodbury, CT \\
\hline Chrysocolla & Many Facets/green rock & \\
\hline Flint Clay & $\begin{array}{l}\text { Christy/Calcined Burley } 4 \text { X8 } \\
\text { mesh, powder }\end{array}$ & Christy \\
\hline Cyrtolite & Many Facets/grey-brown & $\begin{array}{l}\text { Davis Mine, Bancroft, } \\
\text { Ont. }\end{array}$ \\
\hline Fume Silica & TAM Ceramics/Powder, lot 5 & 8 , grey \\
\hline Zircon & $\begin{array}{l}\text { TAM Ceramics/Powder, } \\
\text { GZM, milled Zircon, lot } 43\end{array}$ & TAM Ceramics \\
\hline Topaz & $\begin{array}{l}\text { Many Facets/gemstone, } \\
\text { orange crystal }\end{array}$ & Brazil \\
\hline Zirconium silicate & $\begin{array}{l}\text { Curumbin, Opacifine } 5,6 \\
\text { micron powder }\end{array}$ & Queensland, Australia \\
\hline Zirconium silicate & $\begin{array}{l}\text { Curumbin, Zircon flour, off } \\
\text { white }\end{array}$ & Queensland, Australia \\
\hline Zircon sand & $\begin{array}{l}\text { Curumbin, standard grade, } \\
\text { brown sand }\end{array}$ & Queensland, Australia \\
\hline Hemimorphite & $\begin{array}{l}\text { Many Facets/colorless } \\
\text { crystal region on brown } \\
\text { background }\end{array}$ & Mapimi, Mexico \\
\hline Rhodonite & Many Facets/pink & Colorado \\
\hline Granodiorite & $\begin{array}{l}\text { Ward Scientific } 47 \mathrm{H} 3683 \text {, } \\
\text { marble-like, multi-colored }\end{array}$ & Cold Springs, MN \\
\hline Flint Clay & $\begin{array}{l}\text { Christy/200 mesh calcined } \\
\text { flint }\end{array}$ & \\
\hline Sodium Silicate & CPC/Briquettes & \\
\hline
\end{tabular}


Perridot

Sphene

shale

carbonaceous

Lepidolite

Labradorite

Columbite-

rare/Albite

Mica

Hectorite

Beryl

Forsterite

Chrysotile

Illite Shale

Nontronite

Andalusite

Analclime

Microcline

Bytownite

Orthoclase

Muscovite

Andesine

Albite

Halloysite
Many Facets/green single crystals

Many Facets/black crystal

Ward's Scientific

47H7473/dark grey, smooth

Many Facets also

Canada

Luzerne, PA

San Diego, CA

Rubellite/pinkish-colorless

crystals

Many Facets also anorthite/blue on grey-brown background

Many Facets/off-white Walden Gem Mine, crystals

Bombay Minerals/off-white India powder

Ward's Scientific Hector CA

49H5103/white powder

Ward's Scientific special California

order/pale green large single

hexagonal crystal

Ward's Special order, $\quad$ San Carlos, AZ $49 \mathrm{H} 1557$

Ward's Special order Thetford, Que

49H5865/hairy fibers

Ward's Scientific Rochester, NY

46H0315/orange grey plates

Ward's Scientific

Cheney, WA

49H5108/yellow green

Ward's Scientific

Sanat Theresa, Minas

49H5823/red crystals

Gerais, Brazil

Ward's Scientific

49H0672/white crystals

Ward's Scientific

49H5918/red brown crytals

Ward's Scientific

49H5859/off-white crystals

Ward's Scientific

Mt. St. Hilaire, Que

Richardson Quarry,

Verona, Ont

Beaver Bay, MN

49H5919/colorless-pink

crytals

Ward's Scientific

49H5882/mica-like

Ward's Scientific

$49 \mathrm{H} 5825 /$ colorless yellow

crystals

Ward's Scientific

49H5851/white crstals

Ward's Scientific

India

$49 \mathrm{H} 5102 /$ white soft rock 


\begin{tabular}{|c|c|c|}
\hline Oligoclase & $\begin{array}{l}\text { Ward's Scientific } \\
49 \mathrm{H} 5915 / \text { colorless crystals }\end{array}$ & $\begin{array}{l}\text { Mantena, Minas Gerais, } \\
\text { Brazil }\end{array}$ \\
\hline Schist & Ward's Scientific & Mitchell Co., NC \\
\hline Horneblende & 47H7243/grey silver streaks & \\
\hline Andradite & $\begin{array}{l}\text { Ward's Scientific } \\
46 \mathrm{H} 3373 \text { /orange-brown } \\
\text { crystals }\end{array}$ & Willsboro, NY \\
\hline Horneblende & $\begin{array}{l}\text { Many Facets, brown } \\
\text { hexagonal single crystal }\end{array}$ & Tory Hill, Ont. \\
\hline Serpentine & $\begin{array}{l}\text { Ward's Scientific } 47 \mathrm{H} 4863 \text {, } \\
\text { grey black, smooth }\end{array}$ & Roxbury, VT \\
\hline Epidote & $\begin{array}{l}\text { Ward's Scientific } \\
46 \mathrm{H} 2933 \text { /grey-green, rough }\end{array}$ & Ward's, Calumet, CO \\
\hline Diopside & $\begin{array}{l}\text { Many Facets/olive green } \\
\text { single crystal }\end{array}$ & Wilberforce, Ontario \\
\hline Zircon & $\begin{array}{l}\text { Curumbin, Opacifier/white } \\
\text { powder }\end{array}$ & Queensland, Australia \\
\hline Stilbite & $\begin{array}{l}\text { Many Facets/ zeolite off- } \\
\text { white, single crystals }\end{array}$ & Bombay, India \\
\hline Tremolite & $\begin{array}{l}\text { Many Facets/colorless } \\
\text { crystals on grey background }\end{array}$ & W.Pierrepont, NY \\
\hline Kyanite & $\begin{array}{l}\text { Many Facets/colorless-blue } \\
\text { long crystals }\end{array}$ & Minas Gerais, Brazil \\
\hline Olivine & $\begin{array}{l}\text { Ward's Scientific } \\
46 \mathrm{H} 5838 / \text { light \& dark green } \\
\text { crystals }\end{array}$ & Twin Sisters Range, WA \\
\hline Pumice & $\begin{array}{l}\text { Ward's Scientific } \\
47 \mathrm{H} 6443 / \text { off-white, sponge- } \\
\text { like solid }\end{array}$ & El Cajete, NM \\
\hline $\begin{array}{l}\text { Amazonite/Lepidol } \\
\text { ite }\end{array}$ & Many Facets/blue-green & Russia \\
\hline Tourmaline & $\begin{array}{l}\text { Many Facets/smooth brown } \\
\text { and red gemstones }\end{array}$ & Brazil \\
\hline Fuchsite & $\begin{array}{l}\text { Many Facets/green chrome- } \\
\text { rich Muscovite }\end{array}$ & Minas Gerais, Brazil \\
\hline Jasper & Many Facets & Mexico \\
\hline Sodalite & Many Facets/ blue & Brazil \\
\hline basalt & $\begin{array}{l}\text { Ward's Scientific } \\
47 \mathrm{H} 1043 / \text { grey-black, smooth }\end{array}$ & Lewiston, IN \\
\hline shale argillaceous & $\begin{array}{l}\text { Ward's Scientific } \\
47 \mathrm{H} 7403 / \text { light grey, rough }\end{array}$ & East Bethany, NY \\
\hline Serpentine & $\begin{array}{l}\text { Ward's Scientific, second } \\
\text { specimen see } 48 / \text { off-white } \\
\text { blocks }\end{array}$ & NY \\
\hline Amphibolite & $\begin{array}{l}\text { Ward's Scientific } 47 \mathrm{H} 0428 \\
\text { see } 47 / \text { grey-black, rough }\end{array}$ & Winton, MN \\
\hline
\end{tabular}




\begin{tabular}{|c|c|c|}
\hline Garnet & $\begin{array}{l}\text { Barton Mines, W7F/brown } \\
\text { powder }\end{array}$ & Near North Creek, NY \\
\hline peridotite & $\begin{array}{l}\text { Ward's Scientific } \\
47 \mathrm{H} 6153 \text { /black with some } \\
\text { micro crystals }\end{array}$ & Yellow Dog, MI \\
\hline Montmorillonite & $\begin{array}{l}\text { Ward's Scientific } \\
46 \mathrm{H} 0438 \text { /off-white powder }\end{array}$ & Panther Creek, CO \\
\hline Phlogopite & $\begin{array}{l}\text { Ward's Scientific } \\
46 \mathrm{H} 6193 / \text { silvery, mica-like } \\
\text { sheets }\end{array}$ & Quebec \\
\hline Schist Albite & $\begin{array}{l}\text { Ward's Scientific } \\
47 \mathrm{H} 0298 / \text { rough silvery grey }\end{array}$ & San Bernadino, CA \\
\hline topaz & $\begin{array}{l}\text { Ward's Scientific } 46 \mathrm{H} 8208 \\
\text { see sample above/light grey, } \\
\text { smooth }\end{array}$ & Amelia, VA \\
\hline Wollastonite & $\begin{array}{l}\text { Ward's Scientific } \\
46 \mathrm{H} 8883 \text { /off-white crystals }\end{array}$ & Willboro, NY \\
\hline $\begin{array}{l}\text { cobalt ortho } \\
\text { silicate }\end{array}$ & Pfaltz \& Bauer C24290/ pink & powder \\
\hline Zinc Orthosilicate & $\begin{array}{l}\text { Pfaltz \& Bauer Z00870, lot } \\
034440\end{array}$ & \\
\hline $\begin{array}{l}\text { Lithium meta } \\
\text { silicate }\end{array}$ & Rocky Mountain Research Lo & ot \#DM072472 \\
\hline zirconium silicate & Alfa & \\
\hline & Alfa \#39420 lot \# D20J02 & \\
\hline $\begin{array}{l}\text { calcium } \\
\text { metasilicate }\end{array}$ & Petrach & \\
\hline Obsidian & $\begin{array}{l}\text { Ward's Scientific } \\
46 \mathrm{H} 2333 / \text { black, shiny }\end{array}$ & Millard County, UT \\
\hline Tuff & $\begin{array}{l}\text { Ward's Scientific } 47 \mathrm{H} 8373 \\
\text { also Rhyolite/pale pink, } \\
\text { white \& black spots, rough }\end{array}$ & Ennis, Montana \\
\hline Hornfels & $\begin{array}{l}\text { Ward's Scientific } 47 \mathrm{H} 3908 \\
\text { also Cordierite/grey with light } \\
\text { orange regions }\end{array}$ & Butte, Montana \\
\hline Almandine & $\begin{array}{l}\text { Ward's Scientific } 46 \mathrm{H} 9728 \text {, } \\
\text { garnet/multi-colored, mica- } \\
\text { like with orange \& black } \\
\text { regions }\end{array}$ & $\begin{array}{l}\text { Ward's, River Valley, } \\
\text { Ont. }\end{array}$ \\
\hline Grossular & $\begin{array}{l}\text { Ward's Scientific } \\
46 \mathrm{H} 3393 / \text { light brown with } \\
\text { some white areas }\end{array}$ & York River, Ont. \\
\hline shale arenaceous & $\begin{array}{l}\text { Ward's Scientific } \\
47 \mathrm{H} 7413 / \text { grey, smooth }\end{array}$ & Green Co., NY \\
\hline Trachyte & Ward's Scientific & Bannockburn Twp., Ont. \\
\hline
\end{tabular}




\begin{tabular}{|c|c|c|}
\hline & $\begin{array}{l}\text { 47H8273/light brown \& white } \\
\text { crystals }\end{array}$ & \\
\hline Willemite & $\begin{array}{l}\text { Ward's Scientific } \\
46 \mathrm{H} 8773 \text { /dark grey with } \\
\text { white spots }\end{array}$ & Willemite, NJ \\
\hline kaolin & $\begin{array}{l}\text { Ward's Scientific } 46 \mathrm{H} 0998 \\
\text { see GA sample above/off } \\
\text { white powder }\end{array}$ & Edgar, FL \\
\hline shale ferruginous & Ward's Scientific & Williamsport, PA \\
\hline shale oil & $\begin{array}{l}47 \mathrm{H} 7448 / \text { red brown, smooth } \\
\text { Ward's Scientific } \\
47 \mathrm{H} 7478 / \text { grey-brown, } \\
\text { smooth }\end{array}$ & Garfield, CO \\
\hline Syenite & $\begin{array}{l}\text { Ward's Scientific } \\
47 \mathrm{H} 7943 / \text { grey \& black } \\
\text { crystals }\end{array}$ & Magnet Cove, Arkansas \\
\hline Eclogite & $\begin{array}{l}\text { Ward's Scientific } 47 \mathrm{H} 2853 \\
\text { also omphacite/grey rock }\end{array}$ & Sonoma, CA \\
\hline talc & $\begin{array}{l}\text { Ward's Scientific } \\
46 \mathrm{H} 8003 \text { /off-white, soft }\end{array}$ & Balmat, NY \\
\hline Jade & $\begin{array}{l}\text { Ward's Scientific } 46 \mathrm{H} 0978 \\
\text { also compact nephrite } \\
\text { tremolite/green \& grey }\end{array}$ & British Columbia \\
\hline Beryl & $\begin{array}{l}\text { Ward's Scientific } 46 \mathrm{H} 1123 \text {, } \\
\text { white with some pale orange } \\
\text { areas }\end{array}$ & Custer, SD \\
\hline Diopside & $\begin{array}{l}\text { Ward's Scientific } 46 \mathrm{H} 6453 \text {, } \\
\text { pale green }\end{array}$ & Herschel, Ont \\
\hline Silica gel & Davidson 6120 synthetic/whit & te powder \\
\hline $\begin{array}{l}\text { Celite, Sno Floss } \\
\text { (diatomaceous } \\
\text { earth) }\end{array}$ & Celite, Sno Floss, natural & \\
\hline $\begin{array}{l}\text { Celite, } 209 \\
\text { (diatomaceous } \\
\text { earth) }\end{array}$ & Celite 209, Natural & \\
\hline $\begin{array}{l}\text { Celite FC } \\
\text { (diatomaceous } \\
\text { earth) }\end{array}$ & Celite FC, natural & \\
\hline $\begin{array}{l}\text { Dicalite SA-3 } \\
\text { (diatomaceous } \\
\text { earth) }\end{array}$ & Dicatlite SA-3, natural & Dicalite SA-3 \\
\hline & \multirow{2}{*}{\multicolumn{2}{|c|}{$\begin{array}{l}\text { Ward's Scientific } 46 \mathrm{H} 1123 \text {, white with some pale } \\
\text { orange areas } \\
\text { Ward's Scientific special } \\
\text { order }\end{array}$}} \\
\hline benitoite & & \\
\hline
\end{tabular}




\begin{tabular}{|c|c|c|}
\hline Feldspar & $\begin{array}{l}\text { Bombay Minerals/ } 65 \% \\
\mathrm{SiO} 2,12.5 \% \mathrm{Al} 2 \mathrm{O} 3,11 \% \\
\mathrm{~K} 2 \mathrm{O}, 3.5 \% \mathrm{Na} 2 \mathrm{O}\end{array}$ & India \\
\hline Celite HyFlo & Celite HyFlo, fluxed calcined/ & powder \\
\hline Celite, 545 & $\begin{array}{l}\text { Celite } 545 \text {, fluxed } \\
\text { calcined/powder }\end{array}$ & \\
\hline Enstatite & $\begin{array}{l}\text { Ward's Scientific } \\
46 \mathrm{H} 2888 \text { /olive gree with } \\
\text { white spots }\end{array}$ & Bamble, Norway \\
\hline Garnet sand & Gift from Flanagan/Jordan & \\
\hline Dravite & $\begin{array}{l}\text { Multistone Int'l/brown } \\
\text { tourmaline, large coumninar } \\
\text { black single Xtal }\end{array}$ & unknown location \\
\hline Schorl & $\begin{array}{l}\text { Multistone Int'//black } \\
\text { tourmaline, giant specimen }\end{array}$ & unknown location \\
\hline Shattuckite & Multistone Int'l/ blue green & unknown location \\
\hline Spodumene & $\begin{array}{l}\text { Multistone Int'I/Colorless, } \\
\text { pale green single xtals }\end{array}$ & unknown location \\
\hline gem Silica & $\begin{array}{l}\text { Multistone Int'l/ light blue, } \\
\text { some brown, colorless }\end{array}$ & unknown location \\
\hline Jadeite & $\begin{array}{l}\text { Multistone Int'l/ Big long } \\
\text { piece, grey green streaks }\end{array}$ & unknown location \\
\hline Phenacite & $\begin{array}{l}\text { Multistone Int'// } 8 \text { small } \\
\text { single xtals, colorless }\end{array}$ & unknown location \\
\hline Uvite & $\begin{array}{l}\text { Multistone Int'// single } \\
\text { column xtal }\end{array}$ & unknown location \\
\hline Spessaetine & $\begin{array}{l}\text { Multistone Int'l/ garnet, } \\
\text { mixed colorless, rose tan } \\
\text { xtals }\end{array}$ & unknown location \\
\hline Elbaite & $\begin{array}{l}\text { Multistone Int'// tourmaline, } 1 \\
\text { small xtal }\end{array}$ & \\
\hline Dioptase & $\begin{array}{l}\text { Multistone Int'// blue crystals } \\
\text { on brown rock }\end{array}$ & unknown location \\
\hline Gyrolite & $\begin{array}{l}\text { Multistone Int'l/ } 1 \text { rock with } \\
\text { spherical colorless and white } \\
\text { xtals }\end{array}$ & unknown location \\
\hline Pyrope & $\begin{array}{l}\text { Multistone Int'l/ small } \\
\text { maroon xtals }\end{array}$ & unknown location \\
\hline Idocrase & $\begin{array}{l}\text { Multistone Int'l/ also } \\
\text { vesuvianite, tumbled smooth } \\
\text { green rocks }\end{array}$ & unknown location \\
\hline Babingtonite & $\begin{array}{l}\text { Multistone Int'l/ olive-colored } \\
\text { spheres on olive/colorless } \\
\text { large rock }\end{array}$ & \\
\hline Hyperst & $\begin{array}{l}\text { Multistone Int'// also } \\
\text { orthopyrene, med-sized }\end{array}$ & unknown lo \\
\hline
\end{tabular}


single dark green xtal

Sugilite

Opal

Erionite

Actinolite

Anorthite

Clinoptilolite

Spodumene

Clinoptilolite

Pyrope

Edenite

Jadeite

Nepheline

Phenacite

Spessartine

Lazurite

Shattuckite

Uvite

Gyrolite

IIvaite

Idocrase

Riebeckite
Multistone Int'// 1 purple rock unknown location

Ward's Scientific/ large green sample

Ward's Scientific 49 5874/ Pine Valley, Nevada also Chabazite zeolite, white, powdery

Ward's Scientific 46E Chester, VT 0353/also amphibole,Mica-

like, green, large large multicolored rocks Grass Valley, CA

St. Cloud Mining Co./ also Heulandite zeolite, fine offwhite powder

Ward's Scientific 49 2370/ Minas Gerais, Brazil colorless, clear crystals, colorless clear xtals

Ward's Scientific 49 5866/ Jordan Valley, Oregon

grey powder

Ward's Scientific 49 5850/ 2- Navajo res, Ant Hill, AZ

$3 \mathrm{~mm}$, marron xtals

Ward's Scientific special Cardiff Township near

order/dark, columnar xtals Wilberforce, Ont.

Ward's Scientific/small pale Kotaki, Japan green pieces

Ward's Scientific/ white xtals Bancroft, Ont

Ward's Scientific/colorless, Carai, Minas Gerais, clear xtals

Brazil

Ward's Scientific/med size Pedra Alta, Minas

dark xtals

Gerais, Brazil

Ward's Scientific/also Lapis Andes of Ovalle, Chile

Lazuli,blue stones

Ward's Scientific/ one large Ajo, AZ

blue stone

Ward's Scientific/ green Minas Gerais, Brazil

xtals

Ward's Scientific/ geode- Poona, India

like, green outside white

inside

Ward's Scientific/ dark rock

white xtals,

Ward's Scientific/also

Laxey Mine, South

Mountain, ID

Vesuvianite, dk \& It brown

with black spots

Ward's Scientific/

Lake Jaco, Mexico

amphibole, small black xtals Colorado 


\begin{tabular}{|c|c|c|}
\hline Neptunite & $\begin{array}{l}\text { Ward's Scientific/dark/black } \\
\text { med size crystals }\end{array}$ & $\begin{array}{l}\text { Gem Mine, San Benito } \\
\text { County, CA }\end{array}$ \\
\hline Pyrophyllite & $\begin{array}{l}\text { Ward's Scientific/white } \\
\text { fibrous crystals }\end{array}$ & Hillsboro, NC \\
\hline Leucite & $\begin{array}{l}\text { Ward's Scientific small white } \\
\text { rocks }\end{array}$ & Ariccia, Rome, Italy \\
\hline Hypersthene & $\begin{array}{l}\text { Ward's Scientific/ small } \\
\text { black xtals }\end{array}$ & St. Ludger de Milot, Que \\
\hline Elbaite & $\begin{array}{l}\text { Ward's Scientific/ black } \\
\text { tournaline-like }\end{array}$ & Minas Gerais, Brazil \\
\hline Brewsterite & $\begin{array}{l}\text { Ward's Scientific/ analcime } \\
\text { zeolite, xtals in white rock }\end{array}$ & $\begin{array}{l}\text { Whitesmith Mone, } \\
\text { Strontian, Scotland }\end{array}$ \\
\hline Schorl & $\begin{array}{l}\text { Ward's Scientific/ two large } \\
\text { black, tourmaline-like rocks }\end{array}$ & Riverside, CA \\
\hline Gismondine & $\begin{array}{l}\text { Ward's Scientific/ } \\
\text { Gismondine zeolite, white } \\
\text { xtals on grey stone }\end{array}$ & Germany \\
\hline Gismondine & $\begin{array}{l}\text { Ward's Scientific/ } \\
\text { Gismondine zeolite, } 1 \text { grey } \\
\text { stone }\end{array}$ & Aquacetosa, Italy \\
\hline Zinnwaldite & $\begin{array}{l}\text { Ward's Scientific/ mica-like } \\
\text { sheets }\end{array}$ & Amelia Courthouse, VA \\
\hline Sugilite & $\begin{array}{l}\text { Ward's Scientific/ } 1 \text { purple } \\
\text { rock. }\end{array}$ & Unknown location \\
\hline Cowlesite & $\begin{array}{l}\text { Adam's Minerals COW- } \\
\text { 2/Chabazite zeolite, white } \\
\text { craters on a grey } \\
\text { background }\end{array}$ & unknown location \\
\hline Prehnite & $\begin{array}{l}\text { Adam's Minerals PRE-5/ } \\
\text { Green globs }\end{array}$ & Patterson, NJ \\
\hline Gobbinsite & $\begin{array}{l}\text { Adam's Minerals/ GBB- } \\
1 \text { Gismondine zeolite, with } \\
\text { Levyne } \mathrm{Na} \text {, white xtals on } \\
\text { grey background, rock } \\
\text { portion }\end{array}$ & $\begin{array}{l}\text { Island Magee, N. } \\
\text { Ireland }\end{array}$ \\
\hline Gobbinsite & $\begin{array}{l}\text { Adam's Minerals/ GBB- } \\
1 \text { Gismondine zeolite, with } \\
\text { Levyne } \mathrm{Na} \text {, white xtals on } \\
\text { grey background, crystal } \\
\text { portion }\end{array}$ & $\begin{array}{l}\text { Island Magee, N. } \\
\text { Ireland }\end{array}$ \\
\hline Phillipsite & $\begin{array}{l}\text { Adam's Minerals PHI- } \\
\text { 1zeolite, white/black xtals on } \\
\text { dark background }\end{array}$ & $\begin{array}{l}\text { Limburg, Kaigerstuhl, } \\
\text { Baden, Germany }\end{array}$ \\
\hline Chabazite & $\begin{array}{l}\text { Adam's Minerals/ zeolite, } \\
\text { white xtals on grey } \\
\text { background, crystal portion }\end{array}$ & $\begin{array}{l}\text { Talisker Bay, Isle of } \\
\text { Skye, Scotland }\end{array}$ \\
\hline
\end{tabular}




\begin{tabular}{|c|c|c|}
\hline Chabazite & $\begin{array}{l}\text { Adam's Minerals/ zeolite, } \\
\text { white xtals on grey } \\
\text { background, rock portion }\end{array}$ & $\begin{array}{l}\text { Talisker Bay, Isle of } \\
\text { Skye, Scotland }\end{array}$ \\
\hline Apophyllite & $\begin{array}{l}\text { Adam's Minerals APO- } \\
\text { 10/Large xtals on dark } \\
\text { background, crystal portion }\end{array}$ & Nasik, India \\
\hline Apophyllite & $\begin{array}{l}\text { Adam's Minerals APO- } \\
\text { 10/Large xtals on dark } \\
\text { background, rock portion }\end{array}$ & Nasik, India \\
\hline Thomsonite & $\begin{array}{l}\text { Adam's Minerals THO- } \\
1 / \text { zeolite, white xtal on black } \\
\text { with light green areas, white } \\
\text { crystal portion }\end{array}$ & $\begin{array}{l}\text { Balleyclare Moneymore } \\
\text { County, Loudonary, N. } \\
\text { Ireland }\end{array}$ \\
\hline Thomsonite & $\begin{array}{l}\text { Adam's Minerals THO- } \\
\text { 1/zeolite, white xtal on black } \\
\text { with light green areas, dark } \\
\text { stone portion }\end{array}$ & $\begin{array}{l}\text { Balleyclare Moneymore } \\
\text { County, Loudonary, N. } \\
\text { Ireland }\end{array}$ \\
\hline Heulandite & $\begin{array}{l}\text { Adam's Minerals HEU-4/ } \\
\text { zeolite, off white xtals on } \\
\text { white background on reddish } \\
\text { rock, crystal portion }\end{array}$ & Nakik, India \\
\hline Heulandite & $\begin{array}{l}\text { Adam's Minerals HEU-4/ } \\
\text { zeolite, off white xtals on } \\
\text { white background on reddish } \\
\text { rock, white background } \\
\text { portion }\end{array}$ & Nakik, India \\
\hline Heulandite & $\begin{array}{l}\text { Adam's Minerals HEU-4/ } \\
\text { zeolite, off white xtals on } \\
\text { white background on reddish } \\
\text { rock, dark rock base }\end{array}$ & Nakik, India \\
\hline Clinozoisite & $\begin{array}{l}\text { Roger Poulin } 195 \& 196 / \\
\text { white xtals in grey matrix }\end{array}$ & Cornog, PA \\
\hline Zoisite & $\begin{array}{l}\text { Roger Poulin } 912 \text { \& } \\
\text { 913/white rock with pink } \\
\text { sections }\end{array}$ & Remigny, Que \\
\hline Merlinoite & $\begin{array}{l}\text { Roger Poulin } 490 / \text { Heulandite } \\
\text { zeolite, dark grey rock with } \\
\text { some white patches }\end{array}$ & $\begin{array}{l}\text { Cupaello, S. Rufina, } \\
\text { Rieti, Italy }\end{array}$ \\
\hline Sanidine & $\begin{array}{l}\text { Roger Poulin 678/grey- } \\
\text { black, porous }\end{array}$ & $\begin{array}{l}\text { Hochsimmer, Eifel } \\
\text { District., Germany }\end{array}$ \\
\hline Astrophyllite & $\begin{array}{l}\text { Roger Poulin } 62 \& 63 / \text { also } \\
\text { Aegerine orthoclase White } \\
\text { with inclusions of black and } \\
\text { mica-like }\end{array}$ & $\begin{array}{l}\text { Poudrette Quarry, Mont. } \\
\text { St. Hillaire, Que }\end{array}$ \\
\hline Aegirine & $\begin{array}{l}\text { Roger Poulin } 4-6 \text { / pyroxene, } \\
\text { white and olive rock }\end{array}$ & $\begin{array}{l}\text { Poudrette Quarry, } \\
\text { Rouville County, Mont. }\end{array}$ \\
\hline
\end{tabular}


St. Hillaire, Que

\begin{tabular}{|c|c|c|}
\hline Eudialyte & $\begin{array}{l}\text { Roger Poulin } 272 \& 273 / \\
\text { with Agrellite, colorless, red- } \\
\text { pink, black-mica mixture }\end{array}$ & Kipawa, Que \\
\hline Cancrinite & $\begin{array}{l}\text { Roger Poulin 144-146/ white } \\
\text { xtals }\end{array}$ & Bancroft, Ont. \\
\hline Cookeite & $\begin{array}{l}\text { Roger Poulin } 211 \& \\
212 / \text { golden brown with } \\
\text { quartz xtals }\end{array}$ & Hot Springs, Ark. \\
\hline Epistilbite & $\begin{array}{l}\text { Roger Poulin } 266 / \text { Chabazite } \\
\text { zeolite with stilbite, quartz } \\
\text { white, striated }\end{array}$ & $\begin{array}{l}\text { Gibels Beach, Fiesch, } \\
\text { Wallis, Switzerland }\end{array}$ \\
\hline Levyne & $\begin{array}{l}\text { Roger Poulin } 441 \& \\
442 / \text { Heulandite zeolite, white } \\
\text { xtals in craters on maroon } \\
\text { background }\end{array}$ & $\begin{array}{l}\text { Parkgate Quarry, near } \\
\text { Temple Patrick County, } \\
\text { Antrim, N. Ireland }\end{array}$ \\
\hline Apophyllite & $\begin{array}{l}\text { Roger Poulin } 43 \& 44 \text { / large } \\
\text { xtal on white stilbite on dark } \\
\text { base }\end{array}$ & Poona, India \\
\hline Stellerite & $\begin{array}{l}\text { Roger Poulin } 755- \\
759 / \text { zeolite, tan puff ball } \\
\text { microxtal clusters on } \\
\text { grey/white background, } \\
\text { some calcite xtals }\end{array}$ & Sarbaj, Kazachstan \\
\hline Mesolite & $\begin{array}{l}\text { Roger Poulin } 492 / \text { Natrolite } \\
\text { zeolite, Von Bitter Collection } \\
\# 16.252 b .4 \text {, white xtals on } \\
\text { grey Phonolite }\end{array}$ & $\begin{array}{l}\text { Unterwiesntal, Sachsen } \\
\text { Germany }\end{array}$ \\
\hline Uvarovite & $\begin{array}{l}\text { Roger Poluin } \\
844(60) / \text { garnet, emerald } \\
\text { green on some black }\end{array}$ & Sarany, Urals, Russia \\
\hline Biotite & $\begin{array}{l}\text { Roger Poulin } 96 / \text { black mica, } \\
\text { large black hexagon of black } \\
\text { flakes }\end{array}$ & $\begin{array}{l}\text { Silver Crater Mine, } \\
\text { Bancroft, Ont. }\end{array}$ \\
\hline Lorenzenite & $\begin{array}{l}\text { Roger Poluin } 454-456 / a t \\
\text { least } 3 \text { xtal types on grey } \\
\text { background }\end{array}$ & $\begin{array}{l}\text { Pudrette Quarry, } \\
\text { Rouville Twp., Mt. St. } \\
\text { Hillaire, Que. }\end{array}$ \\
\hline Scapolite & $\begin{array}{l}\text { Roger Poulin } 681 / \\
\text { white/dark rod xtals with } \\
\text { Meionite }\end{array}$ & $\begin{array}{l}\text { Yates Mine, Otter lake, } \\
\text { Que. }\end{array}$ \\
\hline & $\begin{array}{l}\text { Ward's Scientific/ black with } \\
\text { streak red pieces }\end{array}$ & $\begin{array}{l}\text { Cole Quarry, } \\
\text { Madawaska, Ont. }\end{array}$ \\
\hline Allophane & $\begin{array}{l}\text { Ward's Scientific/ black rock } \\
\text { with white patches some tan }\end{array}$ & $\begin{array}{l}\text { Maid of Sunshine Mine, } \\
\text { near Gleeson, Cochise } \\
\text { County, AZ }\end{array}$ \\
\hline
\end{tabular}




\begin{tabular}{|c|c|c|}
\hline Natrolite & $\begin{array}{l}\text { Roger Poulin/ zeolite, } \\
\text { offwhite xtal needles out of } \\
\text { dark grey and white } \\
\text { Roger Poulin } 515 /\end{array}$ & $\begin{array}{l}\text { Poudrette Quarry, } \\
\text { Rouville Twp., Mt. St. } \\
\text { Hillaire, Que. } \\
\text { Tirua. New Zealand }\end{array}$ \\
\hline Mordenite & $\begin{array}{l}\text { Roger Poulin 515/ } \\
\text { Heulandite zeolite, fuzzy } \\
\text { white xtals on grey/white } \\
\text { background }\end{array}$ & Tirua, New Zealand \\
\hline Pectolite & $\begin{array}{l}\text { Roger Poulin } 569-570 / \\
\text { white, fibrous xtals }\end{array}$ & $\begin{array}{l}\text { Teffrey Mine, Asbestos, } \\
\text { Que. }\end{array}$ \\
\hline Tridymite & $\begin{array}{l}\text { Roger Poulin } 818-819 / \\
\text { volcanic, grey, light brown, } \\
\text { black specs }\end{array}$ & $\begin{array}{l}\text { Zovou, Padova Prov., } \\
\text { Veneto, Italy }\end{array}$ \\
\hline Osumilite & $\begin{array}{l}\text { Roger Poulin } 560-561 / \text { grey } \\
\text { rectangle }\end{array}$ & $\begin{array}{l}\text { Mont Arci Quarry, } \\
\text { Sassari, Sardinia, Italy }\end{array}$ \\
\hline Axinite & $\begin{array}{l}\text { Roger Poulin } 71 \text { / purple } \\
\text { xtals on an olive background } \\
\text { (diopside) }\end{array}$ & $\begin{array}{l}\text { Ward's Peak, Mono } \\
\text { City, CA }\end{array}$ \\
\hline Bertrandite & $\begin{array}{l}\text { Roger Poulin } 90(20), 91 \\
(10-75) \text { /colorless xtal, on } \\
\text { green globs (rhodocrosite), } \\
2-3 \text { other xtals too! }\end{array}$ & Kara Oba, Kazachstan \\
\hline Serandite & $\begin{array}{l}\text { Roger Poluin } 693-695 / \text { pink } \\
\text { columnar xtals, on a white, } \\
\text { mica-like background with } \\
\text { calcite-like intrusions } \\
\text { (analcine \&polylidionite) }\end{array}$ & $\begin{array}{l}\text { Poudrette Quarry, } \\
\text { Rouville County, Mont. } \\
\text { St. Hillaire, Que }\end{array}$ \\
\hline Ferrierite & $\begin{array}{l}\text { Roger Poulin } 280 / \text { Chabazite } \\
\text { zeolite, all white rock }\end{array}$ & Kamloops Lake, BC \\
\hline Willendersonite & $\begin{array}{l}\text { Roger poulin } 887 / \text { Chabazite } \\
\text { zeolite, solid grey }\end{array}$ & $\begin{array}{l}\text { San Veranzo Quarry, } \\
\text { Terni, Umbria, Italy }\end{array}$ \\
\hline Augite & $\begin{array}{l}\text { Roger Poulin } 65 / \text { pyroxene, } \\
\text { well-formed faceted, dark } \\
\text { xtals }\end{array}$ & "Tangayika" Africa \\
\hline Clinochlore & $\begin{array}{l}\text { Roger Poulin 191-192/ } \\
\text { chlorite, purple on dark } \\
\text { background (chromite) }\end{array}$ & Erzincan, Turkey \\
\hline Scolectite & $\begin{array}{l}\text { Roger poulin } 686 / \text { zeolite, } \\
\text { brown section on grey }\end{array}$ & $\begin{array}{l}\text { Dunseverick East, N. } \\
\text { Co. Antrim, N. Ireland }\end{array}$ \\
\hline Paranatrolite & $\begin{array}{l}\text { Roger Poulin 564-565/ } \\
\text { Natrolite zeolite, It grey, } \\
\text { white intrusion(tetranatrolite) }\end{array}$ & $\begin{array}{l}\text { Magheramorne Quarry, } \\
\text { near Larne Co., Antrim, } \\
\text { N. Ireland }\end{array}$ \\
\hline Analcime & $\begin{array}{l}\text { Roger Poulin } 23-24 \text {, zeolite, } \\
\text { with natrolite, white thick } \\
\text { needle xtals, white faceted } \\
\text { xtals, black "tournaline-like" }\end{array}$ & $\begin{array}{l}\text { Mont-St. Hillaire, } \\
\text { Montreal, Que. }\end{array}$ \\
\hline Gonnardite & Gismondine zeolite, $(+$ & Hillsport, Island Magee \\
\hline
\end{tabular}




\begin{tabular}{|c|c|c|}
\hline & natrolite) white/purple mix & $\begin{array}{l}\text { County Antrim, N. } \\
\text { Ireland }\end{array}$ \\
\hline Okenite & $\begin{array}{l}\text { Roger Poulin 552/ off-white } \\
\text { large oval }\end{array}$ & Poona, India \\
\hline Garronite & $\begin{array}{l}\text { Roger poulin } 310 / \\
\text { Gismondine zeolite, a few } \\
\text { white spots on grey }\end{array}$ & $\begin{array}{l}\text { Garron Escarpment, } \\
\text { near Galboly, Country } \\
\text { Antrim, N. Ireland }\end{array}$ \\
\hline Baratovite & $\begin{array}{l}\text { Roger Poulin } 79 / \text { white } \\
\text { shine, fish scales on surf }\end{array}$ & $\begin{array}{l}\text { Iwagi Jima, Echi Gun, } \\
\text { Ehime Prefecture, } \\
\text { Japan }\end{array}$ \\
\hline Laumontite & $\begin{array}{l}\text { Roger Poulin 423/ zeolite, } \\
\text { pink xtals on brown } \\
\text { background }\end{array}$ & $\begin{array}{l}\text { Bay of Fundy, } \\
\text { Margaretville, Nova } \\
\text { Scotia }\end{array}$ \\
\hline Hedenbergite & $\begin{array}{l}\text { Roger Poulin } 359 / \\
\text { clinopyroxene, black xtals }\end{array}$ & California \\
\hline Cordierite & $\begin{array}{l}\text { Roger Poulin } 221-222 / \text { solid } \\
\text { dark grey rock }\end{array}$ & $\begin{array}{l}\text { Pudrette Quarry, Mt. St. } \\
\text { Hillaire, Que. }\end{array}$ \\
\hline Cancun sand & Larry Lewis & Cancun, Mexico \\
\hline Petrified wood & Jim Carnahan & unknown location \\
\hline $\begin{array}{l}\text { Palygorskite } \\
\text { (Attopulgite) }\end{array}$ & Ward's Scientific 46E 0700 & Quincy, FL \\
\hline Sepiolite & Ward's Scientific & Eskiki-Sher, Turkey \\
\hline Lizardite & Ward's Scientific & Cornwall, England \\
\hline Antigorite & Ward's Scientific & Eden Mills, VT \\
\hline Palygorskite & Ward's Scientific & Quincy, FL \\
\hline Amosite & $\begin{array}{l}\text { Ward's Scientific } 49 E 5854 / \\
\text { white grey, striated rocks }\end{array}$ & Bozeman, Montana \\
\hline $\begin{array}{l}\text { Fayalite (in } \\
\text { granite) }\end{array}$ & Ward's Scientific 46E 3015 & unknown location \\
\hline chrysocolla & $\begin{array}{l}\text { Ward's Scientific 46E1953/ } \\
\text { bluish rocks }\end{array}$ & Miami, AZ \\
\hline Celite 270 & Celite 270 , calcined & \\
\hline Flint Clay & Christy, 35 mesh $\mathrm{H}$ bond & \\
\hline Flint Clay & Christy, Mine run RPF & \\
\hline
\end{tabular}

\section{Supplementary Figures}

Figure 11

XRD pattern for Celite Sno Floss, black spectrum, Celite 209; dotted red spectrum; and Celite FC; dotted blue spectrum). These natural Celites are amorphous as indicated by the broad peaks throughout the spectrum. A couple of clearly crystalline peaks are observed:

- A phase similar to SiO2, (PDF No. 77-1060); Triclinic, $\mathrm{a}=4.916, \mathrm{~b}=4.917, \mathrm{c}=$ $5.407 ;<90.0 \times 90.0 \times 120.0>$. (Shown in red.) 
- Additionally, a phase similar to Cristobalite - SiO2, (PDF No. 76-938); Tetragonal, a $=4.9898, \mathrm{c}=6.992$, . (Shown in blue.)

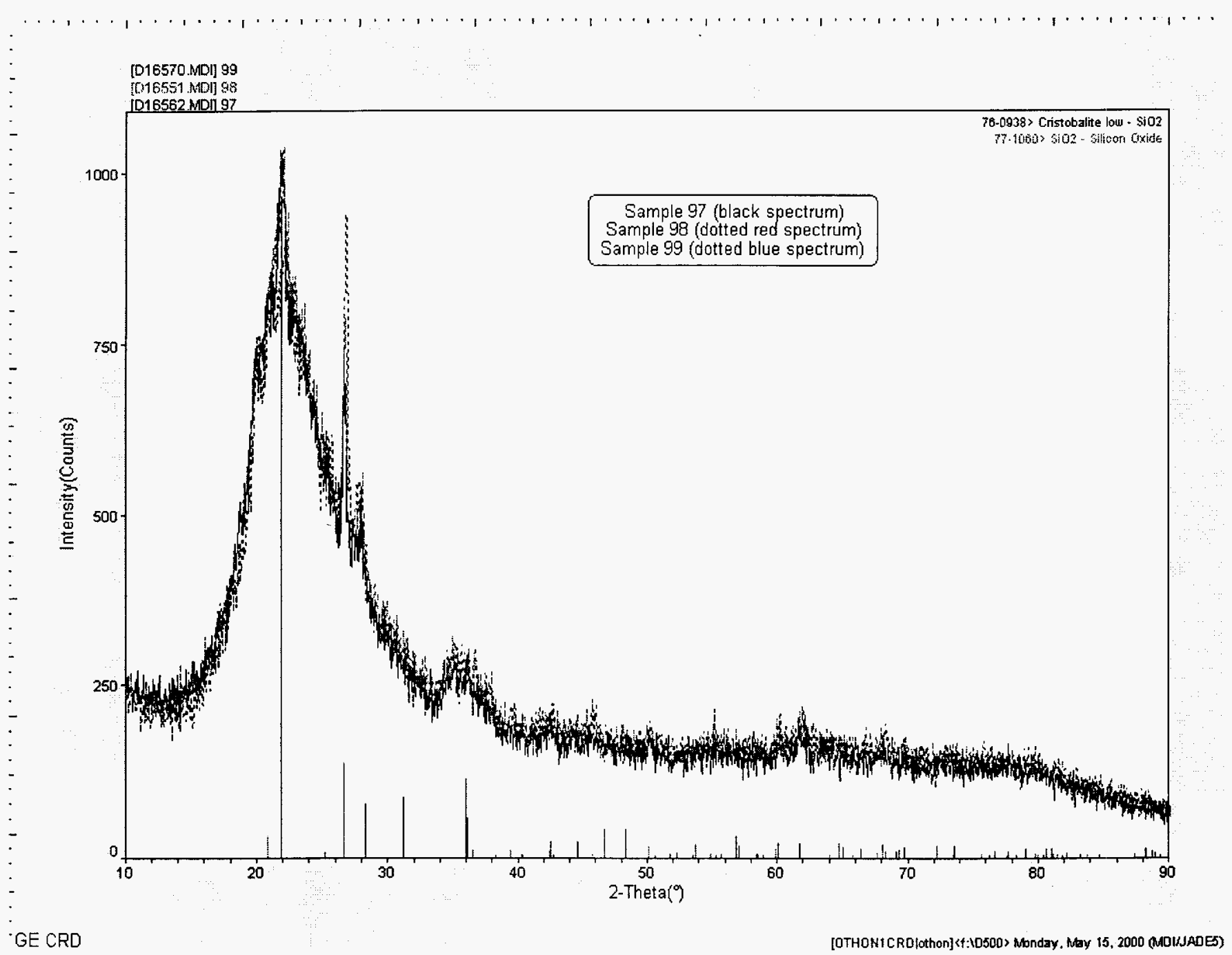


Figure 12

XRD pattern for Celite HyFlo; black spectrum and Celite 545; dotted red spectrum. These Celites are flux calcined and are mostly crystalline. Two different $\mathrm{SiO}_{2}$ phases were observed in these samples:

- A major phase similar in structure to Low Cristobalite - $\mathrm{SiO}_{2}$ (PDF No. 76938) (Shown in blue.)

- A minor phase similar in structure to SiO2, (PDF No. 77-1060) (Shown in red.)

Additionally, the samples appear to have a slightly amorphous component, as seen by the broad, low intensity peaks close to the background levels of the spectra.

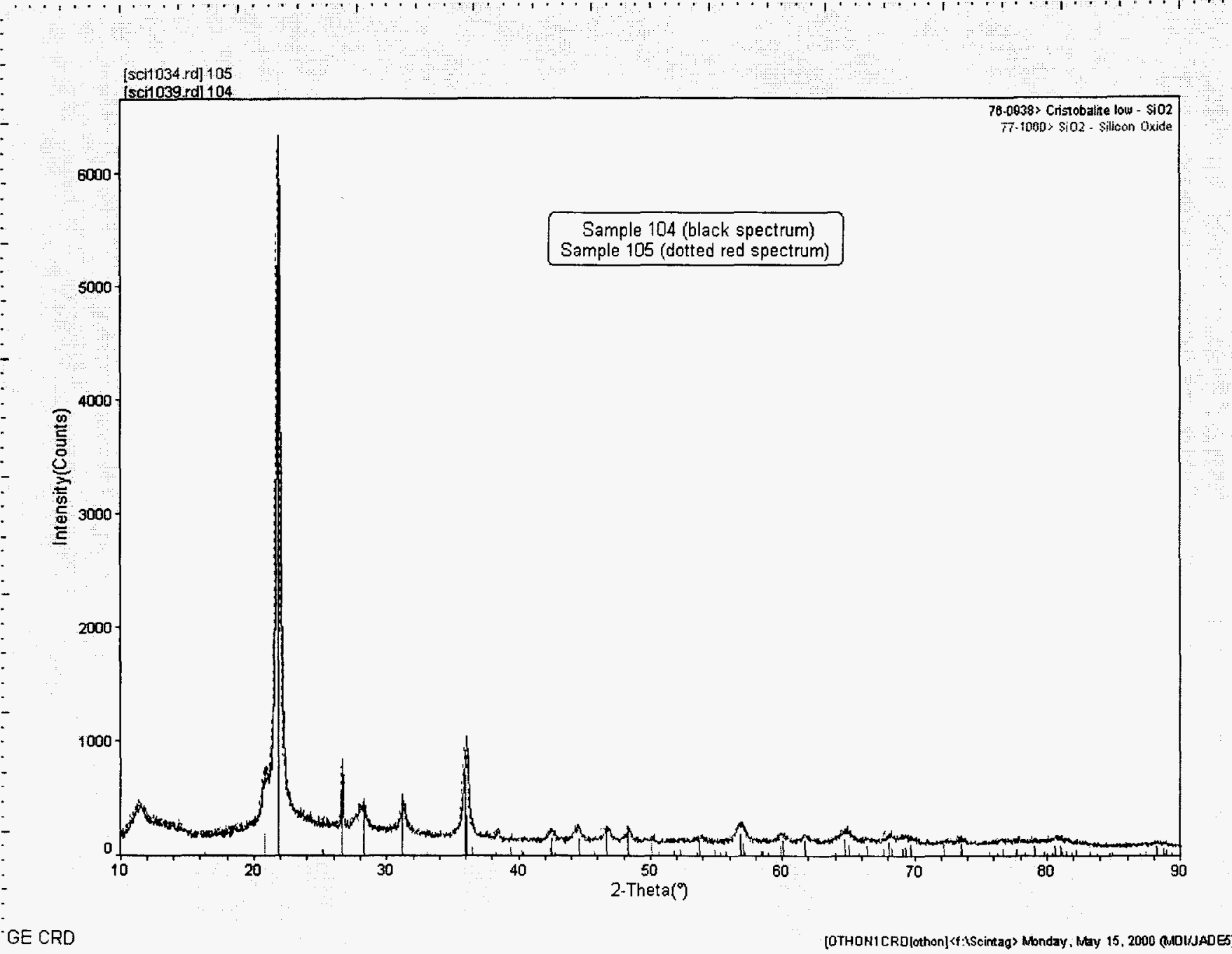


Figure 13

XRD pattern for two Samples of Opal (2-11-00) and (2-7-00)

Both samples are mostly amorphous, phases observed are:

- A major phase of Opal - SiO2!xH2O, (PDF No. 38-448) (Shown in blue.)

- A minor phase with a slightly similar structure to SiO2 - Tridymite, (PDF No.

77-126) (Shown in red.)

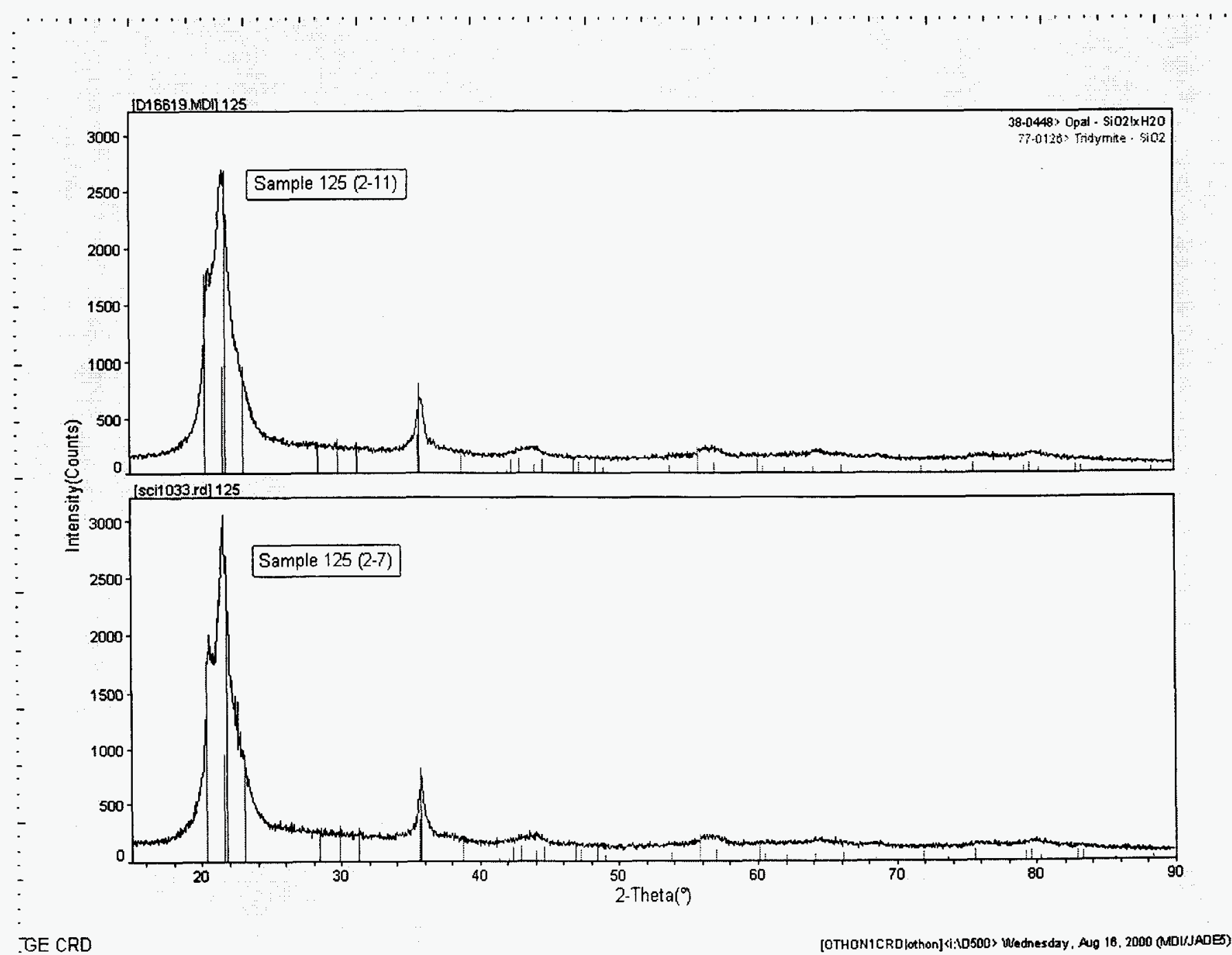


Figure 14

XRD pattern for "Sugilite" (Na,K)AISiO4)

Despite multiple attempts to identify the peaks in this sample, phase identification was not made. Although the suggested "Sugilite" phase was listed in the database (blue lines), the peak structure of the submitted sample does not resemble the peaks in the reference card at all. Unfortunately, a "reasonable" alternate phase was not found for this sample

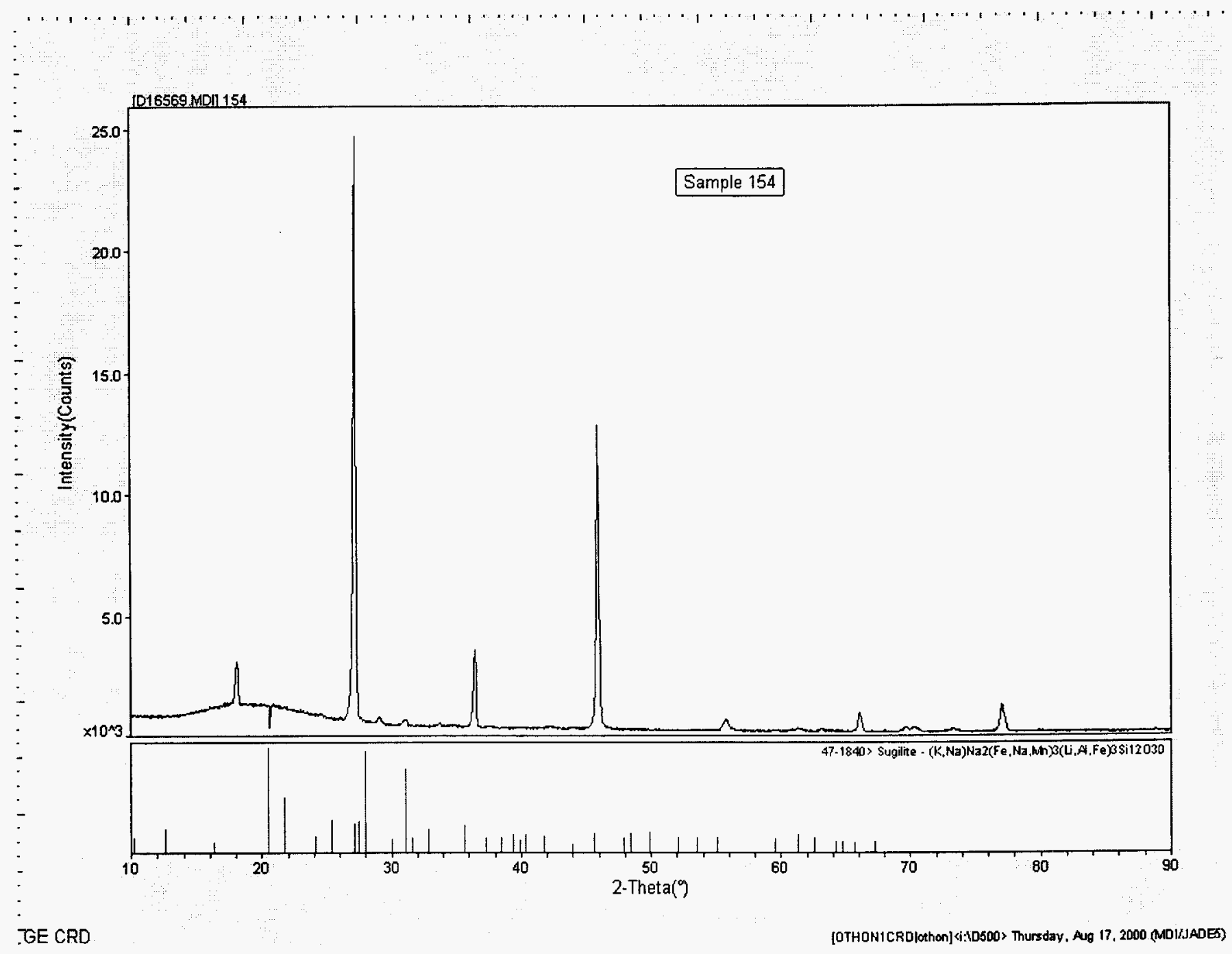


Appendix 4: Submitted to J. Amer. Chem. Soc.

New Route from Si-O to Si-C bonds: Silicone Precursors from Alkoxysilanes and Metal Hydrides

by

Florian J. Schattenmann, * Woodfin V. Ligon, Paul Donahue, Hans Grade, Kara Abatto

Contribution from

GE Corporate Research and Development Center

Niskayuna, NY 12309

\begin{abstract}
The exclusive pathway from silicon-oxygen to silicon-carbon bonds involves nucleophilic attack of an organometallic reagent onto the silicon center. A fundamentally new transformation from silicon-oxygen to silicon-carbon bonds is reported here that proceeds without nucleophilic attack of a carbanion. The reaction of $\mathrm{Si}(\mathrm{OMe})_{4}$ with $\mathrm{NaH}$ yields $\mathrm{MeSi}(\mathrm{OMe})_{3}$ at temperatures above $300^{\circ} \mathrm{C}$. Mechanistic studies indicate that an intact methyl group is transferred from a methoxy group to the silicon center in the $\mathrm{Si}-\mathrm{C}$ bondforming step. This new entry into $\mathrm{Si}-\mathrm{C}$ bond formation directly from $\mathrm{Si}-\mathrm{O}$ bonds is of significance in the search for an alternative commercial route to silicone polymers.
\end{abstract}


Silicone polymers of the general structure $\left(\mathrm{RR}^{\prime} \mathrm{SiO}\right)_{\mathrm{n}}$ are widely used in numerous applications ranging from ingredients in cosmetic and personal care product formulations to lubricants, resins, rubbers and coatings $(1,2)$. Although typically more expensive than organic polymers, silicones distinguish themselves through better performance, unusual properties and ease of synthesis and modification. Several billion pounds of silicones are currently produced every year. The ultimate source of silicon atoms for these materials is silicon dioxide. Considering that about $60 \%$ of the earth's crust is composed of silica and silicates (3), the high cost of silicones is certainly not a function of raw material cost, but rather the result of enormous energy consumption during the manufacturing process. Worldwide throughout the silicones industry silicones are made by essentially the same three-step process. Silicon dioxide is first converted to elemental silicon, which is then reacted with methyl chloride to form a mixture of methylchlorosilanes (4). The methylchlorosilanes are separated by distillation and hydrolyzed to form various types of silicone polymers (5). The major contributor to the high cost of silicones is the vastly energy-intensive carbothermal reduction of silicon dioxide to elemental silicon in an electrochemical furnace at $\sim 1500^{\circ} \mathrm{C}$. The two subsequent steps, methylchlorosilane production and hydrolysis, are both exothermic processes. In addition to the high energy consumption, the current process suffers from high plant maintenance costs due to the corrosive nature of the methylchlorosilanes and $\mathrm{HCl}$, a common byproduct.

New routes to silicones and other organosilicon compounds that avoid the costly production of elemental silicon have been sought after for decades. The success of any new, commercially attractive process depends upon clearing two major barriers: depolymerization of the silicon dioxide and formation of silicon-carbon bonds directly from silicon-oxygen bonds.

Significant advances have been made in the activation and depolymerization of silicon dioxide to produce monomeric silicon containing compounds. Rosenheim et al. (6) reported the conversion of silica into dianionic complexes using catechol under basic conditions. Corriu and coworkers established a synthesis of such dianionic complexes under anhydrous conditions $(7,8)$. Laine et al. reported an efficient route to pentacoordinate silicates from silica using ethylene glycol and $\mathrm{KOH}(9,10)$. Recently, an elegant synthesis of tetramethoxysilane from silica and gaseous dimethyl carbonate was reported by Ono et al. using base as catalyst supported on the silica $(11,12)$. Related examples of successful depolymerization of silica have been reported $(13,14)$. In contrast, no fundamental advances for the direct conversion of silicon-oxygen to silicon-carbon bonds have been reported. To date, all known direct transformations of Si$\mathrm{O}$ to $\mathrm{Si}-\mathrm{C}$ bonds are based on stoichiometric nucleophilic substitution reactions (15) at the silicon center (Figure 1) involving costly and commercially impractical organometallic reagents, almost exclusively of the alkyl lithium and Grignard type $(7,8,14,16)$. Our objective was to establish fundamentally new chemistry with a catalytic pathway from Si$\mathrm{O}$ to $\mathrm{Si}-\mathrm{C}$ bonds as the ultimate goal.

We chose tetramethoxysilane as starting material since substitution of two methoxy groups by methyl groups results in dimethyldimethoxysilane, a direct precursor to silicones. Additionally, $\mathrm{Si}(\mathrm{OMe})_{4}$ is a low-boiling fluid that can easily be used in various reactor types. In an attempt to react tetramethoxysilane under strongly reducing 
conditions, we studied the reaction of $\mathrm{Si}(\mathrm{OMe})_{4}$ with $\mathrm{NaH}$, a reactive metal hydride, in a fixed-bed reactor.

When $\mathrm{Si}(\mathrm{OMe})_{4}$ is passed through a bed of $\mathrm{NaH}$ at temperatures above $200^{\circ} \mathrm{C}$, a new peak besides unreacted $\mathrm{Si}(\mathrm{OMe})_{4}$ was observed in the gas chromatography (GC) trace (retention time: $2.6 \mathrm{~min}$; Figure 2A). The peak represented $\mathrm{HSi}(\mathrm{OMe})_{3}$ as confirmed by gas chromatography-mass spectrometry (GC-MS) and ${ }^{29} \mathrm{Si}$ nuclear magnetic resonance (NMR) (17). By comparison, Kuznetsov showed that no reaction occurs between $\mathrm{Si}(\mathrm{OEt})_{4}$ and $\mathrm{NaH}$ in solution at temperatures up to $168^{\circ} \mathrm{C}(18)$. At temperatures above $275^{\circ} \mathrm{C}$, an additional peak (retention time: $3.7 \mathrm{~min}$ ) was found in the GC trace. The peak increased in intensity as the reactor temperature was raised and represented the only significant product at $325^{\circ} \mathrm{C}$ and above (Figure 2B). Surprisingly, this compound was identified by GC/MS and ${ }^{29} \mathrm{Si}$ NMR to be $\mathrm{MeSi}(\mathrm{OMe})_{3}(17)$. Other hydrides such as $\mathrm{LiH}$ and $\mathrm{NaBH}_{4}$ similarly react with $\mathrm{Si}(\mathrm{OMe})_{4}$ to form $\mathrm{MeSi}(\mathrm{OMe})_{3}$, but are less reactive and require higher reaction temperatures. The formation of $\mathrm{MeSi}(\mathrm{OMe})_{3}$ from tetramethoxysilane and a metal hydride (Figure 2C) represents an unprecedented and unexpected pathway from $\mathrm{Si}-\mathrm{O}$ to $\mathrm{Si}-\mathrm{C}$ bonds. In the following sections we report the disclosure of critical parts of the mechanism.

The low by-product production combined with the high symmetry of the starting material, $\mathrm{Si}(\mathrm{OMe})_{4}$, allowed us to study the mechanism of this unusual reaction in more detail. The question, if $\mathrm{HSi}(\mathrm{OMe})_{3}$ and $\mathrm{MeSi}(\mathrm{OMe})_{3}$ are formed independently from each other or if $\mathrm{HSi}(\mathrm{OMe})_{3}$ is an intermediate in the formation of $\mathrm{MeSi}(\mathrm{OMe})_{3}$ was addressed by reacting $\mathrm{HSi}(\mathrm{OMe})_{3}$ with $\mathrm{NaH}$. $\mathrm{MeSi}(\mathrm{OMe})_{3}$ was observed as a product at temperatures as low as $200^{\circ} \mathrm{C}$, when $\mathrm{HSi}(\mathrm{OMe})_{3}$ was passed through a bed of $\mathrm{NaH}$. The relative amount of $\mathrm{MeSi}(\mathrm{OMe})_{3}$ formed increased as the reactor temperature is raised. At $325^{\circ} \mathrm{C}$, $37 \%$ of the reactor downstream mixture was composed of $\mathrm{MeSi}(\mathrm{OMe})_{3}$. Additionally, the formation of $\mathrm{Me}_{2} \mathrm{Si}(\mathrm{OMe})_{2}$ was observed. In the absence of $\mathrm{NaH}, \mathrm{HSi}(\mathrm{OMe})_{3}$ is thermally stable beyond $350^{\circ} \mathrm{C}$. This result suggests that $\mathrm{MeSi}(\mathrm{OMe})_{3}$ is formed from intermediately formed $\mathrm{HSi}(\mathrm{OMe})_{3}$. Significant disproportionation of $\mathrm{HSi}(\mathrm{OMe})_{3}$ into $\mathrm{SiH}_{4}$ and $\mathrm{Si}(\mathrm{OMe})_{4}$ was observed, a reaction with precedence in the literature $(19,20)$. Deprotonation of $\mathrm{HSi}(\mathrm{OMe})_{3}$ by $\mathrm{NaH}$ to form a sodium silyl species is a conceivable first step in the formation of $\mathrm{MeSi}(\mathrm{OMe})_{3}$ from $\mathrm{HSi}(\mathrm{OMe})_{3}$. The related formation of $\mathrm{KSiEt}_{3}$ from $\mathrm{KH}$ and $\mathrm{HSiEt}_{3}$ has been reported (21). If in fact $\mathrm{NaH}$ reacts as a base with $\mathrm{HSi}(\mathrm{OMe})_{3}$ to form $\mathrm{MeSi}(\mathrm{OMe})_{3}$, then the reaction of $\mathrm{HSi}(\mathrm{OMe})_{3}$ with a different, sufficiently strong base should also lead to formation of $\mathrm{MeSi}(\mathrm{OMe})_{3}$. Indeed, $\mathrm{MeSi}(\mathrm{OMe})_{3}$ is generated in the reaction of $\mathrm{HSi}(\mathrm{OMe})_{3}$ with potassium tert-butoxide $(\mathrm{K}$ $\mathrm{O}-t-\mathrm{Bu})$ at $175^{\circ} \mathrm{C}$. Again, disproportionation of $\mathrm{HSi}(\mathrm{OMe})_{3}$ into $\mathrm{Si}(\mathrm{OMe})_{4}$ and $\mathrm{SiH}_{4}$ was observed. Neat $\mathrm{Si}(\mathrm{OMe})_{4}$ did not react with K-O-t-Bu confirming that only $\mathrm{HSi}(\mathrm{OMe})_{3}$, but not the concurrently formed $\mathrm{Si}(\mathrm{OMe})_{4}$, reacts with base. These results further support the finding that $\mathrm{HSi}(\mathrm{OMe})_{3}$ is an intermediate in the formation of $\mathrm{MeSi}(\mathrm{OMe})_{3}$. $\mathrm{GC} / \mathrm{MS}$ analysis of the carrier gas exiting the reactor during the reaction of $\mathrm{Si}(\mathrm{OMe})_{4}$ and $\mathrm{NaH}$ at $325^{\circ} \mathrm{C}$ revealed the formation of $\mathrm{H}_{2}$ and methane. When $\mathrm{Si}(\mathrm{OMe})_{4}$ was reacted with $\mathrm{LiD}$ at $375^{\circ} \mathrm{C}, \mathrm{HD}$ and $\mathrm{CH}_{3} \mathrm{D}$ were observed as the dominant products. The observed methane formation suggests nucleophilic attack of $\mathrm{H}^{-}$or $\mathrm{D}^{-}$at a $\mathrm{CH}_{3}$-group of $\mathrm{Si}(\mathrm{OMe})_{4}$. The generation of elemental hydrogen is further indication for the deprotonation of $\mathrm{HSi}(\mathrm{OMe})_{3}$ by $\mathrm{NaH}$. 
An important question was whether or not an intact methyl group was transferred in the $\mathrm{Si}-\mathrm{C}$ bond-forming step. Reaction of $\mathrm{Si}(\mathrm{OMe})_{4}$ with $\mathrm{LiD}$ at $400^{\circ} \mathrm{C}$ yielded a mixture that contained $22 \% \mathrm{MeSi}(\mathrm{OMe})_{3}$ as determined by $\mathrm{GC}$ (Figure $3 \mathrm{~A}$ ). The ${ }^{13} \mathrm{C}$ NMR spectrum $\left({ }^{1} \mathrm{H}\right.$ decoupled) of the downstream mixture revealed one dominant peak $(>90 \%)$ in the region expected for methyl groups bound to silicon (Figure 3B). The singlet at $-8.9 \mathrm{ppm}$ suggests that no scrambling of deuterium into the methyl group bound to silicon had occurred. Consistent with the ${ }^{13} \mathrm{C}$ NMR, the ${ }^{1} \mathrm{H}$ NMR exhibited a singlet at $0.11 \mathrm{ppm}$ as the dominant peak in the Si-Me region confirming a deuterium free methyl group bound to $\mathrm{Si}$. In the ${ }^{2} \mathrm{H}$ NMR, a small signal was detected at $-0.05 \mathrm{ppm}$, only a trace amount based on intensity estimates using the ${ }^{13} \mathrm{C}$ satellites of the solvent signal. Consistent with the above described NMR data, the ${ }^{29} \mathrm{Si}$ NMR spectrum exhibits a singlet at $-39.3 \mathrm{ppm}$ as expected for $\mathrm{CH}_{3}-\mathrm{Si}(\mathrm{OMe})_{3}$. MS using chemical ionization did not show significant enrichment of deuterium in $\mathrm{MeSi}(\mathrm{OMe})_{3}$. The NMR and MS studies unambiguously indicate that at least the major part of the formed $\mathrm{MeSi}(\mathrm{OMe})_{3}(>90 \%)$ does not contain deuterium and suggest that an intact methyl group is transferred to the silicon center in the silicon-carbon bond forming step.

Based on the presented data a three-step mechanism was proposed for the formation of $\mathrm{MeSi}(\mathrm{OMe})_{3}$ from $\mathrm{Si}(\mathrm{OMe})_{4}$ and $\mathrm{NaH}$ (Figure 4). Initially $\mathrm{HSi}(\mathrm{OMe})_{3}$ is generated from $\mathrm{Si}(\mathrm{OMe})_{4}$ by nucleophilic attack of $\mathrm{H}^{-}$at the silicon center (Figure $4 \mathrm{~A}$ ). In the second step (Figure 4B), the $\mathrm{NaH}$ acts as a base and reacts with $\mathrm{HSi}(\mathrm{OMe})_{3}$ to form a sodium silyl species, presumably $\mathrm{NaSi}(\mathrm{OMe})_{3}$. The sodium silyl derivative is well suited for nucleophilic attack on a methoxy group of, most likely, another $\mathrm{Si}(\mathrm{OMe})_{4}$ molecule in the Si-C bond forming step (Figure 4C). The formation of methane by nucleophilic attack of $\mathrm{H}^{-}$on a methyl group of $\mathrm{Si}(\mathrm{OMe})_{4}$ (Figure 4D) and the disproportion of $\mathrm{HSi}(\mathrm{OMe})_{3}$ into $\mathrm{Si}(\mathrm{OMe})_{4}$ and $\mathrm{SiH}_{4}$ (Figure 4E) represent unproductive side reactions. Although pentacoordinate silicon species are likely intermediates during the various reaction steps, no signals were found in the region typical for higher coordinated silicon species in the solid state ${ }^{29} \mathrm{Si}$ NMR spectrum of the bed after partial reaction.

The two undesired side reactions, disproportion of $\mathrm{HSi}(\mathrm{OMe})_{3}$ and methane formation, are mainly responsible for the mediocre yields observed in the reaction of $\mathrm{NaH}$ with $\mathrm{Si}(\mathrm{OMe})_{4}$. Cumulative yields of $20-25 \% \mathrm{MeSi}(\mathrm{OMe})_{3}$ based on $\mathrm{NaH}$ were found, when an excess of $\mathrm{Si}(\mathrm{OMe})_{4}$ was passed through the reactor assuming consumption of two $\mathrm{NaH}$ molecules for every $\mathrm{Si}-\mathrm{C}$ bond generated. If $\mathrm{Si}(\mathrm{OMe})_{4}$ is reacted with a slight access of $\mathrm{NaH}$, typical yields for $\mathrm{MeSi}(\mathrm{OMe})_{3}$ based on $\mathrm{Si}(\mathrm{OMe})_{4}$ are $36-40 \%$, again assuming the consumption of two $\mathrm{Si}(\mathrm{OMe})_{4}$ for one $\mathrm{MeSi}(\mathrm{OMe})_{3}$ formed.

Higher substituted alkoxysilanes such as tetraethoxysilane and tetra- $n$-propoxysilane show reactivity analogous to tetramethoxysilane in the reaction with $\mathrm{NaH}$. At lower temperatures, the trialkoxysilanes, $\mathrm{HSi}(\mathrm{OR})_{3}$, are formed, while at higher temperatures the corresponding alkyltrialkoxysilanes are found. Transfer of an intact alkyl group further supports the proposed mechanism. Lower yield and increased byproduct production are observed compared to $\mathrm{Si}(\mathrm{OMe})_{4}$.

All known transformations of $\mathrm{Si}-\mathrm{O}$ to $\mathrm{Si}-\mathrm{C}$ bonds are based on nucleophilic substitution reactions using organometallic reagents such as Grignard or alkyllithium reagents. We have discovered a fundamentally new pathway from $\mathrm{Si}-\mathrm{O}$ to $\mathrm{Si}-\mathrm{C}$ bonds starting from tetraalkoxysilanes and metal hydrides. Through mechanistic studies we have shown that 
the formation of $\mathrm{MeSi}(\mathrm{OMe})_{3}$ from $\mathrm{Si}(\mathrm{OMe})_{4}$ proceeds via formation of $\mathrm{HSi}(\mathrm{OMe})_{3}$. The $\mathrm{Si}-\mathrm{C}$ bond forming step involves methyl transfer from a methoxy group onto the silicon center. Most surprisingly, an electrophilic rather than a nucleophilic alkyl fragment is transferred in the Si-C bond forming step in contrast to any other example of $\mathrm{Si}-\mathrm{C}$ bond formation directly from Si-O bonds. This work provides new prospects in the search of an alternative, economic synthetic route to silicone polymers and organosilanes from the nearly unlimited natural resources of silicon dioxide.

\section{References and Notes}

1. J. Rich, et al., in Kirk-Othmer Encyclopedia of Chemical Technology J. I. Kroschwitz, M. Howe-Grant, Eds. (Wiley, New York, 1997), vol. 22, pp. 82.

2. A. Tomanek, Silicones and Industry (Hanser (Wacker Chemie), Munich, 1991).

3. R. E. Patterson, in Kirk-Othmer Encyclopedia of Chemical Technology J. I.

Kroschwitz, M. Howe-Grant, Eds. (Wiley, New York, 1997), vol. 21, pp. 977.

4. E. G. Rochow, J. Am. Chem. Soc. 67, 963 (1945).

5. W. Noll, Chemistry and Technology of Silicones (Academic, New York, 1968).

6. A. Rosenheim, B. Raibmann, G. Schendel, Z. Anorg. Allg. Chem. 196, 160 (1931).

7. A. Boudin, G. Cerveau, C. Chuit, R. J. P. Corriu, C. Reye, Angew. Chem. Int. Ed. Engl. 25, 474 (1986).

8. A. Boudin, G. Cerveau, C. Chuit, R. J. P. Corriu, C. Reye, Organometallics 7, 1165 (1988).

9. R. M. Laine, et al., Nature 353, 642 (1991).

10. K. Y. Blohowiak, et al., Chem. Mater. 6, 2177 (1994).

11. E. Suzuki, M. Akiyama, Y. Ono, J. Chem. Soc., Chem. Commun. 1992, 136 (1992).

12. Y. Ono, M. Akiyama, E. Suzuki, Chem. Mater. 5, 442 (1993).

13. M. L. Hoppe, R. M. Laine, J. Kampf, M. S. Gordon, L. W. Burggraf, Angew. Chem. Int. Ed. Engl. 32, 287 (1993).

14. G. B. Goodwin, M. E. Kenney, Adv. Chem. Ser. 224, 251 (1990).

15. M. A. Brook, Silicon in Organic, Organometallic, and Polymer Chemistry (Wiley, New York, 2000).

16. A. Boudin, G. Cerveau, C. Chuit, R. J. P. Corriu, C. Reye, J. Organomet. Chem. 362, 265 (1989).

17. E. A. Williams, in The Chemistry of Organic Silicon Compounds S. Patai, Z. Rappoport, Eds. (Wiley, Chichester, U. K., 1989), vol. 1, pp. 548.

18. A. I. Kuznetsov, Zh. Prikl. Khim. 51, 1833 (1978).

19. E. Suzuki, M. Okamoto, Y. Ono, Chem. Lett. 1989, 1487 (1989).

20. S. Xin, C. Aitken, J. F. Harrod, Y. Mu, E. Samuel, Can. J. Chem. 68, 471 (1990).

21. R. J. P. Corriu, C. Guerin, J. Chem. Soc., Chem. Comm. 1980, 168 (1980).

We thank the Department of Energy for generous support (DE-FC02-98CH10931). 


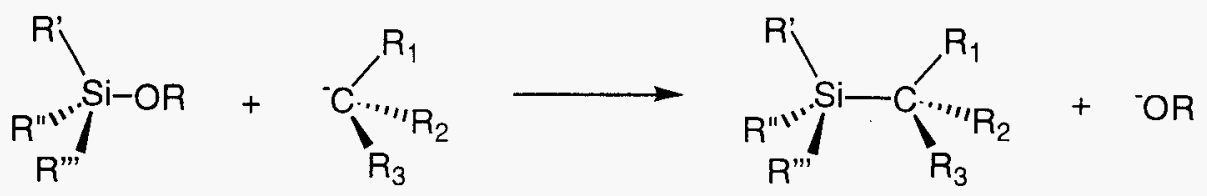

Figure 1. All known direct conversions of $\mathrm{Si}-\mathrm{O}$ to $\mathrm{Si}-\mathrm{C}$ bonds can be reduced to nucleophilic attack of a carbanion on a silicon center during the $\mathrm{Si}-\mathrm{C}$ bond-forming step. 

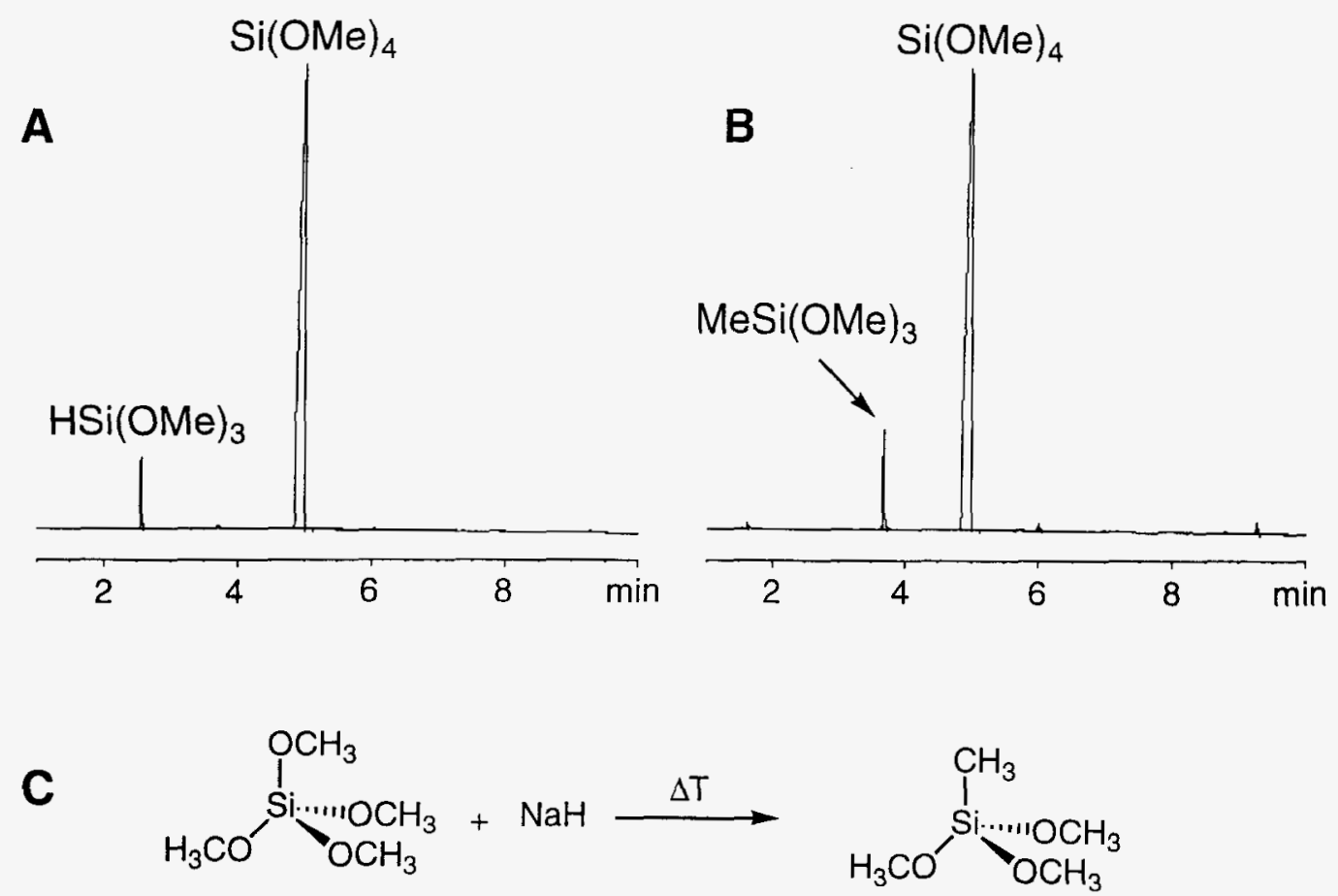

Figure 2. $\mathrm{GC}$ traces of the reactor downstream for the reaction of $\mathrm{Si}(\mathrm{OMe})_{4}$ with $\mathrm{NaH}$ at $275^{\circ} \mathrm{C}(\mathbf{A})$ and at $350^{\circ} \mathrm{C}(\mathbf{B}) . \mathrm{MeSi}(\mathrm{OMe})_{3}$ is the dominant product at $350^{\circ} \mathrm{C}$ in the reaction of $\mathrm{Si}(\mathrm{OMe})_{4}$ with $\mathrm{NaH}(\mathbf{C})$. 

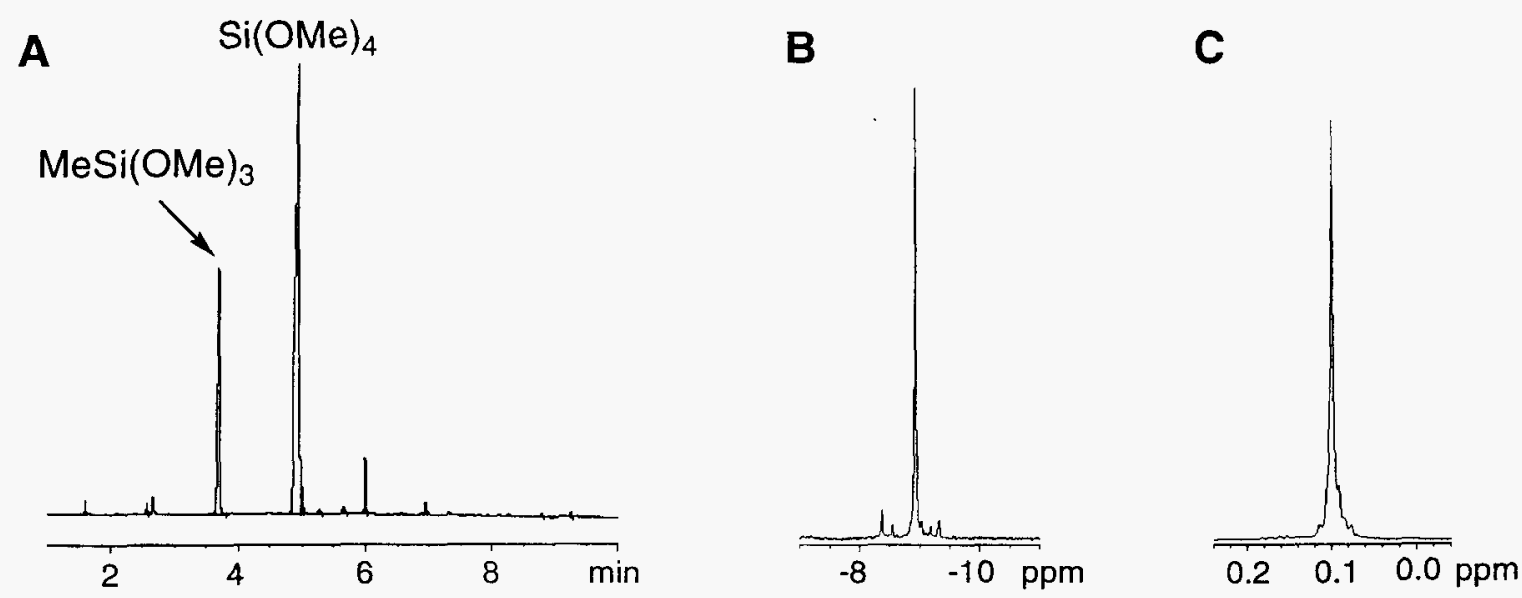

Figure 3. GC trace (A) and NMR data of the reactor downstream for the reaction of $\mathrm{Si}(\mathrm{OMe})_{4}$ with $\mathrm{LiD}$ at $400{ }^{\circ} \mathrm{C}$. The ${ }^{13} \mathrm{C} \mathrm{NMR}(\mathrm{B})$ and ${ }^{1} \mathrm{H}$ NMR (C) spectra each show the region typical for methyl groups directly bound to silicon. A singlet as the dominant peak in the ${ }^{13} \mathrm{C}$ NMR as well as the ${ }^{1} \mathrm{H}$ NMR spectrum indicates that no significant scrambling of deuterium into the methyl group had occurred suggesting transfer of an intact methyl group in the silicon-carbon bond forming step. 


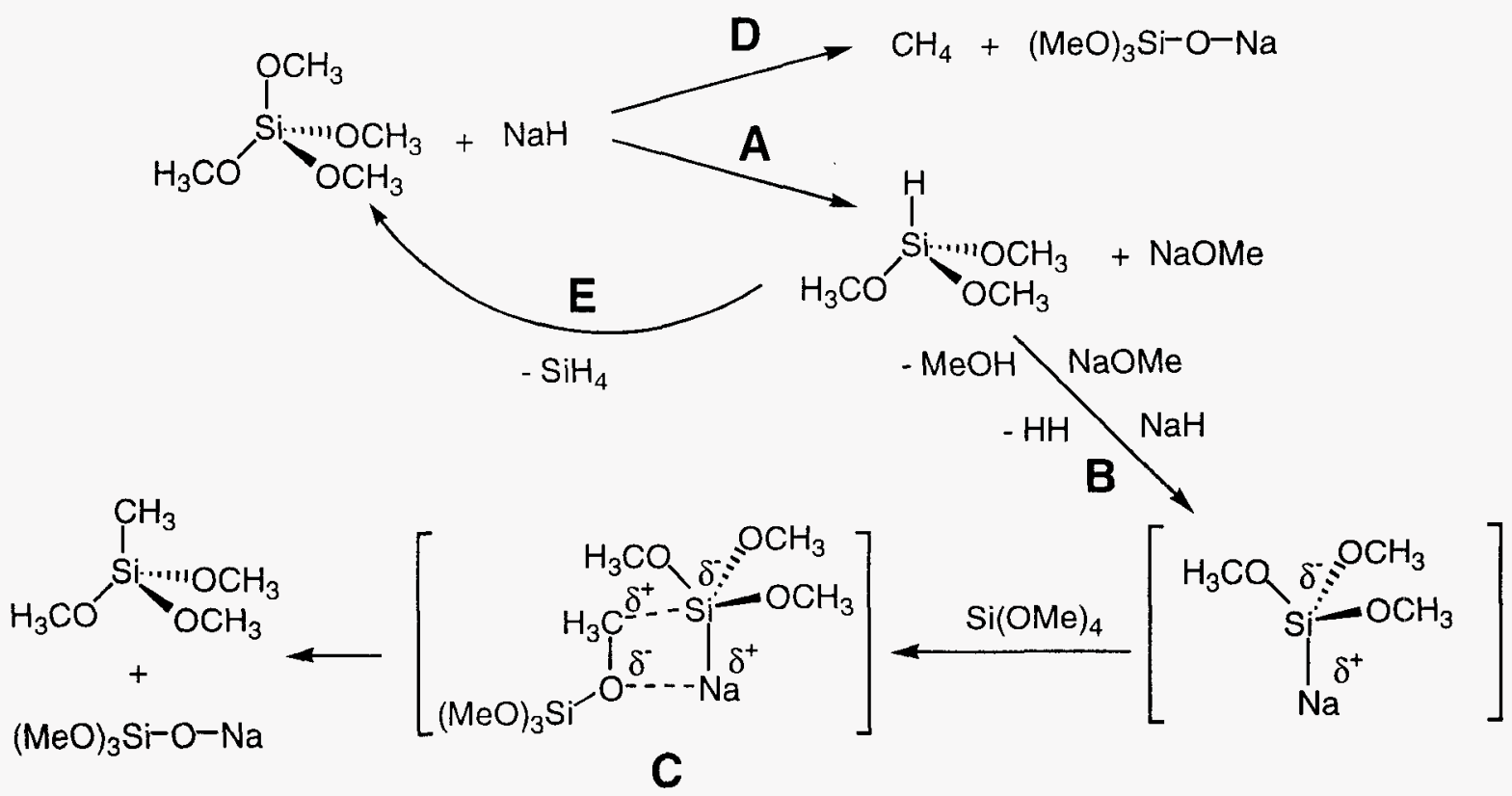

Figure 4. Proposed three-step mechanism of the formation of $\mathrm{MeSi}(\mathrm{OMe})_{3}$ from $\mathrm{Si}(\mathrm{OMe})_{4}$ and $\mathrm{NaH}:(\mathbf{A}) \mathrm{Nucleophilic} \mathrm{attack}$ of $\mathrm{H}^{-}$at $\mathrm{Si}(\mathrm{OMe})_{4} ;(\mathbf{B}) \mathrm{H}$-abstraction to form a sodium silyl derivative; (C) Si-C bond formation by nucleophilic attack of the silyl group. Methane formation (D) and disproportion of $\mathrm{HSi}(\mathrm{OMe})_{3}(\mathbf{E})$ are undesired side reactions. 


\section{New Route from Si-O to Si-C bonds: Silicone Precursors from Alkoxysilanes and Metal Hydrides}

Florian J. Schattenmann,* Woodfin V. Ligon, Paul Donahue, Hans Grade, Kara Abatto

\section{Supplementary Information}

\section{General Methods}

All reactions were performed in a fixed-bed reactor setup as schematically represented in Supplemental Figure 1. Sodium hydride (95\% purity) was purchased from Aldrich and exclusively handled under an inert gas atmosphere. $\mathrm{Si}(\mathrm{OMe})_{4}(99.5 \%$ purity) was purchased from Aldrich and used as is. Analytical methods were performed as follows: GC/MS. Two microliters of the sample were drawn up into a $10 \mu \mathrm{l}$ syringe with a pocket of air in the syringe barrel above the aliquot of sample. Just before injection the 2 $\mu 1$ sample was expelled leaving a "wet needle" which was immediately injected into the GC/MS. The injection split was approximately $10: 1$. The injector was operated at $300^{\circ} \mathrm{C}$ and the column was programmed from $50^{\circ} \mathrm{C}$ to $250^{\circ} \mathrm{C}$ at $10^{\circ} \mathrm{C} / \mathrm{min}$. The column was a J\&W Scientific model DB-5 MS with a length of 30 meters and a width of $0.52 \mathrm{~mm}$. The column had a film thickness of 1.5 micrometers. The carrier gas was hydrogen.

The mass spectrometer was a JEOL model HX110 double focusing magnetic mass spectrometer operated in electron ionization mode at 1000 resolution. The instrument was scanned from 10-800 amu at 1 second per full cycle (scan plus flyback). Spectra obtained were compared with the National Institutes of Science and Technology (NIST) library.

NMR. All data were obtained on GE NMR Instruments Omega nuclear magnetic resonance spectrometers operating at $500 \mathrm{MHz}(11.75 \mathrm{~T})$ for ${ }^{13} \mathrm{C},{ }^{29} \mathrm{Si}$, and ${ }^{2} \mathrm{H}$ and at 300 $\mathrm{MHz}\left(7.06 \mathrm{~T}\right.$ ) for ${ }^{1} \mathrm{H} .{ }^{13} \mathrm{C},{ }^{29} \mathrm{Si}$, and ${ }^{2} \mathrm{H}$ data were obtained using a $10 \mathrm{~mm}$ broadband probe and ${ }^{1} \mathrm{H}$ data was obtained using a $5 \mathrm{~mm}{ }^{1} \mathrm{H}-{ }^{13} \mathrm{C}$ dual frequency probe. All spectra were obtained using $\mathrm{CDCl}_{3}$ as the solvent. Acquisition parameters for ${ }^{13} \mathrm{C}$ (at 125.75 $\mathrm{MHz}$ ) were a sweep width of $30.3 \mathrm{kHz}$ with a $11.2 \mathrm{kHz}$ offset and 32k data points resulting in a $1.08 \mathrm{~s}$ acquisition time. A one-pulse sequence was used with a $45^{\circ}$ flip and 1s pulse delay. A total of 5600 transients were accumulated. ${ }^{29} \mathrm{Si}($ at $99.35 \mathrm{MHz})$ data was obtained using a $20.0 \mathrm{kHz}$ sweep width with a $-5.4 \mathrm{kHz}$ offset and $16 \mathrm{k}$ data points resulting in an $800 \mathrm{~ms}$ acquisition time. An inverse gated pulse sequence was used with broadband decoupling on during acquisition only with a $5 \mathrm{~s}$ pulse delay and $90^{\circ}$ flip angle. Chromium tris-acetyl acetonate was added to the solution as a spin-lattice relaxation reagent to reduce NOE. 9600 transients were accumulated. For ${ }^{2} \mathrm{H}$ (at 76.7 $\mathrm{MHz}$ ) observe a $2.0 \mathrm{kHz}$ sweep width and $384 \mathrm{~Hz}$ offset were employed with $2 \mathrm{k}$ data points to give a $1.024 \mathrm{~s}$ acquisition time. The lock channel was turned off and the lock coil detuned to allow deuterium observation. An inverse gated pulse sequence was employed and 512 transients were obtained. ${ }^{1} \mathrm{H}$ NMR data was obtained at $300.1 \mathrm{MHz}$ using a simple one-pulse pulse sequence. A sweep width of $4.5 \mathrm{KHz}$ and $8 \mathrm{k}$ data points resulted in an acquisition time of $1.8 \mathrm{~s}$. A pulse delay of $8.2 \mathrm{~s}$ and a $30^{\circ}$ flip were also used to acquire 128 scans. All data was processed using an in-house data processing 
package NetNMR. A polynomial baseline correction was applied and a correction to compensate for Bessell filter drop off was also applied.

MS analysis of gas phase. A JEOL SX-102 mass spectrometer was used with the resolution set to 1000 and tuned to $\mathrm{m} / \mathrm{z}=2.250 \mu \mathrm{l}$ of gas phase was injected into an alumina Plot column (program: $3 \mathrm{~min}$ at $-80^{\circ} \mathrm{C}$; temperature ramp: $60^{\circ} \mathrm{C} / \mathrm{min}$ to $10^{\circ} \mathrm{C}$ followed by $25^{\circ} \mathrm{C} / \mathrm{min}$ up to $200^{\circ} \mathrm{C}$.

Elemental analysis of bed. The bed samples were ashed and fused in the presence of $\mathrm{Li}_{2} \mathrm{~B}_{4} \mathrm{O}_{7}$ in $\mathrm{Pt}$ crucibles. Then the samples were dissolved in $\mathrm{HNO}_{3}$ and diluted. The solutions were analyzed on a Varian Liberty II ICP-AES instrument.

\section{Typical example of the reaction of $\mathrm{Si}(\mathrm{OMe})_{4}$ with $\mathrm{NaH}$.}

Sodium hydride $(0.93 \mathrm{~g} ; 38.8 \mathrm{mmol})$ was charged into a fixed-bed flow reactor with vertical furnace and flushed with hydrogen carrier gas at a rate of $20 \mathrm{~mL} / \mathrm{min}$. The initial reactor temperature was $200^{\circ} \mathrm{C}$. The reactor was heated in the presence of hydrogen as carrier gas. Tetramethoxysilane $(2.13 \mathrm{~mL} / \mathrm{h} ; 14.4 \mathrm{mmol} / \mathrm{h})$ was fed into the carrier gas stream using a motor driven syringe. The reactor effluent downstream was collected in fractions using a water-chilled condenser and analyzed by gas chromatography. The reaction was carried out with a temperature ramp. After collecting a fraction, typically in a range between about 0.5 grams and about 2 grams, the reactor temperature was increased by $25^{\circ} \mathrm{C}$ or $50^{\circ} \mathrm{C}$ for screening purposes. Methyltrimethoxysilane $\left[\mathrm{MeSi}(\mathrm{OMe})_{3}\right]$ and trimethoxysilane $\left[\mathrm{HSi}(\mathrm{OMe})_{3}\right]$ formation was confirmed by gas chromatography, GC/MS and multinuclear NMR techniques (1).

\section{Reference}

1. E. A. Williams, in The Chemistry of Organic Silicon Compounds S. Patai, Z. Rappoport, Eds. (Wiley, Chichester, U. K., 1989), vol. 1, pp. 548. 


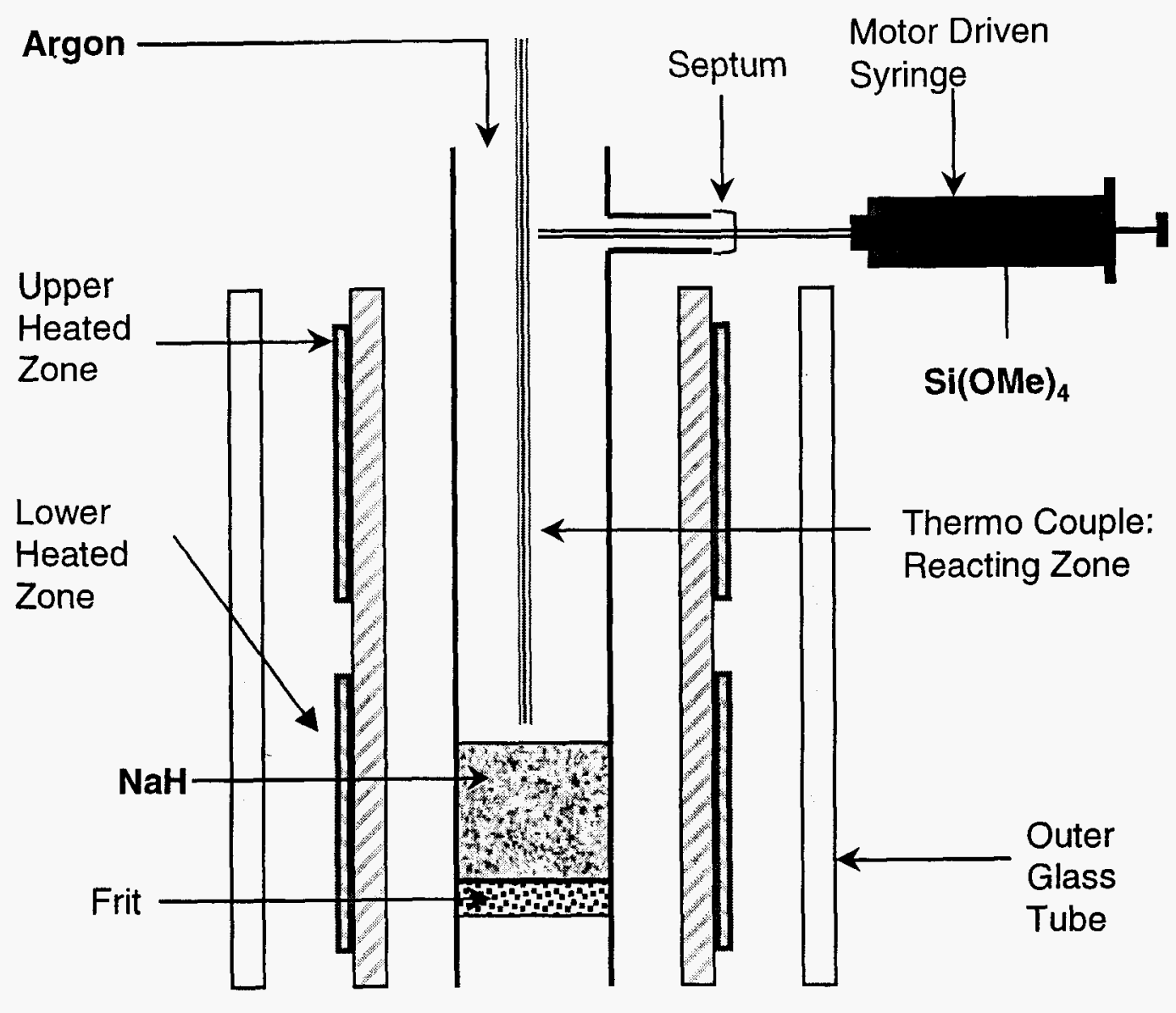

Supplemental Figure 1. Schematic representation of the fixed-bed reactor setup used in the reaction of tetramethoxysilane and $\mathrm{NaH}$.

\section{Appendix 5}

\section{Materials Cost Assessment (Don Rohr, Jr.)}

We performed a material cost assessment of the process concept where silica and dimethylcarbonate (DMC) are converted to tetramethoxysilane (Q') and subsequently reacted to fumed silica for fiber-optic use. The block diagram is shown below: 


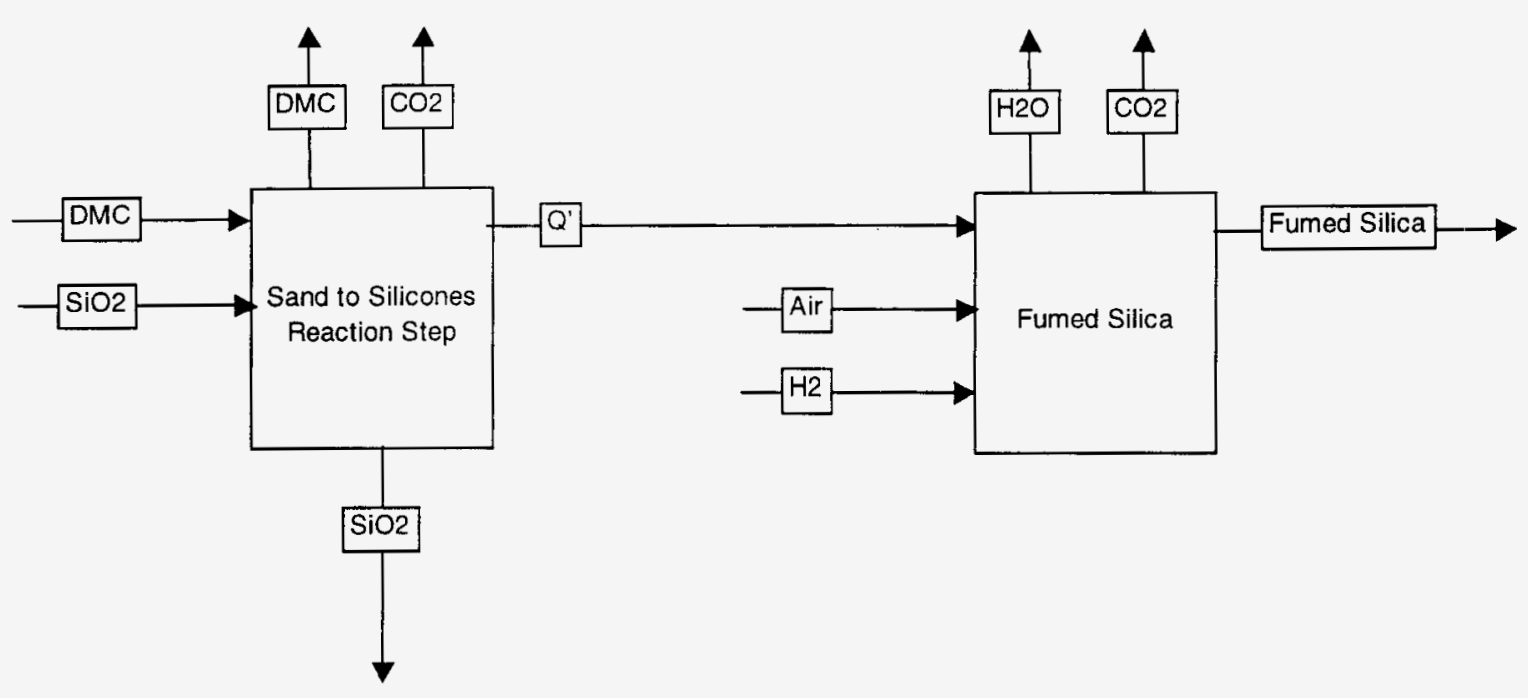

Figure 1: Block Process Diagram

The basic chemical reactions that were considered in each block are given by the following equations.

$$
\mathrm{SiO}_{2}+2 \mathrm{DMC}^{\prime} Q^{\prime}+2 \mathrm{CO}_{2}
$$

Equation 1: Sand To Silicones Reaction

$$
Q^{\prime}+(6+\varepsilon) \mathrm{O}_{2}+\mathrm{N}_{2}(\text { air })+\varepsilon \mathrm{H}_{2} \rightarrow \mathrm{SiO}_{2}+4 \mathrm{CO}_{2}+(6+\varepsilon) \mathrm{H}_{2} \mathrm{O}+\mathrm{N}_{2} \text { (air) }
$$

Equation 2: Q' Combustion

Overall yields were defined for each reaction using an extent-of-reaction concept. For example, if reaction 1 was performed at $50 \%$ yield, 1 mole of $\mathrm{SiO} 2$ and 2 moles of DMC would only produce 0.5 moles of Q'. The remaining reactants were treated as if they were lost to side reactions. As more detailed understanding is developed about side reactions and raw material loss mechanisms, we can add sophistication to the yield calculation.

The formation of silica for use in fiber optic material is usually accomplished by combustion. The yield of silane-precursor combustion operations is usually high. In many instances, the yield difficulty is in further downstream processing and deposition of fumed silica onto perform materials. For the purposes of this study we examined the economics up to and including the combustion of Q', but did not examine deposition for waveguide or other fiberoptic applications. The term $\varepsilon$ in the combustion expression represents excess hydrogen needed for flame temperature adjustment.

Based on the above assumptions, the use quantities shown in Figure 2 were calculated. 
Figure2: Cost Breakdown for 100\% Yield of Q' reaction and Fumed Silica reaction.

\begin{tabular}{|ccccc|}
\hline \multicolumn{4}{c|}{ Material and Cost Breakdown } \\
Price & Price & Usage & Cost & Cost \\
$\$ / l b s$ & $\$ / k g$ & $\mathrm{~kg} / \mathrm{kg}$ Product $\$ / \mathrm{kg}$ Product & $\$ / \mathrm{lb}$ Product \\
\hline
\end{tabular}

\begin{tabular}{|c|c|c|c|c|c|}
\hline $\mathrm{SiO} 2$ & 0.03 & 0.07 & 1.00 & 0.07 & 0.03 \\
\hline (DMC) & 0.25 & 0.55 & 3.00 & 1.65 & 0.75 \\
\hline$Q^{\prime}$ & 0.00 & 0.00 & -2.53 & 0.00 & 0.00 \\
\hline $\mathrm{CO} 2$ & 0.10 & 0.22 & -1.47 & -0.32 & -0.15 \\
\hline$Q^{\prime}$ & 0.00 & 0.00 & 2.53 & 0.00 & 0.00 \\
\hline 02 & 0.00 & 0.00 & 3.33 & 0.00 & 0.00 \\
\hline N2 & 0.00 & 0.00 & 10.97 & 0.00 & 0.00 \\
\hline $\mathrm{H} 2$ & 1.80 & 3.97 & 0.02 & 0.07 & 0.03 \\
\hline $\mathrm{SiO} 2$ & 0.00 & 0.00 & -1.00 & 0.00 & 0.00 \\
\hline CO2 & 0.10 & 0.22 & -2.93 & -0.65 & -0.29 \\
\hline $\mathrm{H} 2 \mathrm{O}$ & 0.00 & 0.00 & -1.95 & 0.00 & 0.00 \\
\hline N2 & 0.00 & 0.00 & -10.97 & 0.00 & 0.00 \\
\hline \multicolumn{4}{|c|}{ Total } & 0.82 & 0.37 \\
\hline
\end{tabular}

As noted in Figure 2, DMC cost plays a significant role in the cost structure.

Additionally, the ability to extract value from the relatively pure $\mathrm{CO}_{2}$ Streams is important. We anticipate co-locating this system by a shift reactor and recycling the $\mathrm{CO}_{2}$ back through for DMC generation.

A further look at cost sensitivity to DMC price underscores the importance of high yield of DMC to useful products. In Figure 3, the material cost for Fumed Silica is plotted versus DMC price and Reaction 1 yield. At the lower cost of $\$ 0.20 / \mathrm{lb} \mathrm{DMC}$ and approximately $70 \%$ yield for Reaction 1 , a material cost of $\$ 0.50 /$ lb Fumed Silica is conceivable. At the other extreme, high DMC prices and low yields can drive material costs to well above $\$ 3.00 /$ lb Fumed Silica.

Figure 3: Fumed Silica Material Cost 


\section{Fumed Silica Material Cost (Parametric in Q'/SiO2 Yield)}

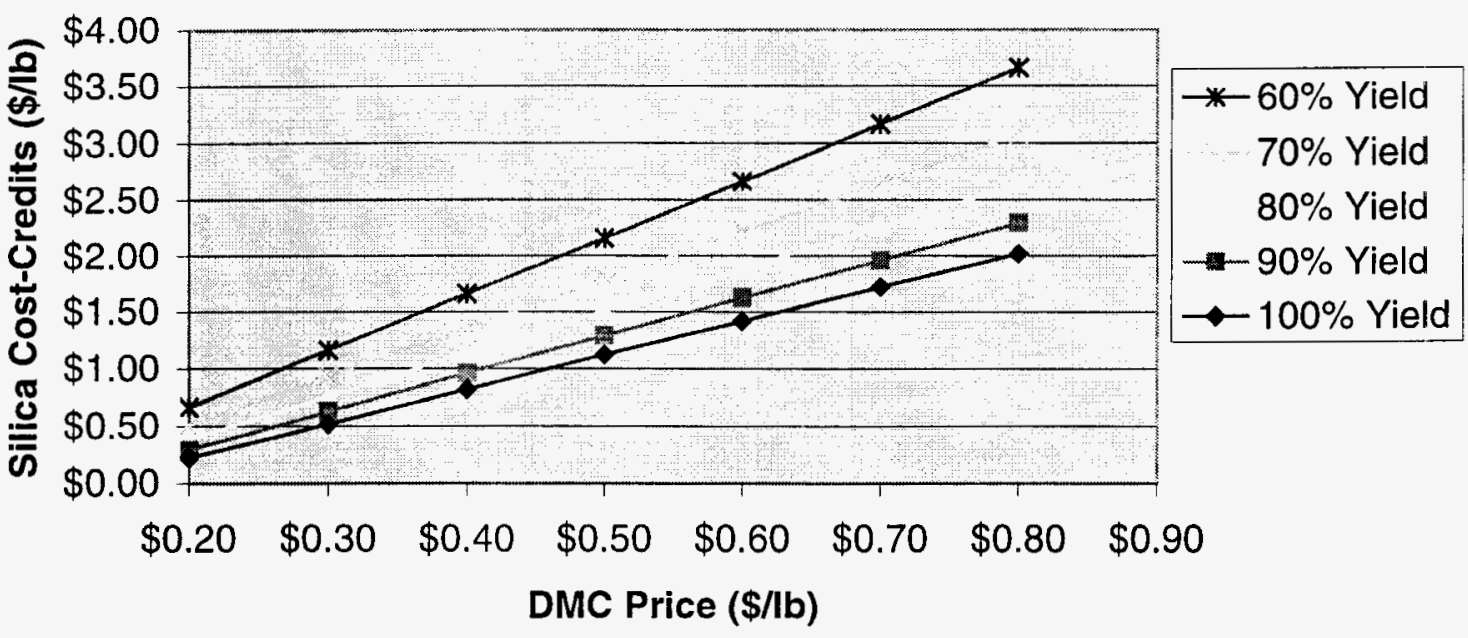

\begin{tabular}{|c|ccccc|}
\hline \multicolumn{5}{|c|}{ Material Cost as a Function of Raws \& Yield } \\
\hline $\begin{array}{c}\text { DMC Price } \\
(\$ / / b)\end{array}$ & \multicolumn{5}{c|}{ Yield of Q'/SiO2 } \\
& 100.00 & 90 & 80 & 70 & 60 \\
\hline$\$ 0.20$ & $\$ 0.22$ & $\$ 0.29$ & $\$ 0.39$ & $\$ 0.50$ & $\$ 0.66$ \\
$\$ 0.30$ & $\$ 0.52$ & $\$ 0.63$ & $\$ 0.76$ & $\$ 0.93$ & $\$ 1.16$ \\
$\$ 0.40$ & $\$ 0.82$ & $\$ 0.96$ & $\$ 1.14$ & $\$ 1.36$ & $\$ 1.66$ \\
$\$ 0.50$ & $\$ 1.12$ & $\$ 1.29$ & $\$ 1.51$ & $\$ 1.79$ & $\$ 2.16$ \\
$\$ 0.60$ & $\$ 1.42$ & $\$ 1.63$ & $\$ 1.89$ & $\$ 2.22$ & $\$ 2.66$ \\
$\$ 0.70$ & $\$ 1.72$ & $\$ 1.96$ & $\$ 2.26$ & $\$ 2.65$ & $\$ 3.16$ \\
$\$ 0.80$ & $\$ 2.02$ & $\$ 2.29$ & $\$ 2.64$ & $\$ 3.07$ & $\$ 3.66$ \\
\hline
\end{tabular}

The key for an economical process is to secure low-cost DMC, minimize side reactions, recycle $\mathrm{CO} 2$ streams, and minimize the cost of the starting silica material. We will continue to explore these process economics as more experimental results become available and as yields improve.

\section{Appendix 6: Use of Q' as a SiO2 Source}

The current methods to make high surface area and/or high purity $\mathrm{SiO} 2$ employ silane reagents. The silane reagents are burned in order to form the high surface area silicon dioxide. Optionally the silane can be purified to high degree and then burned to give very high purity silicon dioxide. The high purity silicon dioxide is the essential ingredient for making fiber optic quartz and other high purity silicon dioxide articles. 
The most common silane currently employed for preparation of $\mathrm{SiO} 2$ is $\mathrm{SiCl} 4(1)$. The use of alkoxy silanes including $(\mathrm{MeO}) 4 \mathrm{Si}$ as a precursor to $\mathrm{SiO} 2$ has been described in PECVD processes (2,3), CVD processes (4), oxidation processes (5), flame hydrolysis (6) and others (7).

All processes for making $\mathrm{SiO} 2$ use synthetic silanes derived from a silicon starting material. Silicon in turn is prepared from mined $\mathrm{SiO} 2$ (quartz) in a high temperature carboelectric process. We are not aware of a process whereby $\mathrm{SiO} 2$ is converted to alkoxy silane, (optionally) purified and then burned to make the appropriate $\mathrm{SiO} 2$ final material.

Results \& Discussion

Low cost silicon dioxide sources including but not limited to diatomaceous earth, opal, metal silicates such as lithium, cobalt, calcium etc., are combined with from 0.5 to $15 \%$ of a base selected from $\mathrm{MOH}(\mathrm{M}=\mathrm{Li}, \mathrm{Na}, \mathrm{K}, \mathrm{Rb}, \mathrm{Cs}), \mathrm{MX}(\mathrm{M}=\mathrm{Li}, \mathrm{Na}, \mathrm{K}, \mathrm{Rb}, \mathrm{Cs}$, $\mathrm{X}=\mathrm{F}, \mathrm{Cl}, \mathrm{Br})$ and others and reacted with an alkyl carbonate $(\mathrm{RO}(\mathrm{CO}) \mathrm{OR}, \mathrm{R}=\mathrm{Me}, \mathrm{Et}$, $\mathrm{Pr}$, etc) at from 200 to $400^{\circ} \mathrm{C}$ produce $(\mathrm{RO}) 4 \mathrm{Si}(\mathrm{R}=\mathrm{Me}$, Et, etc. $)(8)$. The volatile (RO)4Si can then optionally be purified by distillation followed by oxidative burning to make high purity $\mathrm{SiO} 2$. This $\mathrm{SiO} 2$ has high surface area and can be used for filler applications. In addition, the $\mathrm{SiO} 2$ so produced can be further processed to make optical fiber quality quartz.

Another possibility is the direct feed of tetramethoxysilane to a burner where the tetramethoxysilane was produced from the reaction of a $\mathrm{SiO} 2$ source, base and dimethycarbonate.

Burning of Tetramethoxyorthosilicate to make Fumed Silica

Tetramethoxyorthosilicate was placed in the feed bomb of the fumed silica mini-plant. The system was run using six different premix hydrogen setpoints plus a repeat over two separate days, with fumed silica product collected. Surface area measurements were obtained for each sample.

\section{Experimental Procedure}

The unit has MKS flowmeters for all reaction gas feeds, a feed bomb that is used to hold the liquid feed, a pump-jet ejector system that pulls all reactants through the system, a filter where samples can be collected, and a computer with LabVIEWß software that displays and records all pertinent data. There is a process control panel that has solenoid valves that turn on various gas and liquid streams. 
The tetramethoxyorthosilicate was pulled into the bomb through a $1 / 4$ " Teflon tube connected to the side of the feed bomb. The liquid feed lines were flushed through the feed system up to the feed shutoff solenoid by the use of cylinder nitrogen that pressurized the feed bomb to $\sim 20$ psig this procedure permits liquid flow to the system..

The liquid tetramethoxysilane was fed into a hydrogen flame. The hydrogen to air ratio was varied and the surface area was determined for the silicon dioxide obtained

For this series of samples, quench air flowrate was $20,000 \mathrm{sccm}$, premix air flowrate was $10,000 \mathrm{sccm}$, and the annulus hydrogen flowrate was $1000 \mathrm{sccm}$. The liquid feed rate target was $2 \mathrm{gm} / \mathrm{min}$. Premix hydrogen flowrates of 1200,1500 and $200 \mathrm{sccm}$ were run on the first day. On the second day, flowrates were 500, 1200, 2000 and $0 \mathrm{sccm}$. These were typical flowrates that have been used in the past with other types of feeds.

Samples were obtained for each premix hydrogen rate. When running on the second day, with the premix hydrogen at $0 \mathrm{sccm}$, the annulus hydrogen was backed off to $0 \mathrm{sccm}$, with the tetramethoxyorthosilicate still burning. The flame became more streamlined and a different shade of white/blue.

\section{Analytical Work}

Surface area measurements were performed using the Coulter SA3800 unit located in CE431.

The tetramethoxyorthosilicate feedstock samples were not calcined. Each sample was out-gassed under vacuum for 1 hour at $300^{\circ} \mathrm{C}$. After the samples were cooled, they were analyzed. A chart below lists the surface are results in $\mathrm{m}^{2} / \mathrm{gm}$ (corrected against a standard). The graph shows the values.

\begin{tabular}{|c|c|c|}
\hline Analyzed & $\begin{array}{l}\text { Premix } \\
\text { Hydrogen } \\
\text { (sccm) }\end{array}$ & $\begin{array}{c}\text { Corrected Surface } \\
\text { Area } \\
\left(\mathrm{m}^{\wedge} 2 / \mathrm{gm}\right)\end{array}$ \\
\hline 0107231 & 1200 & 95.3 \\
\hline 0107232 & 1500 & 71.4 \\
\hline 0107233 & 200 & 113.6 \\
\hline 0107241 & 500 & $125 . c$ \\
\hline 0107242 & 1200 & 79.6 \\
\hline 0107243 & 2000 & 70.9 \\
\hline 0107244 & 0 & 211.6 \\
\hline
\end{tabular}




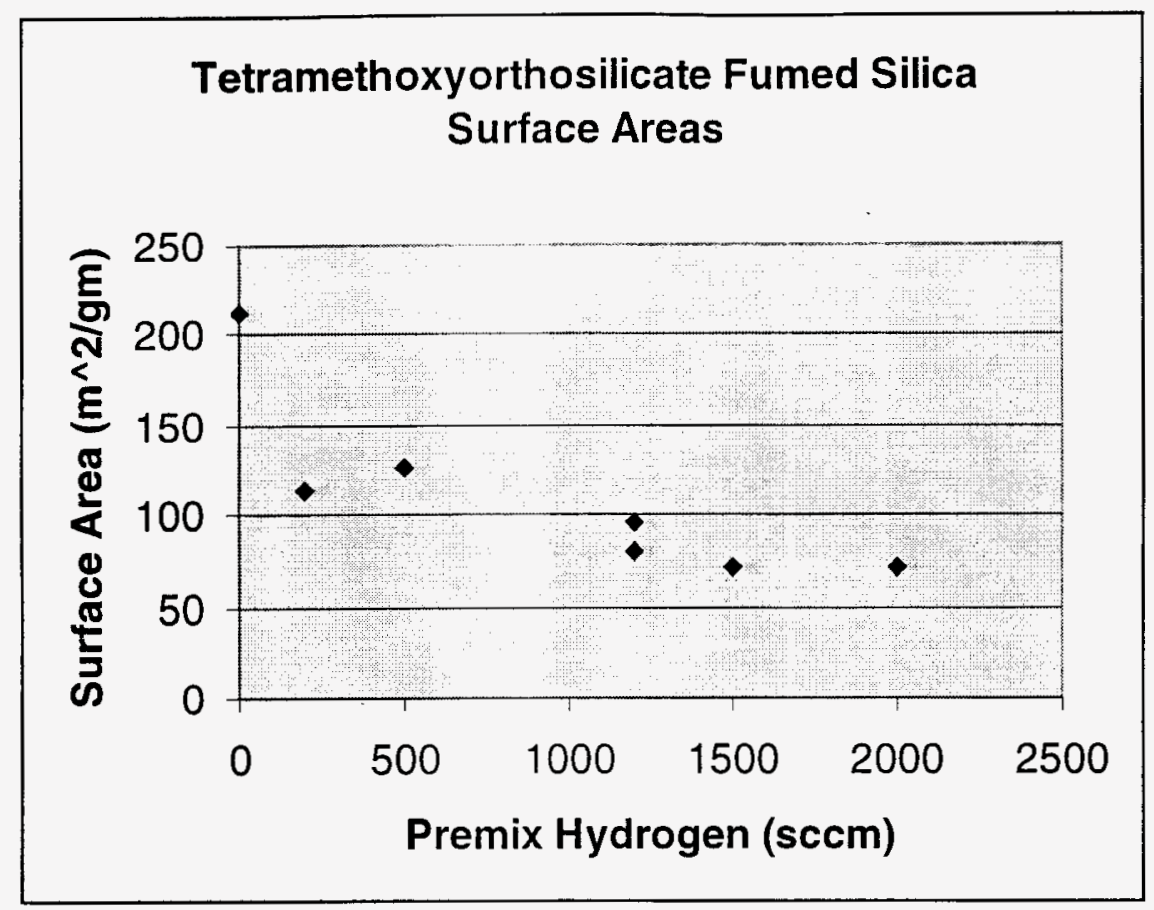

\section{Literature}

1. S. Kosinski, J.B. MacChesney, Kirki-Othmer Encyclopedia of Chemical Technology, Vol. 10 (John Wiley, NY, 1993) pp 521 ff.

2. Fabrication and characteristics of SiOx films by plasma chemical vapor deposition of tetramethylorthosilicate. Yang, M.-R.; Chen, K.-S.; Hsu, S.-T.; Wu, T.-Z., Surf. Coat. Technol. (2000), 123(2-3), 204-209 CAN 132:95252

3. Plasma-enhanced chemical vapor deposition of $\mathrm{SiO} 2$ using novel alkoxysilane precursors. Bogart, K. H. A.; Dalleska, N. F.; Bogart, G. R.; Fisher, Ellen R. J. Vac. Sci. Technol., A (1995), 13(2), 476-80. CAN 122:304204

4. Mechanism of Growth of Silica Monolayer and Generation of Acidity by Chemical Vapor Deposition of Tetramethoxysilane on Alumina. Katada, Naonobu; Toyama, Takuya; Niwa, Miki. J. Phys. Chem. (1994), 98(31), 7647-52. CAN 121:

5. Synthetic quartz glass suitable as a material of optical fibers. Okamoto, Haruo; Sawada, Katsuya; Sekigawa, Syohei; Endo, Mikio; Koide, Hiroyuki. (Shin-Etsu Chemical Industry Co., Ltd.. Japan). Eur. Pat. Appl. (1985) EP 146659 A1 19850703 Designated States R: DE, FR, GB. Patent written in English. Application: EP 83402510 19831222. CAN 103:75262 AN 1985:475262 CAPLUS 
6. Manufacture of a synthetic silica glass body by flame hydrolysis of silanes with multitubular burner nozzle. Ohtsuka, Hisatoshi; Takita, Masatoshi; Fujinoki, Akira. (Shin-Etsu Chemical Co., Ltd.. Japan; Shin-Etsu Quartz Co., Ltd.). Eur. Pat. Appl. (1994), EP 622340 A1 19941102 Designated States R: DE, FR, GB. Patent written in English. Application: EP 94-400841 19940418. Priority: JP 93-100808 19930427. CAN 122:15582 AN 1995:257888 CAPLUS

7. Manufacture of synthetic quartz glass parts. Kawaguchi, Sakae; Shimoma, Akira; Ootsuka, Hisatoshi. (Shin-Etsu Chemical Industry Co., Ltd., Japan). Jpn. Kokai Tokkyo Koho (1989), 4 pp. CODEN: JKXXAF JP 01138145 A2 19890531 Heisei. Patent written in Japanese. Application: JP 87-207136 19870820. CAN 112:11000 AN 1990:11000 CAPLUS

8. L.N. Lewis, F.J. Schattenmann, RD-26,647 (filed 8/20/99) "Method for Making Tetraorganooxysilanes". Issued: US 6,288,257 (Sept.1, 2001).

\section{Appendix 7: Q' as a Precursor to Silane}

Silane $\left(\mathrm{SiH}_{4}\right)$ is an extremely valuable material used in the formation of high purity silicon for the electronics industry. A chemical vapor deposition (CVD) process is used to form high purity silicon and silane is a preferred reagent vs. the next best material, trichlorosilane $(\mathrm{Cl} 3 \mathrm{SiH}){ }^{1}$. Trichlorosilane is formed from reaction of elemental silicon and $\mathrm{HCl}$. Silane is formed from a number of processes using elemental silicon as the starting material ${ }^{2}$. Silicon dioxide (sand or quartz) is converted to chemical-grade elemental silicon in an energy intensive reduction process, a result of the exceptional thermodynamic stability of silica. Thus a process whereby silane is produced from silicon must first reduce silicon dioxide to elemental silicon and then re-oxidize the silicon to silane.

The energy costs associated with a process to make silane from elemental silicon, are mainly a result of the reduction of $\mathrm{Si}(\mathrm{IV})$ to $\mathrm{Si}(0)$ and subsequent re-oxidation to $\mathrm{Si}(\mathrm{IV})$. The conversion of silicon dioxide to elemental silicon in an electrochemical furnace at temperatures $\sim 1500{ }^{\circ} \mathrm{C}$ consumes large amounts of electricity and carbon for reduction.

An alternative synthetic route to the production of silane is one where the oxidation state of silicon remains at +4 throughout the process. Direct conversion of silicon dioxide to tetramethoxysilane has been reported by $\mathrm{Ono}^{3}$ and optimized by $\mathrm{GE}^{4}$.

\section{Results \& Discussion}

It was unexpectedly found that direct production of silanes such as $\mathrm{SiH} 4$ could be accomplished starting directly from a silicon dioxide source. The direct silane production 
could accomplished two ways. A reactor was constructed where the reaction of a silicon dioxide source, base like $\mathrm{KOH}$ and an alkyl carbonate like dimethylcarbonate occurred in an upper zone and the effluent of this first reaction then passed through a bed of a metal hydride such as sodium hydride. The final effluent gas contained silane such as $\mathrm{SiH}_{4}$. In another manifestation of this finding, a silicon dioxide source, a metal hydride, additional optional base and alkylcarbonate were reacted to produce silane directly.

For the first approach silicon dioxide sources can include but are not limited to diatomaceous earth, rice hull ash, silica gel, fumed silica, opal, metal silicates where metal is lithium, cobalt, calcium, etc. and others. Also for the first approach alklycarbonates include dimethylcarbonate and diethylcarbonate. Useful sources of base for our process include $\mathrm{MOH}(\mathrm{M}=\mathrm{Na}, \mathrm{K}, \mathrm{Rb}, \mathrm{Cs}), \mathrm{CsF}, \mathrm{KF}, \mathrm{KCl}, \mathrm{NaCl}$, etc. The metal hydride compounds useful for this invention include, but are not limited to, sodium hydride, potassium hydride, lithium hydride, cesium hydride, calcium hydride, magnesium hydride, sodium borohydride, lithium aluminum hydride, and the like.

A reactor appropriate for carrying out the two reactions in series as described above may be any reactor that permits flow of vapor to pass over a heated solid and permit escape of the product gases into a second zone where the product vapors pass over the metal hydrides and where the silane can be collected at the end. The reactor may be constructed of glass, metal including steel, etc. Solid may be held in place by glass frit, sintered metal disk, etc. vapor may be introduced by syringe pump of liquid followed by heat to vaporize the liquid, boiling chamber for distribution of the liquid vapor or any device that converts the liquid reagent into vapor and then transports the vapor over the solid.

\section{Examples}

Fixed Bed Lab Reactor.

A diagram of the actual lab reactor used is shown in figure 1.

Figure 1

Fixed bed Lab Reactor 


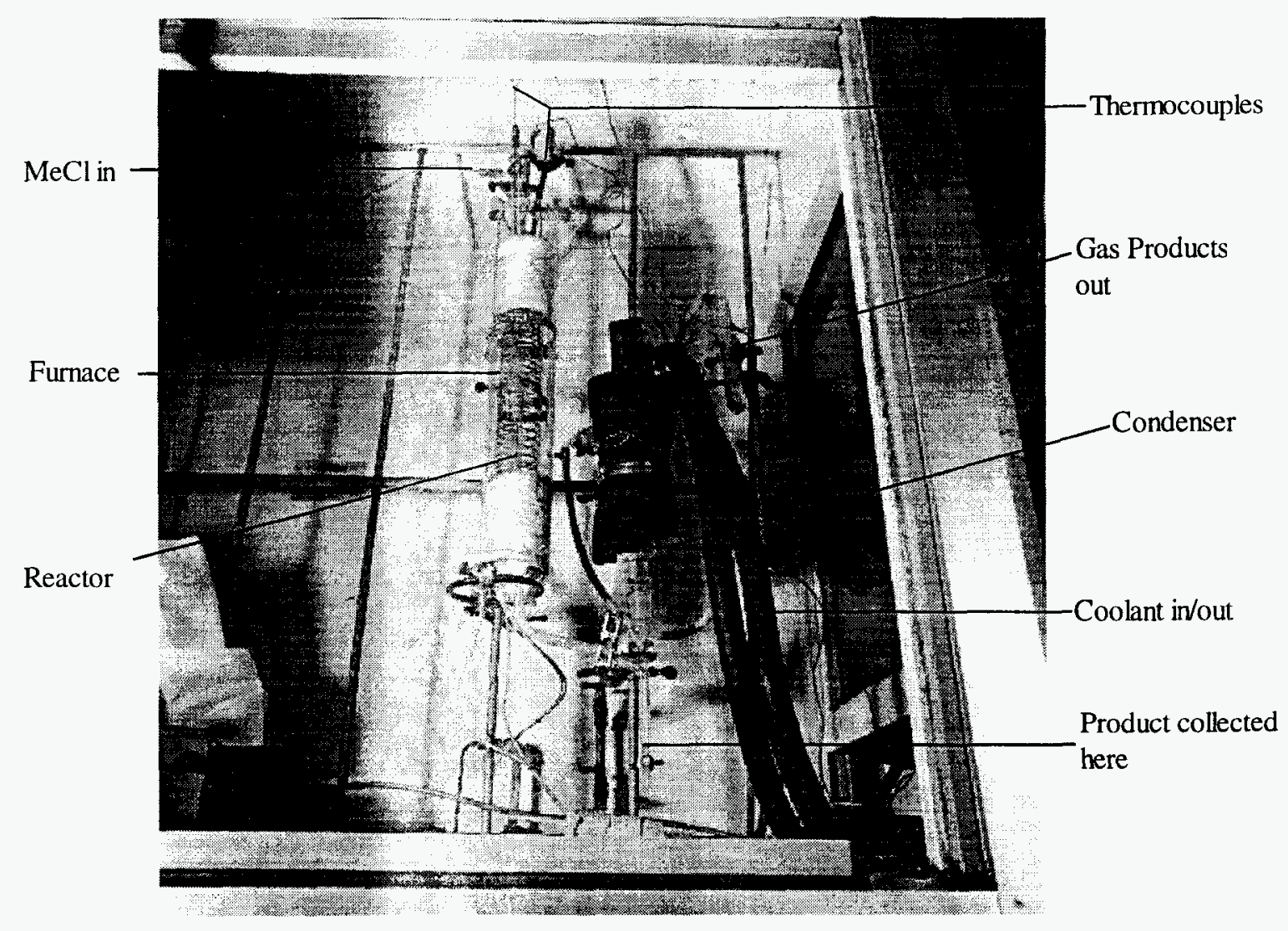

The glass reactor was $100 \mathrm{~mm}$ long by $13 \mathrm{~mm}$ wide with a medium porosity glass frit located $80 \mathrm{~mm}$ from one end. Typically 1-6 grams of solid was loaded into the glass reactor and then heated under a flow of argon. The product was collected at a $0^{\circ} \mathrm{C}$ condenser using a VWR model 1156 recirculating chiller. Gas flow was controlled with a MKS model 1179 mass flow controller using a MKS type 247 four channel read out. The furnace used for most of the experiments here was a Nichrome $\mathrm{R}_{\text {-wire-wound glass tube }}$ heated in two zones with two separate Antech Sales model 59690 Watlow temperature controllers.

Fluid Bed Reactor: The ractor and associated system are shown in Figure 2. The reactor was a $3.8 \mathrm{~cm} \mathrm{D}$ glass lube with a glass frit at the center to support the silicon bed. The reactor was heated in the sime way as the fixed bed reactor, namely by a second concentric $5.1 \mathrm{~cm} \mathrm{ID}$ glass tube coated with tin oxide to which two pairs of electrodes were attached to create two heated sections.

In order to fluidize the silicon it was necessary both to stir the reacting silicon and to vibrate the reactor. Vibration was accomplished by attaching one end of a clamp to the reactor, and the other end $\omega$, he base of a variable intensity test tube shaker. By adjusting the intensity of the vibration and the firmness with which the clamp gripped the reactor, the necessary agitation of the silicon bed was achieved. Typically the vibration was used intermittently during a run. 
Bomb Reactions

A $300 \mathrm{~mL}$ Parr bomb construcled of Hasteloy $\mathrm{C}$ was used and was equipped with a teflon-coated stir bar. The bomb was charged with liquids and gas, could be subjected to freeze/degas/thaw cycles and heated with a temperature controller employing thermocouple feedback. The heater was placed on a magnetic stirrer so that the contents of the bomb were stirred during the reaction.

1.The fixed bed reactor was chirged with sodium hydride. Tetramethoxysilane (Q') was charged to a $10 \mathrm{~mL}$ syringe pump and fed over the bed at $320^{\circ} \mathrm{C}$. Analysis of the gas products by ge and gems showed the presence of $\mathrm{SiH} 4$.

2. The fluid bed reactor was charged with sodium hydride $(10 \mathrm{~g})$. Q' was fed into the reactor via syringe pump at $300^{\circ} \mathrm{C}$. The first $10 \mathrm{~mL}$ of Q' fed to the reactor generated less than $1 \mathrm{~g}$ of condensed producis. The Q' was converted into SiH4 under these conditions.

3. The $300 \mathrm{~mL}$ bomb was charged with $\mathrm{NaH}$ and Q', frozen and degassed two times and then heated to $300^{\circ} \mathrm{C}$. Analysis of the gas formed by gc and $\mathrm{gcms}$ showed the presence of SiH4.

The bomb was charged with $1.94 \mathrm{~g} \mathrm{NaH}$ and $10 \mathrm{~mL}$ of Q' Table 1 shows the change in pressure at different temperatures. Gas samples were taken at each point and the height of the $\mathrm{SiH} 4$ peak noted. The peak was saturated at 46 height units. 
Table 1

\begin{tabular}{|l|r|r|}
\hline $\begin{array}{l}\text { Temp } \\
\text { (C) }\end{array}$ & $\mathrm{P}$ (psi) & SiH4 \\
\hline 186 & 20 & 46 \\
\hline 225 & 50 & 24 \\
\hline 250 & 85 & 7 \\
\hline 300 & 140 & 1 \\
\hline 22 & 60 & 0 \\
\hline
\end{tabular}

The experiment in the bomb wals run a second time and the Temp, pressure and SiH4 concentration is shown below in table 2

Table 2

\begin{tabular}{|r|r|r|}
\hline $\begin{array}{l}\text { Temp } \\
\text { (C) }\end{array}$ & P (psi) & SiH4 \\
\hline 160 & 0 & 9 \\
\hline 190 & 20 & 46 \\
\hline 190 & 30 & 46 \\
\hline 200 & 40 & 46 \\
\hline 225 & 50 & 46 \\
\hline 250 & 70 & 18 \\
\hline
\end{tabular}

Formation of SiH4 was clearly demonstrated by these experiments.

A 3 neck $250 \mathrm{~mL}$ flask was chirged with $0.5 \mathrm{~g} \mathrm{KF}, 1 \mathrm{~g}$ Q' and $50 \mathrm{~mL}$ of DMF. The solution was heated under argon and Q' disappearance vs. time is shown in table 3.

Table 3

\begin{tabular}{|r|r|}
\hline Time (h) & $\begin{array}{l}Q^{\prime} \text { (area } \\
\% \text { ) }\end{array}$ \\
\hline 2 & 382 \\
\hline 14.68 & 276 \\
\hline 15.8 & 315 \\
\hline 17.3 & 27 \\
\hline 18.8 & 179 \\
\hline 20.6 & 52 \\
\hline 22.4 & 0 \\
\hline 23.3 & 0 \\
\hline
\end{tabular}

Literature Cited

1. E. Yablonovitch, Kirk-Othmer Encyclopedia of Chemical Technology, (John Wiley \& Sons, Inc., NY) Vol. 9, p $22+$. 
2. B. Arkles, Kirk-Othmer Encyclopedia of Chemical Technology, (John Wiley \& Sons, Inc., NY) Vol. 22, pp 42-45.

3. Ono, Y.; Akiyama, M.; Suzuki. E. Chem. Mater. 1993, 5, 442.

4. L.N. Lewis, F.J. Schattenmann. RD 26,641, filed 2000.

\section{Appendix 8. Reactions of Metal oxides other than $\mathrm{SiO} 2$ with DMC and Base}

The direct reaction of silicon dioxide with base and dimethylcarbonate has been reported $(1,2)$, eq. 1 . For germanium a reaction analogous to eq 1 has not been reported.<smiles></smiles>

Formation of $\mathrm{Ge}-\mathrm{C}$ bonds requires one of two methods. In a way analogous to silicon, there is a Ge direct process, eq 2 $(3,4)$. The other method is metathesis type substitution

$\mathrm{Ge}+\mathrm{MeCl} \stackrel{\mathrm{Cu}}{\longrightarrow} \mathrm{Me}_{\mathrm{s}} \mathrm{GeCl}_{4-\mathrm{x}}$

like those of $\mathrm{Ge}-\mathrm{Cl}$ compounds with alkyl lithium or Grignard reagents.

Germanium oxide has important uses in fabrication of optical devices (5-9). Precursors to $\mathrm{GeO}_{2}$ include $\mathrm{GeCl}_{4}$ and $\mathrm{Ge}(\mathrm{OR})_{4}$. The only reference to formation of $\mathrm{Ge}(\mathrm{OMe})_{4}$ reacts $\mathrm{GeCl}_{4}$ with $\mathrm{MeOH}$.

Results \& Discussion

It was unexpectedly found that when $\mathrm{GeO}_{2}$ was combined with base and reacted with dimethylcarbonate over $200 \mathrm{C}$. Ge $(\mathrm{OMe})_{4}$ was formed in high yield. While only a few experiments were performed. it is likely that bases appropriate for this reaction include, but are not limited to $\mathrm{MOH}$ where $\mathrm{M}=\mathrm{Li}, \mathrm{Na}, \mathrm{K}, \mathrm{Rb}, \mathrm{Cs}, \mathrm{M}(\mathrm{OH}) 2$ where $\mathrm{M}=\mathrm{Mg}, \mathrm{Ca}$, $\mathrm{Sr}$ and $\mathrm{Ba}$. And MF where $\mathrm{M}=\mathrm{Li}$. $\mathrm{Na}$ and $\mathrm{K}$ and $\mathrm{MCl}$, where $\mathrm{M}=\mathrm{Li}, \mathrm{Na}$ and $\mathrm{K}$. There is no obvious limitation on the germanium oxide except that higher surface area is preferred. The reaction was performed with dimethylcarbonate but other alkyl carbonates including ethyl, n-propyl, i-propyl, butyl etc. are possible. Additionally diarylcarbonates may be suitable reagents for this reaction. The reaction was carried out in a fixed bed reactor but may be carried oul in il fluid bed reactor, stirred bed reactor or in high boiling solvent with agitation. 
It was unexpectedly found that when the reaction between $\mathrm{GeO}_{2}$ and base with dimethylcarbonate was performed over about $275^{\circ} \mathrm{C}$, additional formation of methyltrimethoxygermane occurred. The direct formation of $\mathrm{Ge}-\mathrm{C}$ bond-containing material is unprecedented uncler these conditions. It is likely that residence time of the dimethylcarbonate over the rciction mass will lead to more or less formation of the two germanium products: $(\mathrm{MeO})_{4}$ (ie and $\mathrm{MeGe}(\mathrm{OMe})_{3}$.

\section{Examples}

\section{Fixed Bed Lab Reactor.}

A diagram of the actual lab rcictor used is shown in figure 1. (Appendix 7)

1.A mixture of $\mathrm{GeO}_{2}$ (surface areal will be measured) and $5 \% \mathrm{KOH}$ was mixed in water, stirred and then heated with sirring to dryness. The $\mathrm{GeO}_{2} / \mathrm{KOH}$ mixture was then added to a fixed bed reactor $(1 \mathrm{~g})$ and then heated to $250^{\circ} \mathrm{C}$ under a $\mathrm{Ar}$ flow $(5 \mathrm{~mL} / \mathrm{min}) .80 \%$ of the $\mathrm{GeO} 2$ reacted to make the single product, $\mathrm{Ge}(\mathrm{OMe})_{4}$. The product was confirmed by gc, gcms and ${ }^{1} \mathrm{H}$ and ${ }^{13} \mathrm{C}$ NMR analysis. GC analysis showed a single peak RT just below cyclooctane internal standard. GCMS analysis showed that the mass spectrum of the observed peak had a peak envelope centered around $196 \mathrm{amu}$. Fragments indicated loss of OMe groups. Ge has 5 maturally occurring isotopes giving rise to the envelope pattern. 1H NMR showed a single resonance at $3.59 \mathrm{ppm}\left(\mathrm{CDCl}_{3}\right)$ and ${ }^{13} \mathrm{C} \mathrm{NMR}$ showed a single resonance at $53.96 \mathrm{ppm}$.

2. The experiment in example I was repeated except that the temperature was $350^{\circ} \mathrm{C}$. $\mathrm{GC}$ analysis showed that $\mathrm{Ge}(\mathrm{OMc})_{4}$ and $\mathrm{MeGe}(\mathrm{OMe})_{3}$ were produced in a 3:1 ratio. Total $\mathrm{GeO}_{2}$ conversion was $72 \%$. Confirmation of the formation of $\mathrm{MeGe}(\mathrm{OMe}) 3$ was accomplished with gcms (El) and $\mathrm{gcms}\left(\mathrm{CI}, \mathrm{H}^{+}\right)$. The latter technique showed the parent ion centered around 179 amu. Friagments were observed as follows for $\mathrm{M}^{+}{ }_{-} \mathrm{CH}_{3}$, and $\mathrm{M}^{+}$-OMe. ${ }^{1} \mathrm{H}$ NMR showe! the presence of new methoxy resonances at $3.53 \mathrm{ppm}$ and Ge- $\mathrm{CH}_{3}$ methyl resonance at ().59 $\mathrm{ppm}$ while ${ }^{13} \mathrm{C}$ nmr showed the presence of new methoxy carbon resonance al $.50 .82 \mathrm{ppm}$ and $\mathrm{CH}_{3}-\mathrm{Ge}$ methyl resonance at $-5.3 \mathrm{ppm}$; cf. reference 10.

\section{Literature Cited}

1. Ono, Y.; Akiyama, M.; Suzuki. E. Chem. Mater. 1993, 5, 442.

2. L.N. Lewis, F.J. Schattenmann. RD 26,647, "Method for Making Tetraorganooxysilanes," filci $: / 2() / 99$ (will be issued fall 2001). 
3. E.J. Bulten, MTP Int. Re :. Sci., Inorg. Chem. Ser., 2 (1975) 4, 241.

4. M.E. Lee, Synth. React. Ino'g. Met. Org-Chem. (1990) $20,77$.

5. Silica glass for optical fiicers. (Nippon Telegraph and Telephone Public Corp., Japan). Jpn. Kokai Tokkyo Koho (1982), 4 pp. CODEN: JKXXAF JP 57191238 A2 19821125 Showa. Patcllt written in Japanese. Application: JP 81-76461 19810522. CAN 98:184408 AN 1983:184408 CAPLUS

6. Optical glass. Yokogawa. Kyoshi; Kamiya, Kazuo; Omura, Toshio. (Shin-Etsu Chemical Industry Co., Ltd.. Japan). Jpn. Kokai Tokkyo Koho (1985), 4 pp. CODEN: JKXXAF JP 60151242 A2 19850809 Showa. Patent written in Japanese. Application: JP 84-6121 19840117. CAN 104:94045 AN 1986:94045 CAPLUS

7. Film formation. Susa. Kenzo; Matsuyama, Iwao. (Hitachi, Ltd., Japan). Jpn. Kokai Tokkyo Koho (1986). 4 pp. CODEN: JKXXAF JP 61035847 A2 19860220 Showa. Patent written in Japanese. Application: JP 84-155218 19840727. CAN 105:106232 AN 1986:506232 CAPLUS

8. Manufacture of spherical glass lenses with radial gradient. Konishi, Shiro. (Hitachi Cable, Ltd., Japan). Jpn. Kokai Tokkyo Koho (1987), 3 pp. CODEN: JKXXAF JP 62197328 A2 19870901 Showa. Patent written in Japanese. Application: JP 86-36244 19860220. CAN 107:181973 AN 1987:581973 CAPLUS

9. Methods for multicore war eguide fabrication. Nishimoto, Hiroshi. (Nec Corp., Japan). Jpn. Kokai Tokkyo Koho (1997), 5 pp. CODEN: JKXXAF JP 09133827 A2 19970520 Heisei. Patent written in Japanese. Application: JP 95-314935 19951109. CAN 127:72786 AN 1997:453819 CAPLUS

10. Drake, J.E.; Glavincevski. B.N.; Humphries, R.E.; Majid, A. Can. J. Chem., 1979, 57, 1426-1430.

Trimethoxymethylgermane: ${ }^{1.3} \mathrm{C} \mathrm{NMR}\left(\mathrm{CDCl} 3\right.$, TMS): $\mathrm{H} 3 \mathrm{CGe}\left(\mathrm{OCH}_{3}\right)_{3}-7.43 \mathrm{ppm}$ and $\mathrm{MeGe}(\mathrm{OCH} 3)_{3} 51.1 \mathrm{ppm}$ 'This ref. also gives the methyl proton nmr data, but not the methoxide resonances. ${ }^{1} \mathrm{H} \backslash \mathrm{MR} 0.51 \mathrm{ppm}$ ref. TMS for $\mathrm{CH}_{3} \mathrm{Ge}$ protons (actual data is referenced to Yoder et. al. J. lin) Nucl. Chem. 1971, 33, 2697.).

Germanium-73, oxygen-17, carbon-13 NMR spectra of alkoxygermanes. Liepins, E.; Zicmane, I.; Lukevics, E. Inst. Org., Synth., Riga, USSR. J. Organomet. Chem. (1986), 306(3), 327-35. CODEN: JORCAI ISSN: 0022-328X. Journal written in English. CAN 106:21405-t AN 1987:214054 CAPLUS 